\title{
Parenting a Child with Life-Threatening Food Allergy: \\ The Mother's Perspective
}

\author{
Cathy Gillespie
}

\begin{abstract}
A Thesis submitted to the
Faculty of Graduate Studies

in partial fulfillment of the

requirements for the degree of
\end{abstract}

Master of Nursing

Faculty of Nursing

University of Manitoba

Winnipeg, Manitoba

${ }^{\circledR}$ Copyright by Cathy Gillespie 2002. 
National Library

of Canada

Acquisitions and Bibliographic Services

395 Wellington Street Ottawa ON K1A ON4 Canada
Bibliothèque nationale du Canada

Acquisitions et services bibliographiques

395 , rue Wellington

Ottawa ON K1A ON4

Canada
The author has granted a nonexclusive licence allowing the National Library of Canada to reproduce, loan, distribute or sell copies of this thesis in microform, paper or electronic formats.
L'auteur a accordé une licence non exclusive permettant à la Bibliothèque nationale du Canada de reproduire, prêter, distribuer ou vendre des copies de cette thèse sous la forme de microfiche/film, de reproduction sur papier ou sur format électronique.

L'auteur conserve la propriété du droit d'auteur qui protège cette thèse. $\mathrm{Ni}$ la thèse ni des extraits substantiels de celle-ci ne doivent être imprimés ou autrement reproduits sans son autorisation. 
THE UNIVERSITY OF MANITOBA

FACULTY OF GRADUATE STUDIES

COPYRIGHT PERMISSION PAGE

Parenting a Child with Life-Threatening Food Allergy:

The Mother's Perspective

BY

Cathy Gillespie

A Thesis/Practicum submitted to the Faculty of Graduate Studies of The University of Manitoba in partial fulfillment of the requirements of the degree

of

MASTER OF NURSING

CATHY GILLESPIE $@ 2002$

Permission has been granted to the Library of The University of Manitoba to lend or sell copies of this thesis/practicum, to the National Library of Canada to microfilm this thesis and to lend or sell copies of the film, and to University Microfilm Inc. to publish an abstract of this thesis/practicum.

The author reserves other publication rights, and neither this thesis/practicum nor extensive extracts from it may be printed or otherwise reproduced without the author's written permission. 


\begin{abstract}
The purpose of this study was to arrive at an understanding of the mother's lived experience of parenting a child with a life-threatening food allergy. Phenomenology was used to guide the exploration of the experience. Six mothers of children $6-12$ years old at risk for a life-threatening food reaction and carrying epinephrine were interviewed individually using a semi-structured interview format. Each mother was interviewed on two occasions. Interviews were audiotaped and data analysis was carried out concurrently with data collection. "Living with Risk" was the dominant study theme or essence, supported by five sub-themes. These themes included "Living with Fear", "Worrying About Well-Being", "Looking for Control", "Relying on Resources", and "It's Hard But It's Not". The mothers were able to provide insight into what it is like to mother a child with this condition.
\end{abstract}




\section{ACKNOWLEDGEMENTS}

I would like to thank the following for their contributions made in support of this research project:

- the mothers who were so willing to share their experience

my thesis committee: Dr. Karen Chalmers, Dr. Roberta Woodgate, and Dr. Wade Watson for their encouragement and willingness to share their expertise

Dolly and Michael Gembey and the Health Sciences Foundation for funding the project

Nancy Boni, Diane Dilay, and Dr. Jan Roberts for their valuable assistance with recruitment of the mothers

my husband Michael, son Jeremy, and mother Cassie for their patience and support

my friends and colleagues for their interest and being their to listen 
TABLE OF CONTENTS

\begin{tabular}{|c|c|}
\hline & Page \\
\hline ABSTRACT & ii \\
\hline ACKNOWLEDGEMENTS & iii \\
\hline STATEMENT OF THE PROBLEM & 1 \\
\hline 1.1 Introduction & 1 \\
\hline 1.2 Food Allergy: Definition and Prevalence & 1 \\
\hline 1.3 Food-Induced Anaphylaxis & 2 \\
\hline 1.4 The Psychosocial Impact & 6 \\
\hline 1.5 The Role of the Nurse & 9 \\
\hline 1.6 Purpose of the Study & 10 \\
\hline 1.7 Conclusion & 11 \\
\hline
\end{tabular}

2. REVIEW OF THE LITERATURE 12

2.1 Introduction $\quad 12$

2.2 Biomedical Perspective of Food Allergies 12

2.3 The Family and Chronic Medical Conditions 18

2.4 Impact of Chronic Illness $\quad 21$

2.5 The Role of the Nurse 27

2.6 Asthma and Diabetes as Comparative Conditions 27

2.7 Similarities and Differences in the Conditions 28

2.8 Parents' Perspective of Asthma 29

2.9 Parents' Perspective of Diabetes - $\quad 35$

2.10 Parents' Perspective of Life-Threatening Food Allergies $\quad 40$ 
2.11 Conclusion 42

3. METHODOLOGY 44

3.1 Introduction 44

3.2 Qualitative Methodology 44

3.3 Phenomenology 46

3.4 The Research Design 51

3.5 Data Collection $\quad 54$

3.6 Data Analysis $\quad 56$

$\begin{array}{ll}\text { 3.7 Measures of Rigor } & 58\end{array}$

3.8 Ethical Considerations $\quad 59$

3.9 Limitations of the Study $\quad 62$

3.10 Conclusion $\quad 62$

4. FINDINGS 63

4.1 Introduction 63

4.2 Description of the Sample 63

4.3 Living with Risk 67

4.4 Living with Fear 68

4.5 Worry About Well-Being $\quad 79$

4.6 Looking for Control $\quad 82$

$\begin{array}{ll}4.7 \text { Relying on Resources } & 100\end{array}$

4.8 It's Hard But It's Not 109

4.9 Conclusion $\quad-\quad 111$

$\begin{array}{ll}\text { 5. DISCUSSION } & 113\end{array}$ 


\title{
CHAPTER ONE
}

\section{STA TEMENT OF THE PROBLEM}

\author{
Introduction
}

Life-threatening food allergy is a serious and increasingly more common concern in the pediatric population. Following the appearance of this problem in a child, the threat always exists that he or she might die following ingestion of what would normally be an innocent substance. It is expected that this physical condition will have a significant psychological and social impact not only on the child, but also on the family as a whole and its individual members. It is important that nurses and other healthcare providers working with these children and their families understand the whole picture in order that they can best support a family in adjusting to the condition. Therefore, information is required on how the experience might be seen from the perspective of all those involved. This chapter outlines the arguments that support pursuing a study of the maternal experience of parenting a child with a life-threatening food allergy. This includes the biomedical view of the problem, the possible impact on the family, the management requirements for the condition, and the importance of the nursing role.

Food Allergy: Definition and Prevalence

Food allergy, also referred to as food hypersensitivity, can be defined as an abnormal or exaggerated immune response to a food protein or antigen resulting in a variety of clinical manifestations. The response may be IgE-mediated or related to other immunecomplex or cell-mediated reactions (Sampson, 1997a). In this discussion it is the IgE- 
mediated response that is of interest, and for it to occur the individual must first develop IgE antibodies against the specific food. This sensitization requires some amount of exposure to that food. Once formed, the food-specific IgE antibodies attach largely to the surface of mast cells and basophils. Mast cells are found in connective tissue throughout the body, but especially in the lining of the respiratory and gastrointestinal systems and beneath the surface of the skin, while basophils circulate in the blood. Future introduction of the protein into the body causes an antigen-antibody interaction as the food antigen attaches to and cross-links the food-specific IgE antibodies. This results in degranulation of the cell, release of chemical mediators such as histamine, generation of new mediators, and the signs and symptoms of an allergic response.

Reactions to foods have been identified for centuries (Sampson, 1999a), and food allergy is frequently recognized as a concern by parents. In reality, true food allergies are not as common as the general public believes. According to Sampson and Burks (1996) and based on medical literature, adverse reactions, which refer to any abnormal response to foods including allergic reactions, occur in $2 \%-8 \%$ of infants and children. The incidence of food allergy seems to be highest in the earliest years of life possibly affecting 6\% - 8\% of infants and declines over the first decade (Sampson, 1997b, 1999b), although a food allergy can develop at any age.

\section{Food-Induced Anaphylaxis}

Allergic responses can be manifested in different ways and due to a variety of causes. Anaphylaxis is one type of response and can be caused by a variety of triggers including the ingestion of a food antigen by a sensitized child. Anaphylaxis is an immediate, 
systemic, hypersensitivity reaction due to an IgE-mediated immunologic release of mediators from mast cells and basophils (Lieberman, 1998). In general, there is a rapid onset of symptoms following exposure to the antigen. Chemical mediators such as histamine are released into the system causing smooth muscle spasm (especially in the bronchi, coronary arteries and gastrointestinal tract), an increase in vascular permeability, vasodilation, reflex activation of vagal effector pathways, and myocardial depression (Lieberman). The reaction usually occurs within seconds to minutes after the exposure, but may take longer. Less frequently it begins after the first hour. The later the onset the less severe the reaction is likely to be (Burks \& Sampson, 1997). Multiple systems are involved including the gastrointestinal, respiratory, cutaneous, and cardiovascular. Signs and symptoms of anaphylaxis may include itching and swelling of the tongue, palatal itching or tingling, throat itching and tightness, nausea, colicky abdominal cramps, vomiting and diarrhea, generalized erythema and pruritus, urticaria and angioedema, nasal pruritus and congestion, rhinorrhea, hoarseness, dry staccato cough, stridor, dyspnea and/or wheezing, cyanosis, chest pain, hypotension, faintness, cardiac arrhythmia, and shock. Death may occur due to respiratory and/or vascular collapse. A person suffering from anaphylaxis may also experience a feeling of what has been described as a "sense of doom". These symptoms, the severity, combination, and their sequence can vary. In food-induced anaphylaxis the first symptoms may involve the oropharynx (Burks \& Sampson).

According to a position statement by the Allergy Section of the Canadian Pediatric Society (CPS) (1994), deaths from food-induced anaphylaxis are increasing each year, though the exact reason is unknown. At this time there is neither a cure nor adequate 
preventative therapy for food-induced anaphylaxis. Research has focused on use of medications and immunotherapy, but as yet neither have been shown to be adequately effective (Sampson, 1997b). Though avoidance is desirable accidental exposure occurs, as illustrated in a study of the fatal and nonfatal reactions in children (Sampson,

Mendelson, \& Rosen, 1992).

\section{Assessment of a Life-Threatening Food Allergy}

Identifying a child's risk for food-related anaphylaxis is essential, and any child believed to have suffered an immediate or serious reaction following ingestion of food should be referred to an allergist for a complete assessment. The first step is to get an adequate history of any reactions. In addition, signs of any personal allergic conditions should be noted as well as a family history of atopy. For this type of reaction, history may have a reasonable predictive value (Sampson, 1999b). Questions to consider about the specific reaction include those that can identify an allergic reaction to food as the problem, ruling out other possible causes such as ingestion of a toxin or a vasovagal reaction. Information about the child's setting and activities at the beginning of the reaction should be obtained and any previous reactions, even though milder, identified. A sense of the severity of the reaction can be determined by considering the immediacy of the symptoms following ingestion, their duration, and treatment required for control. Other considerations should include type and quantity of the food, the length of time since the reaction, where the food was prepared, obtained, or consumed, and the state of the food (e.g. raw, cooked, processed). Exercise as a possible cofactor should be considered. 
Allergy skin tests are commonly done by the prick test method as part of the assessment, and the foods chosen for testing to confirm the identity of the allergen(s) are best based on the information gathered in the history. These tests can be done on a child of any age. A blood test is also possible, the radio allergosorbent test (RAST), but is generally considered less sensitive than properly applied prick tests and is more expensive. RAST involves the examination of basophils in vitro for degranulation in the presence of a dilute suspension of the suspected food allergen. It is used less often than skin tests, but may be used for diagnosis in cases in which skin tests may be a problem, to help confirm negative skin tests, or for predictive assistance when considering whether an allergy has been outgrown and an oral food challenge safe.

\section{Management of a Life-Threatening Food Allergy}

As anaphylactic food sensitivity cannot be cured, nor is there presently a medical treatment to make the child less susceptible to a possible life-threatening reaction, families must understand the seriousness of the condition. The first goal of management is to prevent a reaction through avoidance of the offending food or in the case of fooddependent exercise-induced anaphylaxis within the sensitive time frame. Children and their families require counseling in regards to avoidance of the foods and careful label reading looking for any terms that might indicate the presence of the allergen. When more than one major food group is involved, counseling by a dietitian may be advisable to ensure that the child is getting adequate nutrition. Where possible, such as in the case of peanut, the food should be kept out of the home environment entirely. Advice should be given on how to deal with the problem in other childcare settings and places where food is consumed. Depending on the particular food, some situations should be avoided 
all together such as dining in Chinese or Thai restaurants. In some cases even the odour of a food may be an issue. Also, children and families must consider items other than those they eat, such as pet food or birdseed. For very young children, it is advisable that high-risk foods be avoided in their early years of life in hope of preventing problems, if either they or their immediate family has shown signs of atopy. Besides counseling on problem prevention, families need to know how to respond to a reaction and develop a plan they can follow if an accidental exposure and reaction should occur.

Families are likely to need support in dealing with this problem as they try to see that their child is protected from harm and at the same time encourage normal development towards eventual independence. One form of assistance can be found through parent support groups and information networks. Families should be made aware of the existence of these resources.

\section{The Psychosocial Impact of a Child's Chronic Medical Condition}

Recognition exists that a chronic medical condition will have an impact beyond that which it has on the affected individual's physical well-being. It is expected that the condition will affect the whole family, and it is likely, though some similarities may exist, there will also be variations in how both families and individuals perceive the condition and respond to it.

\section{The Family}

Children generally reside within family units, and the family is considered an essential social group for the survival of society. A variety of theories exist to describe and explain the family, make predictions about it, and help in planning interventions to 
support it. From a nursing perspective a couple of the more popular ones, which may be valuable for studying chronic illness, include family systems theory and family stress theory.

Family systems theory, developed from general systems theory in science, sees the family as a whole system (Wong, 1995a). Of importance in this theory is the interaction between components (family members), the system (family), and the environment. It is believed that change in one family member creates change in the other family members, causing change in the original member. The environment can affect the family and its members, as they in turn can affect the environment. Family stress theory explains how families react to stressful events and suggests factors that promote adaptation (Wong,).

According to Friedman and Heady (1998) roles are a generally homogenous set of behaviours culturally defined and expected of the person filling the particular position. Though the role may be defined by society, it is individualized according to personal experience and personality. As behaviour does not occur in isolation, role behaviour should meet the expectations of the others involved, making all family members' roles complementary.

Parenting is ideally a shared role in which both parents accept responsibility for the child and through their leadership the family fulfills its obligations to the child and society. Functions required from the family include; socialization to the norms, values, and expected behaviours of the particular society; support for healthy physical, emotional, and cognitive growth and development; and protection from harm. The ultimate geal is for the child to become an independent, contributing adult within the society with which he or she lives. 
The family and the child pass through different stages over time with different tasks to accomplish. In infancy, parents interpret all of the child's needs. The preschool child begins to separate from the parent, while the school age child separates more from the family and becomes a part of the community. The adolescent increasingly makes independent decisions based on influences from outside the family and home environment. All of these stages can be harder for both child and parent when a chronic condition is present.

\section{Chronic Illness, Stress, Coping, and Adaptation}

A variety of definitions exist for chronic illness. Thomas (as cited in Austin, 1991) describes chronic illness a physical impairment that rarely is cured, has acute and stable periods, and interferes with maximum function. A frequently used definition in the nursing literature is that of Pless and Pinkerton (as cited in Yoos, 1987). It is a condition interfering with normal activities daily for at least 3 months a year, hospitalization for one month a year, or the potential for either due to the diagnosis. The definition from Miller and Janosik (as cited in Futcher, 1988) includes long periods of supervision, observation, or care. It involves a residual disability or pathological alteration. A diagnosis of a life-threatening food allergy does not really fit any of these definitions, but it should be considered a chronic condition. It is a deviant physical condition that is there for a long duration if not for life, requires constant vigilance, and can interfere with normal activities. Webster's dictionary (1983) defines chronic as something of long duration or always present.

"Psychological stress is a particular relationship between the person and the environment that is appraised by the person as taxing or exceeding his or her resources 
and endangering his or her well-being." (Lazarus \& Folkman, 1984, p. 19). Stressors are the environmental stimuli causing the psychological stress and require action (Hymovich \& Hagopian, 1992). This response or action is coping, which Lazarus and Folkman describe as a dynamic process in which cognitive and behavioural efforts are used to deal with the excessive demands. The efforts or strategies used for coping can be positive or negative, and the eventual outcome of coping is adaptation.

A child's chronic illness can be a major source of stress both to the child and family depending on the family's and the individuals' appraisals of the situation. The appraisal part of the process is essential, and the belief that different factors may affect the condition's impact has been acknowledged (Jessop \& Stein, 1985). Chronic illness stressors can result from the requirements for management of the condition, resources, relationships, and life-style adjustments (Hymovich \& Hagopian, 1992). It seems likely, considering family systems theory, that the way in which a parent appraises a chronic medical condition not only affects the parent, but will also have a major effect on the child and his or her development.

\section{The Role of the Nurse}

Nurses are involved with children suffering from life-threatening food allergies and their families in a variety of settings including the hospital, clinic, and community. They may help with assessment of the problem, education of and support to the family, and ensuring the child's safety as he or she interacts in different environments.

Effective nursing care related to children with chronic medical conditions requires that the practitioner understands how the individual family members might perceive and 
experience the situation. Many different factors can affect this process causing variations to occur, but recognition of any common themes and reactions may contribute to better nursing assessments and interventions. However, it cannot be assumed that all chronic conditions will be seen and experienced in the same way, though some commonalties appear to exist. Although a large volume of information in the literature focusing on the impact of chronic illness on the family is available, next to none of it deals with the family of a child with life-threatening food allergies.

Nursing should be able to play a significant role in helping the parents of children with life-threatening food allergies by better understanding their perceptions and appraisal of this condition within the context of their family. Help towards adaptation may be offered through identifying the sources of stress, assessing the coping strategies and resources, offering support, information and guidance, and by referrals to other services as needed.

\section{Purpose of the Study}

As little has been reported about the psychosocial impact on family members of having a child with a life-threatening food allergy, the purpose of this study is to understand what it is like from the mother's perspective to parent such a child. Special attention will be paid to what characterizes the experience, the meaning the mothers assign to the experience, how they see the stressors and ways of coping, and how they've adapted to the existence of this condition.

Phenomenology, a qualitative approach to gathering information when little is known about a subject, is used to elicit the mother's experience. A group of mothers parenting 
children with severe food allergies were selected and individually interviewed. A narrative of the experience emerged from their stories.

\section{Conclusion}

The number of children diagnosed as having a serious food allergy seems to be rising, especially amongst young children. This is a chronic condition highlighted by the fact that children's lives are at risk from ingestion of frequently common foods. Though the condition is well recognized by the medical community, as of yet there is no adequate treatment. Prevention of reactions through food avoidance is recommended, but accidents occur. Families must live with this stress-producing situation, which seems likely to affect all family members. Nurses may be in a position to help families living with this condition, but need to understand more than just the biomedical component to offer proper support. 


\title{
CHAPTER TWO
}

\section{REVIEW OF THE LITERATURE}

\author{
Introduction
}

This chapter reviews the literature to establish a background that might be useful against which to examine the issue of parenting a child with a life-threatening food allergy. The review identifies some of what is known biomedically about food-induced anaphylaxis. It also describes the interaction between the family and a chronic condition. Though little has been documented about the psychosocial impact of food-induced anaphylaxis specifically, attention is given to two conditions, asthma and diabetes, that may have some similarities of concern. Finally the literature related to food-induced anaphylaxis is explored.

The Biomedical Perspective of Food Allergies

It has been difficult to identify the true incidence of food-induced anaphylaxis (Kagy \& Blaiss, 1988; Lieberman, 1998). An International Classification of Diseases code was only introduced in 1997 for specific food-induced anaphylaxis and has not yet resulted in an accurate picture of the incidence of this condition (Clark, Gaeta, Kamarthi, \& Camargo, 2001). Many cases may be misdiagnosed or not reported. A Danish study looking at all cases of anaphylaxis in a year identified 3.2 such cases per 100,000 people, of which 5\% were fatal. A Mayo clinic survey of causes for anaphylaxis over 3.5 years suggested 33\% were due to food. From these reviews Burks and Sampson (1997) estimated 2500 cases of food-induced anaphylaxis occur in the US each year with 125 resulting in death. In addition, a Colorado survey by Bock (in Burks \& Sampson) 
estimated 950 American cases of severe food-induced anaphylaxis per year, which was felt to possibly be an underestimate. Food-induced anaphylaxis is described as the most common cause for treatment of anaphylaxis in US emergency rooms.

Though any food protein may cause anaphylaxis, some foods are more likely to cause problems than other ones. Foods most likely to cause a reaction include peanut, tree nuts, fish, shellfish, cow's milk, egg, some fruit (e.g. banana, kiwi), seeds, cereals and grains. Peanut, tree nuts, fish and shellfish are of special concern as they have most often been related to anaphylaxis and are less likely outgrown (Burks \& Sampson, 1997). Common properties have been identified for the major food allergens. They tend to be watersoluble glycoproteins with molecular weights of $10,000-60,000$ daltons. They remain stable under heat, acid, and protease exposure (Burks, 1999).

Approximately $90 \%$ of young children allergic to foods react to egg, milk, peanut, soy and wheat, while $85 \%$ of those adolescents and adults react to fish, shellfish, peanuts and tree nuts (Sampson, 1999a). Twenty-five percent of young children with egg or milk allergy are likely to develop other food allergies (Sampson, 1999b). It has also been noted that a society's eating patterns influence the prevalence of specific food allergies, as rate of exposure varies from one area to another. For example, peanut is a more common problem in North America than in many countries, while rice, a food we consider of low risk, is a more common allergen in Japan (Burks \& Sampson, 1997). Allergy to milk, egg, soybean, and wheat are generally outgrown, and $85 \%$ of children lose their milk sensitivity by their third year of life. Sensitivity to peanut, tree nuts, fish, and seafood are more likely to persist into adulthood. Ownby (1999) also suggests that food allergies acquired in later childhood are less likely to disappear. 
Factors have been identified that seem to predispose a child to developing foodinduced anaphylaxis including a personal history of atopy, the genetic predisposition towards forming IgE antibodies. They also include a family history of atopy, age, and dietary exposure (Burks \& Sampson, 1997).

Under normal conditions a barrier system develops in the human intestinal tract that limits entrance of intact proteins and decreases immune responsiveness to food protein. Stomach acid, pepsins, pancreatic enzymes and intestinal peptidases are a part of this system. Large proteins are broken down and absorbed by mucosal endothelial cells, where they are further broken down by lysomes. Even in a mature system a small amount of antigenic material does pass through this barrier causing an immune response, but most people develop a tolerance to this antigen. An abnormality in any element of this system can increase antigenic penetration of the barrier. This may help to explain the greater risk for developing food allergy in the young child whose protective mechanisms are still immature. The system must learn to process food effectively, develop immunity against pathogens, and develop tolerance to new foods. How the immune system learns to tolerate food rather than become sensitized is not fully understood, but early introduction of foods has been shown to be related to increased IgE production in those genetically predisposed to form IgE antibodies (Sampson, 1999b). Some studies suggest that exclusive breast feeding for the first few months may help in the development of tolerance (Sampson, 1999a).

Though some exposure to the food is required for sensitization to occur, the child may not need to ingest the food directly. Sensitization may occur through breast milk, if the mother has eaten the food. In some situations the exposures may be unknown, such as 
lack of communication about milk given in the nursery or unidentified contamination of some other food. On occasion cross-sensitization occurs from another food in the same biological family. It is not yet clear whether sensitization occurs in utero (Burks \& Sampson, 1997). Only a trace of the antigen may be required to cause anaphylaxis in a sensitized child.

Certain factors appear to influence antigen absorption and symptom onset. These include the amount of allergen ingested, whether it is consumed alone or with other foods, the degree of cooking which may make the protein less soluble, and any existing gastrointestinal upset that can make the mucosal wall more permeable (Sampson, 1997a).

In some individuals a known co-factor for anaphylaxis is exercise (Sampson, 1999a). Food-dependent exercise-induced anaphylaxis follows ingestion of a specific food in combination with exercise. Rarely it may follow a combination of any food and exercise. The problem is most likely to occur if exercise follows ingestion within 2 - 4 hours, while either alone is tolerated. Food-dependent exercise-induced anaphylaxis is more common in late teens and young adults. Foods commonly associated with exercise-induced anaphylaxis include wheat, shellfish, fruit, milk, celery, and fish.

A.review of 266 cases of anaphylaxis in children and adults by Kemp, Lockey, Wolf, and Lieberman (in Kagy \& Blaiss, 1998) found the most common system affected was the skin (especially urticaria and angioedema), followed by the respiratory tract. The reaction may occur as one phase, be biphasic, or less often protracted over days (Lieberman, 1998). In $25 \%-30 \%$ of cases symptoms settle and then may reappear in 1 3 hours (Burks \& Sampson, 1997). Mild symptoms may be a warning for more serious problems to come. 
Anaphylaxis to egg was first recorded in the 16 th century and to fish in the 17 th century (Sampson, 1999a). In 1905 anaphylaxis was noted post milk ingestion and more currently in 1969 ten cases of anaphylaxis were described following a variety of foods (Burks \& Sampson, 1996). Yunginger et al (1988) appear to have published the first examination of fatal food-induced anaphylaxis with their analysis of a group of seven individuals aged $11-43$ years. They concluded that the majority of the seven were highly atopic, reactions were more likely to occur away from home, the early signs and symptoms of a reaction were not always attended to, and some attempts to treat the reactions were inappropriate. Sampson, Mendelson, and Rosen (1992) reviewed six fatal and seven near-fatal cases of food-induced anaphylaxis in children $2-17$ years of age. All 23 children were highly atopic and also had asthma, believed to be reasonably controlled in most of the children. The food to which they were known to be allergic was unexpectedly ingested. Symptoms appeared quickly within 3 to 30 minutes, half had a "settling" of symptoms and then proceeded on to a major respiratory collapse. Not all the children had epinephrine for self-administration prescribed and of those who did, the majority did not have it available at the time of the reaction. None of the children who died received epinephrine before severe respiratory symptoms appeared, whereas the other children received it earlier. The majority of fatal reactions occurred in a public setting, while all the nonfatal reactions occurred in private homes, though not necessarily the child's home.

A number of reasons may exist as to why it would seem that the incidence of food-induced anaphylaxis in general is increasing. To some extent it may be due to an increased recognition of the problem including greater media attention, but other reasons 
have been suggested for an actual increase. One view focuses on changes in the North American diet over the last several years. It is suggested that there has been an increased intake of peanuts, nuts, fish, and seafood (Sampson, 1997a). More processed foods with added ingredients are being consumed as the population looks for meals that are fast and easy to fit into a current lifestyle where more women are likely to be in the work force. In addition more dining takes place outside the home where a greater variety of foods are being consumed. Food-dependent exercise-induced anaphylaxis may be increasing in adolescents and young adults due to the increased popularity of exercise (Sampson).

Sampson et al. (1992) refer to the accidental ingestion of an allergen and a survey by Bock and Atkins. These researchers showed a rate of accidental ingestion of peanut within one year of their survey occurring in $50 \%$ of children, and $75 \%$ of the children had eaten peanut within the previous five years. Cross-contamination of foods can become a problem during processing, storage, or preparation resulting in presence of the antigen in an unsuspected source. Labeling errors also occur, so presence of the antigen may not be identified. All children at risk for this problem must have self-injectable epinephrine available at all times, and those responsible for their care such as parents, baby-sitters, daycare workers, school personnel, etc., must know how and when to administer it. When developmentally appropriate, the children themselves should also be taught the injection procedure. Epinephrine is the treatment of choice for anaphylaxis, as it suppresses mediator release from the mast cells and basophils and works on vasodilation, edema, and bronchoconstriction. According to the Allergy Section of the CPS (1994), epinephrine must be given at the earliest sign of a problem, such as itching or swelling of the lips or mouth, tightening of the throat, or nausea. It should be given before respiratory 
distress occurs to try to ensure the continuity of adequate ventilation and circulation. In rare cases even early treatment has not been enough to prevent death. A plan should always be in place to immediately transport the child to the nearest emergency facility following injection, where the child should be observed for at least three to four hours or even longer according to the Canadian recommendations. This approach to prevent deaths includes plans for schools, daycares, and other childcare areas. Children who spend significant amounts of time away from their parents' care should wear a Medic Alert bracelet.

As suggested, some food allergies may be outgrown. Depending on the food, at least one year of avoidance is recommended before the sensitivity is reassessed. Following this, the child can be retested. If tests are negative, an oral food challenge, under controlled conditions, can be performed. If successfully tolerated, the food may be cautiously reintroduced into the child's diet.

\section{The Family and Chronic Medical Conditions}

Any medical condition affecting the child is believed to affect the family, just as the family has an effect on the condition and how it is managed. The pediatric nursing literature indicates a great deal of interest has been shown in the family and chronic illness including its impact, the coping strategies employed, and adaptation to the new situation. Research into the effects of chronic illness has been both from the perspective of it as a single entity and through looking at specific chronic conditions. The diagnosis - of a life-threatening food allergy suggests a chronic medical condition, although it may not fit the common definition of chronic illness. To date, nursing research into the 
psychosocial effects of this particular condition appears to be nonexistent, though some general understanding of its impact may be deduced from the general literature on chronic illness and lay reports about life-threatening food allergies.

It should be acknowledged that families come in different shapes and sizes, but all family members have roles and responsibilities related to maintaining the family and carrying out its functions. This is especially the case for parents. Mothers are most often referred to in the nursing literature, but an increasing amount of information is becoming available about fathers (Hanson \& Bozett, 1987; Katz \& Krulik, 1999; McKeever, 1981). Family Theory

Nursing research is frequently based on the assumptions of connection and interaction between family members and the belief in a dynamic relationship between the chronically ill child and his or her family members (Austin, 1991). The family is considered to be highly adaptable, and feedback occurs within the family so that needs and strengths can be identified (Wong, 1995a). Positive feedback is likely to lead to change, but negative feedback is more likely to cause resistance. Families may be open systems and welcome new ideas, resources, information, and opportunities. They may also be closed, reject input, and see change as a threat. This idea may help to explain why some families seem to welcome support and intervention, while others are more difficult to reach. Though the family system has periods of growth, change, and stability, balance between these stages is desirable. The family system can both cause change and react to change.

Family stress theory identifies stress as inevitable (Wong, 1995a). Stressors can be predictable and unpredictable and can occur from positive and negative situations. Stress 
can be cumulative, and demands can come from different settings. If too many stressors build up it can be overwhelming and lead to a crisis. Coping strategies and adaptation are required for families to perform their functions and for survival. Two important theories fit under the umbrella of family stress theory and include Hill's Family Stress Theory, the ABCX Model, which focuses on the precrisis stage and the Resiliency Model, which focuses on the postcrisis stage (Friedman, Svavarsdottir, \& McCubbin, 1998). The former may help to explain why families respond differently to similar situations through an interaction between characteristics of the event (A), family resources (B), and definition of the event (C) to result in a crisis (X).

The Role and Responsibilities of Parents

Traditionally North American women and men have filled different and seemingly complementary roles in the family. Women have been the housekeepers, cooks, companions, child caretakers, family caregivers, and health leaders. McGoldrick (as cited in Friedman, 1998) and Freidman and Heady (1998) view women as the primary health decision-makers, educators, counselors, and caregivers. In caring for ill children Burke, Kauffmann, Harrison, and Wiskin (1999) found a common view was of the mother being primarily responsible and of others as "helping" her with "her job". In the past at least, fathers have been the providers, economically supporting the family. They have also offered spousal support and protection for the family. Their direct contributions towards childcare and socialization have been more limited.

The family and parental roles are directly affected by some of our most recent trends. -They include an economy which seems to support the need for two incomes, an increase in single parent families, the feminist movement with an expectation of expanded and 
equal roles for women, and the fact that more women are remaining in the workforce after having children. As female roles have been changing, there is an increasing expectation that fathers will take a greater role in child care and socialization, but in reality there has been a modest increase in involvement, and variations exist according to social class (Friedman \& Heady; Hanson \& Bozett, 1987).

The Impact of Chronic Illness

Family systems theory and family stress theory suggest that a child's chronic illness can upset the family's equilibrium and cause stress or tension to all members. In her review of nursing research on family adaptation to a child's chronic illness, Austin (1991) identified parental responses to the initial diagnosis as anxiety, shock, anger, guilt, and fear. McKeever (1981) adds numbness and disbelief from her studies of fathers. The diagnosis can affect parental roles and functions, how they view themselves and the child, their normal activities, careers, and their social relationships, especially with each other.

Much though not all of the information about the demands, coping strategies and adjustments related to chronic illness come from mothers. Based on her review of the literature, Heaman (1995) suggests that this is possibly because they are more available and have more direct input into the caregiver role. It may also be that mothers are more willing to share their perceptions and feelings.

Chronic Illness as a Stressor

Stress is a normal part of life occurring from environmental, social, and physical demands. It can occur from normal growth and development or as a result of a stressful 
event (Hymovich \& Hagopian, 1992). It can result from major events or even "daily hassles" (Lazarus \& Folkman, 1984). Gallo (1991) discusses a pileup of demands, resulting from an initial stressor, prior strains, consequences of coping attempts, normative transitions, and intrafamilial and social ambiguity.

Evidence exists suggesting that both the visibility or the lack of visibility of the condition can be important (Jessop \& Stein,1985). The level of the child's daily function, surgical procedures, and whether it is necessary to anticipate change in the child's condition, or combinations of these factors may make a difference. The perception of uncertainty may be an important issue in chronic illness. Elliott and Eisdorfer (as cited in Hymovich \& Hagopian, 1992) identify additional factors including length and frequency of occurrence, controllability, timing in regards to other life events, extent to which it is anticipated, and expected consequence of the condition.

Kurnat and Moore's (1999) review of the literature suggested that common sources of stress for parents of children with chronic conditions come from lack of understanding of the condition, management strategies, and developmental needs. Stressors may include financial burden, lack of information, uncertainty about the future, requirements for excessive time or energy, fear of the child dying, marital strain, feelings of other family members, the need to deal with schools and other child caregivers, dealing with siblings, interference with routines, work, or other activities, and dealing with health care providers. The Burke Assessment Guide to Stressors and Tasks in Families with a Child with a Chronic Condition outlines many of these stressors quite well (Burke et al., 1999). Cohen (1993) suggests diagnosis of a life-threatening chronic illness can challenge a person's assumptions about the world, impacting on existing knowledge, beliefs, values, 
and expectations, leading to uncertainty. For the individual, there appears to be no logic, justice, or fairness. The ambiguity can cause confusion and disorganization, and the unknown is feared. In a cross-cultural study of chronic illness, mothers identified the behaviour of their children as a source of stress (Krulik et al., 1999). It was suggested that these mothers might not feel adequate positive reinforcement for their caregiving efforts. In addition, patterns of stress were found to vary by culture and also need to be considered.

\section{Coping with a Child's Chronic Illness}

Once something is appraised as a stressor there is a need to deal with it. According to Lazarus and Folkman (1984) the functions of coping might include problem-solving, avoidance, decision-making, decreasing tension, and restoring equilibrium. Coping requires both strategies and resources. In her review of parental coping strategies, Holaday (1984) suggested that they have three functions: to change a situation, to control meaning of the experience before stress appears, or to control existing stress. Holaday also believes coping efforts can occur at a conscious and unconscious level and Lazarus and Folkman believe that some appraisal of stress occurs at the unconscious level.

Coping strategies have been divided into problem-focused and emotion-focused (Lazarus \& Folkman, 1984). Block, Brandt, and Magyary (1995) defined emotionfocused strategies as promoting distancing from stress and problem-focused as changing or managing a stressful situation. Examples of emotion-focused strategies include minimization, avoidance, distancing, positive comparison, selective attention, self-blame, self-punishment, changing of meaning, drug and alcohol use, relaxation techniques, and exercise (Lazarus \& Folkman; LaMontagne, Hepworth, Johnson \& Deshpande, 1994). 
Denial, another technique, may appear on the surface to be a negative strategy, but in some cases can be beneficial (Holaday, 1984). Defining the problem, learning new skills, finding solutions, analyzing costs and benefits of solutions, and managing the environment are examples of problem-focused strategies. Holaday suggests assigning meaning to the illness, efforts to normalize the child's life, and establishing a system of social support are helpful strategies for many parents. Gallo (1991) divides the most common coping strategies into avoidance, elimination, and assimilation. Cohen (1993) identifies "living a day at a time" as helping to reduce uncertainty for some parents.

Resources are required in support of the coping process. These may include health and energy, optimism, a sense of mastery, problem-solving skills, social skills, social supports, and money or materials (Austin, 1991; Gibson, 1988; Hayes, 1997; Lazarus \& Folkman, 1984). Resources may come from within the individual, family, or community and include support from spouses, friends, family, religion, or educational networks (Kurnat \& Moore, 1999; McCubbin, 1989). Single parent families may have fewer resources available for coping (Austin, 1991). In studying families of children having cystic fibrosis, Venters (1981) found that families did better when the burden of the illness was shared both within the family and with someone outside of the family, but the identity of the outsider is unclear and could possibly make a difference. Also the cultural background of the families is not identified and could have an affect on whether families choose to share with outsiders or not.

A variety of factors can influence how an individual copes, some of which are person factors and others situation factors (LaMontagne, Johnson, \& Hepworth, 1995). Personal factors that have been shown to have effect include age, gender, ethnicity, anxiety, and 
locus of control (Cheng \& Tang, 1995; Heaman, 1995; Hughes, McCollum, Sheftel, \& Sanchez, 1994; Wills, 1999). For example, fathers may be less likely to attend support groups (Baumann \& Braddick, 1999; McKeever, 1981). Situation factors might include socioeconomic status, environmental characteristics, availability of social supports, and previous experience with crisis (LaMontagne et al.)

\section{Chronic Illness and Adaptation}

Adaptation is frequently referred to as the outcome or goal of coping in the nursing literature. In describing McCubbin and Patterson's model of family adaptation, Gallo (1991) talks of adaptation as a "new sense of balance in the family system", while White (as cited in Clawson, 1996) sees the goals of adaptation as growth, reproduction, and autonomy. According to Friedman et al. (1998), adaptation is a process, which manages stressor demands through coping, using resources, and problem-solving. Burgess, as cited in this same source, defines it as an altered state which may be positive or negative, and McCubbin and Patterson (as cited in Gallo) identify a continuum from poor to good adaptation. The success of problem management, strong family relationships, achievement of goals, decreased anxiety, treatment compliance, and maintenance of normal activities and social relationships can be signs of positive adaptation, while feeling helpless, defeated, negative, or demoralized may be signs of negative adaptation (Holaday, 1984; Kurnat \& Moore, 1999; Lazarus \& Folkman, 1984). Normalization and focusing on what the child can do is considered desirable (Clawson, 1996), but Austin's (1991) review notes that normalization is a culturally based concept with different meanings depending on the cultural context. In addition, what may appear to be normal 
on the surface may be based on family adjustments, which can send conflicting messages to the child.

Adaptation may be affected by many factors. Austin (1991) includes condition variables such as severity and prognosis, demographic variables such as culture, socioeconomic status, and child variables as age, gender, and developmental stage. It is likely parental personality traits, knowledge, attitudes, values, and skills may also have influence on adaptation. In discussing fathers and family adaptation, Katz and Krulik (1999) have added the utilization of services, support groups, and intervention programs; social acceptance; and public awareness.

Canam (1993) has approached adaptation through eight adaptive tasks to be accomplished by parents of children with chronic conditions. First, the condition must be accepted and sense made of the situation. She suggests that the mother's perception especially is important. The condition must be managed day to day based on accurate and complete information. The child's normal developmental needs must be met with physical risks being balanced with emotional benefits. The family's developmental needs, considering relationships, roles, and communication, must be supported. The ability to cope with ongoing stress and crises is essential. Family members must be assisted with managing their feelings, which may include anxiety, guilt fear, resentment, anger, and depression. Parents must be able to educate others about the child's condition. The last of the tasks involves being able to establish a support network.

Adaptation may require changes in family structure, functions, roles and responsibilities, and many authors refer to an adaptation phase or process which takes 
place over time (Clawson, 1996). Austin's (1991) review found that nursing research paid little attention to stages of adaptation.

The Role of the Nurse in Chronic Illness

Yoos (1987) suggests anticipatory guidance is helpful in chronic conditions including discussion of common questions, fears, expectations of the condition, possible impact on development and behaviour. The nurse may help to reduce stress through help in transitioning the child into the school system. Nurses are often viewed as important supports (Burke et al., 1999).

\section{Asthma and Diabetes as Comparative Conditions}

Asthma and diabetes have been selected as diseases that may share some common issues with life-threatening food allergies when parents' perceptions and experiences are considered.

Asthma is a common chronic respiratory condition affecting at least $10 \%$ of the pediatric population in Canada. Asthma is characterized by cough, wheeze, dyspnea, and chest tightness, which may occur alone or in combination. It can vary from being very mild to severe, but in most children asthma can be well controlled with an appropriate management plan of environmental control and medication. Children with asthma generally appear normal and can live normal lives, if control is achieved. When acute asthma episodes occur it can be frightening for parents, and in spite of increased knowledge and management tools death is still an occasional, though usually preventable outcome. 
Diabetes occurring in childhood is most often Type 1 diabetes, an insulin-dependent form, usually appearing before 20 years of age and having its peak incidence between 10 and 15 years (Wong 1995b). The onset is typically abrupt. To control the condition, blood glucose must be monitored and a balance between insulin, diet, and exercise maintained. Even with good control, hypoglycemia occasionally occurs, and it tends to occur quickly. An explanation for its occurrence is usually apparent, but not always. Parents and children, when possible, must recognize its symptoms and institute immediate treatment. Hyperglycemia, which has a slower onset, can also occur. Though serious long-term complications are common, good diabetic control can greatly prolong their onset.

\section{Similarities and Differences in the Conditions}

Many similarities exist between asthma, diabetes, and life-threatening food allergies. Most of the time all of these children appear normal and well, and it is only when having a reaction that the child appears different to other children. The three conditions all require lifestyle changes not only for the child, but the whole family, and constant monitoring is a necessity. Signs signaling the occurrence of acute problems must be recognized early and appropriate treatment initiated. Acute problems can be frightening in all three situations. Other caregivers need to be taught about the child's problem and its management, whether it be asthma, diabetes, or a food allergy, and parents need to be able to trust that these people will provide a safe environment and handle any problems effectively. To a greater or lesser extent, the child's life depends on it. Common entities in the environment may present a problem, triggering a reaction. In addition, these 
conditions may all be life long, and as children age parents will have to gradually give up control and children accept more responsibility for managing the condition.

The majority of children who have asthma also have allergy triggers, so as in the case of life-threatening food allergies normal environmental conditions can trigger reactions. In both situations, monitoring the environment and trying to prevent exposure to harmful conditions and substances is essential. When a problem occurs, both require a quick relief medication, and it must be immediately accessible. It is less likely that a severe asthma attack will progress over minutes as commonly occurs with severe food allergies, and the latter reaction has a higher risk for progressing on to death. More often there is some warning hours or days in advance with asthma. Unlike with life-threatening food allergy, many children having asthma need regular medication to control their asthma.

Both diabetes and a life-threatening food allergy are usually diagnosed after a sudden acute episode. Both conditions require monitoring of food intake, and poor food choices can result in a significant reaction for the child. In the case of diabetes it is not a specific food, and food is not the only issue that requires monitoring. Unlike food allergies, diabetes requires obvious daily reminders of the condition through blood glucose monitoring and insulin administration. Both conditions require that families and eventually the children gain some comfort level with administering medication through an injection, but diabetes requires actually performing the procedure on a daily basis.

\section{Parents' Perspectives of Asthma}

Nursing research has been fairly active in gathering information about parents' perspectives of asthma. This has been accomplished through structured questionnaires 
and less structured interviews. Information has been gathered from individuals and through focus groups. Research has looked at areas such as financial, social, and emotional impact of asthma; beliefs about the child; coping strategies and resources; and phases towards adaptation to the condition.

\section{The Financial, Social, and Emotional Impact of Asthma}

In conducting focus groups with 52 parents of children with asthma, Kieckhefer and Ratcliffe (2000) asked about parents' fears and identified nine themes including uncertainty, long-term medication effects, the condition won't go away/get better, dying, concern about normal lifestyle, increased susceptibility, hospitalization, noncompliance of youth, anaphylaxis, and dependency on medications. Uncertainty was most frequently mentioned ( $22 \%$ of total), and medication effects and prognosis were mentioned by at least $10 \%$ of all parents. In addition, many parents expressed a need for more information and wanted providers to know they were scared.

The issue of uncertainty has emerged in other research related to pediatric asthma (Horner, 1997; Jerrett \& Costello, 1996; MacDonald, 1996). Horner found the prediagnosis phase was identified as the most difficult in her study of 12 families. This uncertain time was described as "groping in the dark", and feelings of helplessness, fear, and frustration were common with acute episodes. Diagnosis was felt to reduce uncertainty in Horner's study and give meaning to a situation that has been confusing and frustrating according to Jerrett \& Costello . In addition, MacDonald identified "mastering uncertainty" as the overall theme for eight mothers interviewed about the meaning of the asthma. Fear based on uncertainties was apparent initially, but over time as the mothers gained knowledge and experience, they were able to take better control of the situation. 
Other emotional reactions have been identified at various times in the experience of parenting a child with asthma. They include sadness, anxiety, self-guilt, insecurity, dismay, fatigue, hostility towards the child, terror, and disbelief (Clark, 1997; Donnelly, Donnelly, \& Thong, 1987; Park \& Martinson, 1998).

The financial burden of asthma was evident in studies from Mailick, Holden, and Walther (1994) and Donnelly et al. (1987). Asthma treatments, medical services, and missed work due to acute illness can contribute to this burden. Using a slightly revised version of the Impact of Illness on Family Scale with 23 low-income African American and Hispanic caretakers of children with asthma, Mailick et al. found personal strain correlated with financial burden. Donnelly et al., looking at the impact of asthma on families, identified a sense of financial burden in slightly less than $50 \%$ of parents.

Evidence suggests that asthma impacts on parents' activities and social relationships. Park and Martinson (1998) found parents felt restrictions in their lifestyles with fathers feeling an impact on the quality of their work and relationships with coworkers. Mothers were limited in social experience, and both identified restrictions on personal activities. Family vacation and leisure activities were also affected, and Donnelly et al. (1987) identified this in more than $50 \%$ of the parents they questioned. Conflict between parents was often related to the child. Some of the parents studied by Donnelly et al. believed families of children with asthma are more closely knit, but slightly less than $50 \%$ of the parents felt they had less time for other children in the family. Mailick et al. (1994) showed personal strain to correlate with social isolation in their study.

Parents' roles and responsibilities may need to change when asthma occurs in the family. This seems especially so for mothers. Mothers are required to add the role of 
asthma manager (Jerrett \& Costello, 1996), and fathers may see themselves as supporters to their wives in this role (Horner, 1997).

Beliefs About the Child

Park \& Martinson (1998) interviewed Korean families and asked parents for their views of their children with asthma. These perceptions tended towards the negative and included a belief of physical limitation, psychological change, and requirements for social adjustment. Children were seen as dependent, irritable, inattentive, and selfcentred. Donnelly et al. (1987) used a self-designed questionnaire to explore parents' attitudes related to their children with asthma. More than half considered the children more dependent and needing asthma to gain attention, and felt asthma would affect sports activities and school performance. Some families also expected their children to have a poorer relationship with friends and siblings, and that asthma would retard growth. Other beliefs included that these children exhibited a degree of self-pity, poor self-opinion, and slow maturity, but also that they tried harder and were more responsible.

\section{Coping Strategies and Resources}

Coping with stressors involves the use of a variety of strategies supported by the availability of different resources. Mailick et al. (1994) identified the use of active coping, planning, religion, and acceptance as most frequent for the parents in their study. These authors suggested that religion might provide both emotional support and give meaning to the illness burden. They also found that a bigger financial burden was related to the increased use of supports, and that this increased use correlated with a less negative impact on illness mastery. In their efforts to actively deal with asthma in their children, Horner's mothers (1997) were noted to ask questions, some tried alternative 
measures, and some, who felt unsupported by their care provider, demanded attention. Having trust in health care providers and inclusion in care decisions seemed to have positive effects for others (Jerrett \& Costello, 1996; Macdonald, 1996). Asher and Price (1998) found a range of experience and satisfaction with regards to parents' interactions with professionals and emphasized the necessity of equality, communication, and education to increase parental satisfaction. Denial, avoidance, and confrontation have been identified as possible strategies for dealing with the diagnosis of asthma (Clark, 1997). Confronting the diagnosis involves a realistic look at the diagnosis and its impact and therefore seemed to be a more positive approach. Clark also identified the importance to parents of feeling supported. The family, other caregivers, physicians, and the larger social system were all important in providing this support. Park \& Martinson (1998) raise the idea of cultural impact on coping related to asthma by noting that their Korean families were traditional in their roles and tended to deal with problems within the family.

\section{Phases Towards Adaptation}

There seems that some evidence is available supporting the existence of different phases in parents' adjustment to asthma. One such study looked at the parents of preschoolers and their experiences in integrating asthma into daily life. Based on this qualitative study, Clark (1997) proposed that parents first need to ascribe meaning to the diagnosis of asthma or define it in their own terms. This process depends on previous experience and the severity of the condition. The second phase is related to learning to manage the asthma, and action is taken according to the meaning ascribed. Parents learn to observe in a more knowing way and make comparisons. Clark's parents participated to 
varying degrees in monitoring treatment effects and learning to prevent problems. They ranged in their level of trust with regards to professionals. The final phase of adjustment involves the incorporation of the disease into parents' lives with some degree of control and future orientation as they maintain their selected approach towards the child and condition and anticipate future needs and consequences. In this study this included teaching others, researching new environments, and negotiating with the child. The perception of severity, support, and child's health all were especially influential in how parents made their way through this process.

"Catching the Asthma Before it Gets Out of Hand" was the central theme identified in Horner's 1998 study of 12 families of children having asthma. She felt these families passed through overlapping phases as they first focused on learning about asthma and trying to gain control of it. As they gained knowledge and experience they moved into a phase of dealing with the asthma focusing more on recognizing problems, responding to them, and evaluating their responses. Eventually parents began to come to terms with the asthma, and it became more peripheral to their lives. Horner described how parents buffered between family expectations and those from the external environment, especially the school, and how they balanced between risks and benefits trying to encourage normal experiences for the children. The meaning of asthma changed over time from being the central focus of their lives to moving into the background.

Gaining control of asthma was also identified by Jerrett and Costello (1996) as a process beginning with diagnosis and continuing over time as parents became more skilled in management. Parents described phases of being out of control, being involved, 
and being in control when asthma is integrated into family life. Specific strategies were identified for each phase.

\section{Parents' Perspectives of Diabetes}

Studies related to parents of children with diabetes have also looked at the impact of the condition on the family, concerns expressed by parents, strategies and resources that parents have used in coping with the problem, and to some extent adaptation. The Social, Emotional, and Financial Impact of Diabetes

In her case study of a family of an eight year old child recently diagnosed as having insulin-dependent diabetes, Gallo (1991) describes the mother's initial reaction of shock and disbelief accompanied by fear, crying, and anger. Similar reactions were identified by Faulkner (1996); Hatton, Canam, Thorne, and Hughes (1995); and Hodges and Parker (1987) along with additional emotions such as guilt, frustration, and anxiety. Hatton et al. interviewed eight couples caring for infants or toddlers with diabetes who following diagnosis expressed feelings of horror, shock, being overwhelmed, of just surviving, being unable to comprehend, grief, exhaustion, helplessness, hopelessness, self-blame, blame for others, inadequacy, being out of control, and depression. While Kovacs et al. (1985) felt depression, anxiety, and distress on average were mild and at a subclinical level in their parents, these reactions were seen as more of a problem for mothers than for fathers. Over time these responses improved.

Diabetes alters a family's life and places an extra burden on parenting (Faulkner, 1996; Gallo, 1991), especially for mothers. Normal activities may need to be modified and more responsibility accepted for monitoring \& managing the diabetes including 
scheduling food, activities, and insulin. Faulkner suggests that her mothers tended to be managers, teachers, and caregivers, while her fathers were breadwinners, leaders, and disciplinarians. It would seem that they fell into the traditional roles for North American parents. Kovacs et al. (1985) noted mothers most often were responsible for clinic and research contacts. Fathers were more involved at the beginning and less so later on. Lifestyle changes may involve mothers quitting work and fathers rearranging their work schedules in order to manage the diabetes (Hatton et al.,1995). Based on self-report mothers may have a decreased sense of bonding due to their responsibility for causing pain and limiting diet, but depending on the degree of involvement fathers may feel closer to the child (Hatton et al.). A child's diabetes brings about a number of losses not only for the child, but also for the parents. These include a loss of income, freedom, flexibility, and supports (Hatton et al.).

Social isolation is another issue for parents of these children (Gallo, 1991; Hodges \& Parker, 1987). Initially the family in Gallo's study felt isolated from people previously close and found that others were fearful of caring for their child. Difficulty with communication between spouses is a possible issue and Hatton et al.'s parents (1995) found the research interviews to be therapeutic and a help towards a better understanding of each other. Though marital relationships can be affected by chronic disease in children, Kovacs et al. (1985) identified a high number of harmonious marriages in their group. Divorced parents of children with diabetes may experience greater dissatisfaction with their quality of life than married parents according to Faulkner and Clark (1998), who used the Parents Diabetes Quality of Life Questionnaire (PDQLQ), a 42-item questionnaire, with 56 parents. 
Research has shown diabetes may also be a significant financial burden for families of children with this problem (Gallo, 1991). Besides the direct costs of managing the diabetes, family incomes may be decreased as mothers quit working and/or fathers adjust their schedules. Faulkner and Clark's research (1998) revealed that diabetes was connected with a sense of burden, and that low-income families experienced greater dissatisfaction with their quality of life than those who had greater financial means.

Some other issues related to diabetes have been raised in the nursing literature. Faulkner and Clark (1998) found that a significant relationship existed between life satisfaction and metabolic control. This same study showed having to tell others about their child's diabetes, explaining what diabetes is, finding themselves overprotective, and taking ownership of the condition had the most impact on quality of life. In addition, Faulkner's study (1996) raised the issue of focusing too much on the condition, and a mother suggested that it can "consume" life causing you to go "wacky". Hatton et al. (1995) support this view of being consumed in their interviews with eight couples who identified an intense feeling of responsibility for their young child post diagnosis and that the condition was consuming their lives.

\section{$\underline{\text { Parents Concerns }}$}

Through group interviews with 14 parents, Hodges \& Parker (1987) identified a number of concerns for that group related to having a child with diabetes. These concerns included managing the diabetic regimen (insulin, blood, and urine testing), coping with restraints (food, discipline, economic, and scheduling), dealing with school problems (lack of confidence in teachers' knowledge and management abilities), and working with the health care team (trust, support, and management). Parker, Swift, Botha, and 
Raymond (1994) also identified school problems from a mail-out questionnaire

completed by 262 parents of children who developed diabetes before 2 years of age. Staff ignorance about diabetes and their inability to cope with it was the most often identified school problem. Families also continued over time to worry about hypoglycemic episodes, employment prospects, and complications. Parents of female children expressed more concern than those of males. The transition from parent to child for control of the condition was a difficult time for parents. Top concerns for another group of parents were worries about being overprotective, complications, and denial of medical insurance followed by fear children would pass out, diabetes would disrupt school activities, and about having other children. Mothers worried more, but the sample mainly included mothers (Faulkner \& Clark, 1998). Hatton et al.'s parents (1995) shared many of these same concerns plus worries about the need for long-term care and about growth and psychological development considering what the children were being subjected to.

\section{Coping Strategies and Resources}

Religion, a common coping strategy for many, was identified by both Gallo (1991) and Faulkner (1996) as being used to cope with the situation surrounding diabetes. Gallo using a case study to illustrate a family's adaptation to diabetes suggests parents can assign meaning to their child's illness. In this case her mother used religion and redefined the situation to help find meaning. This family used both existing resources and developed new ones along with strategies for coping.

Some parents may begin to cope by realizing that they have no choice and that their child is dependent on them. Other strategies may include assertiveness, dealing with the child's needs, seeking and accepting support from friends, family, and others (Hatton et 
al., 1995). Parents also looked for a cause, considered alternatives, and hoped for a cure. On going home from the hospital after diagnosis, these families felt a great sense of loss related to a sudden lack of professional support.

\section{Adaptation}

Gallo (1991) felt adaptation began in her illustrative family when the parents started to work towards organization and balance related to the diabetes and their lives. Attempts to normalize their lives, master diabetes management, find family stability, and work together as a couple were all seen as steps towards adaptation. The level of worry and concern about the child declined over the first year and largely over the first 6 months for parents in Kovacs et al.'s study (1985). Most mothers were assessed as being appropriately involved in caring for their child. Parker et al. (1994) suggest that over time parents may become less anxious at least about the practical aspects of diabetes such as urine and blood monitoring and injections.

Hatton et al. (1995) identify at about 6 - 8 months post diagnosis a third phase in the experience of their parents of toddlers and infants. Families were able to feel a bit more relaxed and in better control. There was a sense that the diabetes could be integrated into their lives. Time, knowledge, and seeing their child grow all seemed to promote the feelings of this phase, which the authors called long-term adaptation. Parents took charge, began to trust, developed supports and balanced hope with realism. Though in general things were more settled, new problems continued to occur as the child matured. Struggles between child and parents became a problem as children got stronger and started to assert themselves. Also the children began to enter new environments with new people. 
Parents' Perspectives of Life-Threatening Food Allergies

It is quite conceivable that families of children with life-threatening food allergies would suffer from some of the same stressors, use some of the coping strategies identified, and adapt in similar ways as families of children with other chronic conditions. It is also possible that there may be some unique stressors, perceptions, coping patterns, or adaptation goals that are specific to this threat. Little information is available in the professional literature as to how parents of children with life-threatening food allergies see their experience. Some anecdotal reports can be found in the lay literature.

\section{Perspectives from the Professional Literature}

Though an occasional medical article about life-threatening food allergies mentions family concerns or impact related to having a child with this problem (Vickers, Maynard \& Ewan, 1997; Yunginger, 1992) only two articles were identified that actually focus, in some form, on the psychosocial aspect of a child having this condition.

One report identified is anecdotal from a parent who is also a nurse (Bunce, 1997). In reference to the allergy in the mother's words, "It takes over your life". You must be constantly "vigilant". Witnessing her child's reaction evoked definite fear. She describes the time spent and the difficulty in researching foods. This mother was able to trust only her mother-in-law to care for her child. Normalization was recognized as an important goal. Limitations were placed on the mother's activities and she felt the need to quit work. She was very aware of dangers in the play group environment and always on call to the group. Unpredictability was an ongoing source of stress requiring constant monitoring for new problems. Even traveling presented problems. 
A recent article (Primeau et al, 2000) may be the first real sign of concern about the psychosocial impact of a food allergy in the literature. The objective of this study was to compare children ( $<18$ years old) and adults having peanut allergy to those having rheumatological diseases with regards to quality of life and family relations. For the children, a parent or guardian filled out the questionnaires including a visual analogue scale indicating how much they felt the allergy disrupted their child's activities and a family impact questionnaire used to assess impact in a number of other chronic childhood conditions. It is unclear which parent figure filled out the questionnaires in this study, though it might be expected that mothers were in the majority. The study results indicated for the participants there was disruption in both daily activities and in family relations. In comparison to children with rheumatological conditions disruption in activity and 'Familial Social Interaction' was found to be significantly greater for children with peanut allergy. For 'Personal Strain' the two groups scored similarly, for 'Mastery' the peanut-allergic families did slightly better and were significantly better when scoring 'Financial Burden'. In spite of the limitations noted by the authors and the fact that questionnaires are limited in the information they can gather, this study identifies that a child's peanut allergy does have an impact on the family and that this is an important area for further research.

\section{Perspectives from the Lay Literature}

Collins (2000) gives a father's point of view about having a child with life-threatening food allergies. He describes the presence of a "cool calmness" and generalizes this as a father's approach, but in this case his occupation as a navy jet pilot may have some influence on this attitude. He emphasizes his belief in the need to ensure normalcy, and 
fears his child being "pigeon holed" by the condition. Collins describes thinking about the allergy as "mind numbing", and almost scaring him into denial. He encourages fathers to be actively involved in dealing with the problem of life-threatening food allergies. Another father's thoughts (Hopper, 2000) follow upon his experience with his daughter's anaphalactic reaction, which he describes as a "fire fight", "deadly foe", "relentless enemy", and "tough opponent". Hopper suggests that his beliefs as a father, that he must protect his child, solve important problems, and be strong rather than appearing vulnerable, does not always work with this particular condition. He can't completely eliminate or solve it, but dealing with it has been a growth experience. Both fathers feel that mothers and fathers react differently to the problem.

Another report comes from a mother (MAIN, 2000) who expected support from family, friends, and community for her child, and was shocked by her child care worker's reaction and lack of concern for the child. This mother also felt it took her family a long time to "get it" and still $31 / 2$ years post diagnosis cannot trust the child's grandparents to care for the child. This mother describes being overwhelmed to the point of crying initially when grocery shopping, but stated that now they have accepted the changes they have made and have established a certain "comfort level".

\section{Conclusion}

Understanding how parents see and respond to a variety of chronic diseases points the way to how parents may view and experience their child's life-threatening food allergy. One can make some guesses about the condition's effects. Some evidence for similarities is found in the previous anecdotes, but it cannot be assumed that this provides a complete 
picture for this unique problem. There may be other concerns about or ways of dealing with the condition that professionals, who do not live with it, have not identified. Much more might be gained through nursing research directed at asking the families who live with a child's diagnosis of a life-threatening food allergy. 


\section{CHAPTER THREE}

\section{METHODOLOGY}

\section{Introduction}

Chapter three will discuss the research methodology chosen to study the experience of mothering a child with a life-threatening food allergy. The chapter will begin with the reasoning behind the decision for the selected methodology. It will provide an explanation of phenomenology, the specific approach chosen, and outline the research design including the study sample, setting, data collection, and data analysis. The chapter will conclude by outlining the expected limitations of the study.

\section{Qualitative Methodology}

Quality of nursing care provided to any individual is greatly influenced by the degree to which the nurse understands the recipient's personal context, the medical condition, and the possibilities of the issues that may be involved as the two interrelate. Though it is always important to consider the family in providing care, it is especially so if the problem affects a child.

When little is known about a situation, qualitative research can make a valuable contribution by helping to reveal an understanding of the specific experience based on the perspective of the individuals involved. The experience of what it is like to be the mother of a child with a serious food allergy is an example of such a situation warranting further understanding. Qualitative research allows for an in-depth exploration of the phenomenon of interest as a whole with importance placed on the views of those 
experiencing the situation rather than views predicted by the researcher (Polit \& Hungler, 1995). An attempt is made to view the whole context of the experience rather than attempting to control for any aspects. Information is collected in an unstructured or semistructured format, and the subjective view is considered important. The data is analyzed in a systematic manner in order to assist the researcher in describing, understanding, and explaining the phenomenon of interest.

The researcher has a variety of qualitative methods to choose from, but the one chosen depends on factors such as the researcher's comfort with and knowledge of the different methods and the information desired. The method chosen for this study was phenomenology, an approach dependent on an intense interest in a specific human experience and the reality of what it is really like to live this experience (van Manen, 1997). Phenomenology, according to Cohen (1987), is the study of the appearance of things, and good phenomenology touches our soul according to Morse (1992). Through it we can attempt to feel the experience, and further value comes from what it can offer others (Ray, 1984).

Phenomenology was chosen for this study for a couple of reasons. The first based on the researcher's experience both in dealing with families experiencing this situation and as a parent herself. She wondered what it would be like to be these parents, how they understand the experience, and if health care professionals could make the experience easier for them in any way. Secondly, the biomedical issues of life-threatening food allergy in children are extensively covered in the professional literature. What is lacking is discussion from the psychosocial perspective. A phenomenological approach was expected to be able to provide some insight into how parents live, see, and interpret the 
experience. It is believed that this knowledge, if shared, can help sensitize other nurses to the possibilities for other parents and provide some guidance for care in future encounters. Van Manen (1997) suggests that by gaining an understanding of the meaning of an experience from the perspective of those living it, one can act more thoughtfully and tactfully in those situations.

\section{Phenomenology}

\section{$\underline{\text { Historical Background }}$}

Phenomenology is an inductive and descriptive approach (Streubert \& Carpenter, 1999). It focuses on and describes the phenomena of everyday lived experience. The term phenomenology has existed for centuries. It has its roots in philosophy and has been identified as a philosophy, research method, an approach, and as a movement due to its dynamic nature (Ray, 1994; Speigelberg, 1982). What is considered the phenomenological movement began in the latter half of the 19th century and has often been discussed in the terms of phases (Spiegelberg; Streubert \& Carpenter). The first phase is considered the preparatory phase and is associated with Franz Bretano and Carl Stumpf, scholars in the field of psychology interested in phenomena. Though not actually considered phenomenologists, they laid some of the groundwork for current phenomenology and trained and influenced some of the later phenomenologists. Stumpf emphasized that phenomenology could have scientific rigor. Bretano was interested in our inner perceptions of phenomenon and intentionality, a belief that the conscious was always conscious of something (Cohen, 1987; Streubert \& Carpenter). 
The second phase, according to Spiegelberg (1982) was the real beginning of the movement. It developed out of Germany and was led by Edmund Husserl, who was interested in the roots of knowledge, the phenomena themselves, and the concerns of human beings. Consciousness was a key concept for Husserl, and he believed the existence of phenomena depended on this consciousness or awareness of the self and others. Husserl felt that knowledge would come from a study of phenomena as they existed in the consciousness of the people to whom they appeared, as in truth comes from within. This knowledge surfaces through reflection. He also suggested that human experience has meaningful structure and searched for insights into the essence of that structure (Cohen \& Omery, 1994; Ray, 1994). His approach to phenomenology is identified as epistemological or descriptive phenomenology, the goal of which is to describe and clarify the meaning of experience from the perspective of the person living it (Ray). According to Cohen and Omery, following this method means the researcher's preexisting beliefs are set aside, the experiences described are reflected upon, and the essential structures described.

Also associated with the second phase of the phenomenology movement was Martin Heidegger with an ontological focus. He was interested in the meaning of Being or existence and looked for it in the every day world (Cohen \& Omery, 1994). For Heidegger phenomena existed autonomously not dependent on consciousness. His approach is called hermeneutic or interpretive phenomenology, and he considered it a philosophical rather than a scientific approach (Cohen \& Omery). Hermeneutics originally referred to interpretation of biblical texts and has been applied to interpretation of other historical documents, but in Heidegger's case the reference is to interpretation of 
language or dialogue (Ray, 1994). The purpose of hermeneutic phenomenology is related to "bringing out the normally hidden purposes of such goal-determined beings as man" (Spiegelberg, 1982, pp. 385). Heidegger was interested in the hidden meanings of the phenomena. According to his approach preexisting beliefs are not set aside, but are uncovered and contribute to meaning (Ray, 1994). From this point of view, description alone is inadequate. Revealing or interpreting meaning is necessary for understanding. Meaning is affected by historical and cultural influences, and humans are treated as "being-in-the-world" (Cohen \& Omery). The goal is to understand the everyday experience.

The third phase, beginning in the 1930s, is associated with France and men such as Jean Paul Sartre and Maurice Merleau-Ponty (Spiegelberg, 1982; Streubert \& Carpenter, 1999). With Sartre phenomenology became more concerned with human existence and phenomena occurring within the context of human existence. Merleau-Ponty emphasized the importance of perception and thought it to be the basis of knowledge. Rather than finding truth within as did Husserl, Marleau-Ponty felt man existed in the world, and that is where man would understand himself. He was more interested in existent fact than essence, and existence was seen as expression of preconscious behaviour. The body provides access to the world. Consciousness allows us awareness of being there, so the body and mind are connected (Munhall, 1994). Actions are based on perceptions and original awareness of phenomena (Streubert \& Carpenter). Marleau-Ponty's phenomenology deals with concrete life not just consciousness.

Cohen and Omery (1994) describe schools of phenomenological research founded largely on the philosophy of Husserl and Heidegger, who have had the greatest influence 
on current phenomenology research. The school based on Husserl's descriptive philosophy is referred to as the Duquesne school. It includes researchers such as Giorgi, Colaizzi, Fischer, and van Kaam. A second school is based on Heidegger's interpretive hermeneutic philosophy. The third school is referred to as the Utrecht school, and this approach combines both a descriptive and interpretive philosophy of phenomenology. Max van Manen, a current Canadian educator, exemplifies this school in his hermeneutic phenomenology mode of inquiry.

\section{Phenomenology as a Research Method}

It is difficult to identify commonalties amongst the views of the different phenomenologists, but Spiegelberg (1982) felt that there is some general agreement on the method, which includes the aim of examining phenomena in a broader sense than allowed for by traditional scientific research. It is an approach that encourages freedom from preconceptions and oversimplification. According to Spiegelberg the method may include any number of the following: investigating specific phenomena, investigating general essences, identifying relationships among essences, watching modes of appearing, watching the appearance of phenomena in consciousness, suspending belief in the existence of phenomena, and interpreting their meaning. The phenomenological approach is a systematic approach (Streubert \& Carpenter, 1999; van Manen, 1997). It has specific techniques to get at understanding such as questioning, reflecting, focusing, and intuiting. It is intersubjective in that it requires the researcher and a second person for dialogue about the phenomenon (van Manen). Different methods exist to guide this type of research, and the choice is based on-the phenomenon of interest (Streubert $\&$ Carpenter). 
The aim of this type of study is to produce an interpretation of a human experience that may help others understand what it is like for some people in that particular situation (Munhall, 1994). The perceptions of individuals who live the experience are elicited in an attempt to identify and describe the essence of the experience. The idea of essence relates back to Husserl and refers to the structure or pattern of the experience of interest, its qualities and properties. It is what appears to characterize the phenomenon and makes it uniquely what it is. It is the basic unit yielding common understanding of the phenomenon (Streubert \& Carpenter, 1999; van Manen, 1997) and is seen by van Manen as a universal. Attention is paid to the details of life including lived time, space, body, and human relations looking for meaning in every day experience, as according to van Manen we know things through our body, relationships and interactions with things. Phenomenological research and writing can elicit these meanings.

The phenomenological approach used for this study of parenting children with lifethreatening food allergies was based on the hermeneutic method set out by van Manen (1997), who identifies six activities in performing a phenomenological study. These activities include: 1) commitment to questioning a phenomenon and making sense of it through one possible interpretation 2) examining an experience as it is lived 3) reflecting on themes that characterize this experience 4) coming to a description through writing and rewriting 5) maintaining a strong focus on the question and 6) considering both the whole and the parts and stepping back so as not to be lost in the parts. Remembering and reflecting on the experience through meditation, daydreams, conversation and inspiration can help to yield meaning of the experience. Free imaginative variation is a term applied 
to looking at the phenomenon in different ways to identify whether it would be the same without a particular theme (van Manen).

Phenomenology is the study of lived experienced (van Manen, 1997). The researcher tries to understand the nature or meaning of an everyday experience. We access the world through our consciousness and phenomena of interest must be present in consciousness. Reflection is retrospective, and characterized by thoughtfulness. Individuals give meaning to their experience and the results of the research must remain connected to the research for meaning to exist. This approach assumes that others can understand human lives through thinking, insight, and dialogue. An attempt is made to describe actions, behaviours, intentions, and experience that come out of the daily world of the participant. The researcher is an observer and a reader.

The researcher doing phenomenology goes into the experience trying to set aside any existing notions that she or he might have about the experience. For this reason the study is not designed around any theoretical framework and the literature review prior to beginning the study is minimal if existent at all. The role of theory is controversial (Ray, 1994), but the general use of a theoretical framework to guide the study is considered to be inconsistent with the phenomenological approach (Cohen \& Omery, 1994). The study is started with the idea of a general approach, but without firmly fixed procedures, techniques, and concepts.

\section{The Research Design}

\section{Population and Sample}

The population of interest for this study was mothers of children who are at risk of having a life-threatening reaction from ingesting a food. Mothers were the focus, as they 
are still usually the primary caregivers. It is difficult to specify the incidence of this problem in the general pediatric population, as International Classification of Diseases coding related to food-induced anaphylaxis has been fairly recent and may not yet be adequate in defining incidence (Clark et al., 2001; Lieberman, 1998; Kagy \& Blaiss, 1988). As more attention is focused in this direction attempts are being made to better determine the incidence. For example, an anaphylaxis survey conducted amongst Canadian pediatricians and pediatric subspecialists between January 1, 2000 and June 30, 2001 identified more than 700 cases of anaphylaxis in children and reported that $81 \%$ of these cases were triggered by food (Simons, Chad, \& Gold, 2002). Food allergies are frequently first diagnosed in the very young, but can be diagnosed at any age.

Statistical techniques for predetermining an appropriate sample size for qualitative studies do not exist. The aim is for a sample that provides a desirable depth and range of information. It is generally considered that an adequate sample size is evident at the time of a study's completion. In qualitative research the number of interviews, observations, or events may make up the sample size as much as the number of people (Sandelowski, 1995). The number of actual participants is normally quite small in a phenomenological study. It was originally proposed that for this study a minimum of 6 - 10 participants would be interviewed, allowing for the fact that the actual number on completion could be higher depending on attrition, the needs of the study, and the advice of the thesis committee. In the end six mothers were selected for study participation.

Qualitative research participants are chosen based on their knowledge of the experience of interest and their ability and willingness to reflect on and communicate this knowledge (Coyne, 1997; Streubert \& Carpenter, 1999). This is referred to as selective or 
purposeful sampling. The participants for this study were mothers of children who had been diagnosed by an allergist as being at risk for a life-threatening food allergy, and who also carry epinephrine for injection in case of a reaction. The mothers were recruited from a private pediatric allergist's office and from a support group, the Manitoba Anaphylaxis Information Network (MAIN). It was believed that these populations would allow access to mothers fitting the study criteria, but avoiding mothers the researcher might have responsibility for through her regular professional activities. An initial recruitment script for representatives of these two groups is attached as Appendix A. Mothers were recruited whose children were $5-12$ years old. This age range was chosen as this group of children is moving out into the community and the researcher was especially interested in this transition period. The mothers were able to read, write, and speak English; able to give informed consent; and resided in Winnipeg or within 10 minutes of the city's limits. Mothers were excluded if the children had other significant chronic conditions such as diabetes, seizures, cancer, behaviour disorders etc. Children with asthma or other allergies were not excluded, as these conditions commonly coexist. Children were excluded if they attended the Children's Hospital Allergy Clinic where the researcher is employed. Initial contact about the study came from the nurse in the private allergist's office, or from the support group facilitator by phone at which time the recruitment script was read to the possible participants. For parents who agreed to contact from the researcher, a call was made by her to further discuss the study and prepare those who were interested for the first interview. A script is attached as Appendix B.

\section{The Research Setting}

Based on the desire to ensure participants were comfortable during the interview process and in a natural setting, the interviews were conducted in the participants' homes. 
An offer was made to conduct the interview elsewhere if preferred, but all mothers agreed that their homes were suitable. An attempt was made to ensure the homes were free from as much distraction as possible at the time of the interviews, though some interruptions occurred from the telephone or children present at the time.

\section{Data Collection}

Interviews are central to gathering information in a phenomenology study, and the information or data for this particular study was collected through individual interviews that explored the participants' memories, reflections, and descriptions related to how they saw parenting their food-sensitive children. In regards to interviewing, May (1991) has noted that factors such as structure, timing, and content of the interviews may change over time to meet the needs of the study, and this was the expectation of the researcher when initiating the study.

One interview is likely insufficient for a phenomenology study. A second interview is appropriate at least to clarify information, check meaning, and determine whether any new information can be collected. It was suggested that for this study at least two interviews per mother would be completed. A third interview was to be done by phone if necessary to further clarify the information provided. The number of interviews was expected to reflect the time required for the researcher to gather enough material to develop a richer, deeper understanding of the experience of interest (van Manen, 1997). The participants were encouraged to reveal as much as they could and were willing to about their experience. Interviewing continued until the researcher and her advisor believed data saturation had occurred, i.e. no new themes were emerging. Two interviews 
were conducted with each mother in person, and were approximately $11 / 2$ to 2 hours in length according to the participants' need to express their thoughts. Phone contact was made with four of the mothers to finalize their participation and averaged approximately 10 minutes in length. It was not possible to reach one of the mothers and the sixth mother was interviewed in person shortly before the end of the study. In person interviews took place between March 2001 and March 2002.

The interviews were conducted following a semi-structured format. A limited amount of demographic information was collected at the first interview according to Appendix C. This allowed for some sense of the child's food allergy history, the family context, and helped the researcher and participant ease into the interview process. Following this the mothers were asked to describe for the researcher what it was like for them to have a child with a life-threatening food allergy. The researcher remained as a respectful listener, as much as possible, using neutral prompts and where necessary open-ended clarifying questions (Munhall, 1994; Streubert \& Carpenter, 1999). Some of the original proposed questions are listed in Appendix D, but as suggested by Morse (1992) questioning was kept flexible to fit with what the mothers revealed and what was needed to further understand the experience. An attempt was made to gather information with some degree of consistency in focus and depth to allow for some conclusions about the experience as suggested by May. Attention was also paid to body language and voice. The second interview was used to clarify information, focus on specific areas, and seek confirmation of the researcher's view of what the mothers seemed to be saying as a group and what the individual mother herself had revealed. The mothers were also given the chance to add anything else they wished. The interviews were audiotaped for which 
consent was obtained at the outset. A professional transcriber transcribed eleven of the interview tapes, and the researcher made notes from the twelfth tape. A sampling of transcriptions was shared with the researcher's advisor to obtain support and guidance.

The researcher kept a journal throughout the research study to record observations, reflections, and support bracketing. A researcher always brings his or her own assumptions, theories, biases, and experiences to a research study. As much as possible, these beliefs should be set aside or at least identified if one is attempting to truly see an experience from another person's perspective. This process is referred to as bracketing (Munhall, 1994). Trying to approach the experience as free as possible from these beliefs relates to Husserl's concept of phenomenological reduction, an attempt to return to an original awareness of the phenomenon (Streubert \& Carpenter, 1999). Complete reduction is unlikely according to Merleau-Ponty (Spiegelberg, 1982) and not necessary according to Heidegger (Ray, 1994), but recording ideas, feelings, and responses can help separate the researcher's perspective from that of the informant, and give more meaning to the researcher's final interpretation.

\section{Data Analysis}

Data analysis begins with data collection and requires the researcher becoming immersed in the data (Streubert \& Carpenter, 1999). In this study each tape was listened to following the interview and prior to transcription to review the interview experience and to make sure the tape was clear. It was listened to again after transcription looking for accuracy and supporting the immersion process. It was listened to again further into the analysis process for further clarification and perspective. The transcriptions were 
reviewed repeatedly looking for significant statements in an attempt to find meaning and understanding through looking for meaning units or themes; the structures of the experience (van Manen, 1997). The transcripts were coded and themes developed. The themes were compared between participants and thoughts clarified as necessary. The concept of intuiting has been described as rearranging the data until it produces a common understanding of the phenomenon, concentrating on the phenomenon without becoming absorbed, looking and listening, and logical insight (Cohen \& Omery, 1994; Spielgelberg, 1984; Streubert \& Carpenter). Intuiting was used to determine meaningful relationships between the themes to support a holistic description of the phenomenon. Streubert and Carpenter's (1999) caution about making conclusions too early in the analysis was kept in mind during the analysis process. Throughout, analysis writing and rewriting was thought to support reflection on the information provided. Examples were used to illustrate how the description came together. It is recognized that there never can be a single complete description of a phenomenon, but what is described is a possible experience (van Manen). Phenomenological research is not truly summarized, and full and final descriptions of a phenomenon are never possible.

Errors can occur in the data analysis stage based on missing data, coding errors, misinterpretation of data, judgment errors, unclear or illegible notes, poor transcriptions, etc. (Brink, 1991). Care was taken to minimize these problems as much as possible. The quality of the audiotapes and transcriptions was generally very good. The comments from the mothers about the researcher's interpretations were carefully considered and the interpretations altered as seemed appropriate. 


\section{Measures of Rigor}

Rigor in qualitative research refers to attention to the spirit of the qualitative approach and in the end should be determined by the extent to which the research is able to portray the experience being studied (Sandelowski, 1993) and is free from error (Brink, 1991). Rigor needs to be considered throughout the study. The researcher's advisor monitored her progression through the study process to help ensure appropriate attention at each stage. Participants were carefully selected who could speak to the experience. Data collection attempted to avoid answers reflective of social desirability (Brink) and was believed to get at the participant's perspective of the experience.

Trustworthiness is a concept used in evaluation of qualitative work and largely involves the ability to follow the trail of the research to the descriptions and interpretations made by the researcher (Sandelowski, 1993). An audit trail is available in this study through the transcripts, use of quotations from those transcripts to support the researcher's interpretations, and the researcher's journal. Some of these have been shared with the researcher's advisor during the study and aspects of them will be evident in any report of this research.

Munhall (1994) refers to the "phenomenological nod" as a measure of rigor. This suggests a recognition and that what the researcher reports is agreed upon by the reader, supporting the trustworthiness of the findings. Member validation is one way of eliciting this "nod" and involves confirmation of the researcher's findings by the study participants, but it is not without problem (Sandelowski, 1993). Participants may only partially see themselves in a combined report. This researcher did share her understanding of each participant's interview with that person to elicit clarification as 
necessary and a summary of the group report. In almost all cases the participants agreed with everything in their own summary and though they did not always see themselves in all aspects of the group summary they believed they could understand it in other mothers. Transferability, the fact that others outside the group recognize the experience even though no two researchers will necessarily see the data in the same way, appears to be another way of getting the "nod". Confirmability occurs when enough information is reported so others can say it fits. Munhall's (1994) use of the terms resonancy and recognizability of the experience reflect these concepts. In this case, ideas from the experiences were discussed with other colleagues working with similar families and with the thesis advisor. They were presented to the support group facilitator, the parent of a child with a serious food allergy. In addition some of the same thoughts were heard from other parents of children with severe food allergies in other settings.

Munhall (1994) also asks whether the interpretation and means of getting the information seem reasonable and whether enough representations of the experience have been considered. The latter suggests looking beyond the participants to other representations of the experience e.g. other conversations, media articles, literature. Brink (1991) discusses pragmatic validity where data is compared against and fits with other appropriate sources. This researcher did look beyond the experience of the six mothers for confirmation and besides listening to other parents, monitored some of the lay newsletters, and attended one support group meeting.

\section{Ethical Considerations}

Ethical considerations relate to ensuring that the research study is carried out in a morally sound manner, so that the rights and comfort of the participants are ensured and 
the principles of nonmaleficence, autonomy, beneficence, and justice are appropriately adhered to (Streubert \& Carpenter, 1999). Before this study began, the proposal was reviewed and approved by the Research Ethics Board responsible for nursing at the University of Manitoba to ensure it met the appropriate criteria.

Munhall (1994) suggests a number of important concerns that the researcher should address beginning with describing the experience as faithfully as possible according to what the participants disclose. This researcher did check back with the participants to see if what she understood is what they meant. In addition, sensitivity was maintained to the fact that these individuals were revealing themselves. The researcher was prepared to handle any emotional reactions, and on one occasion did find a study participant was mildly upset by reliving one of her experiences. The researcher offered support and the participant seemed quite comfortable in continuing the interview. None of the mothers were currently overwhelmed by their experience. If any mother had been, she would have been referred to the child's physician to discuss professional counseling. On occasion a suggestion was made to a mother if it seemed appropriate for the child's safety.

Written informed consent (Appendix E), within the limitations of qualitative research (Streubert \& Carpenter, 1999), was obtained from mothers at the first meeting before the collection of any information, and on an ongoing basis verbal consent was assured at each encounter. It is always possible for new and unexpected issues to arise at any time from a participant's interviews, so ongoing consent or process informed consent (Streubert \& Carpenter) is necessary. The mothers were given a copy of the original consent form, which included contact information for both the researcher and her thesis Chair. The researcher recognized that a participant always has the option of withdrawing 
from a study without any adverse effects either for themselves or their child, and this was made clear to the mothers in the consent.

Confidentiality was maintained throughout and following the study. No participant, family, or child has been identified by name at any time to any person other than the researcher. The consent indicated that confidentiality would only be negated by a legal requirement to disclose identity as in the case of child abuse. Each mother was assigned a code number. Only the researcher is able to match them to their real identity. Audiotapes and transcripts will be stored in a locked, secure location in the researcher's home until they are destroyed. The consent outlined what will be shared, including how the study results may be disseminated. If the need for rich description in reports at any time threatens confidentiality, justification will be given to the participant and permission and verification will be obtained if possible, as suggested by Robley (as cited in Streubert \& Carpenter, 1999). Munhall (1994) suggests that sometimes a participant may want to reveal a secret, which may put the researcher in an awkward position. She feels that this should be discouraged and participants carefully reminded that all communication is meant to be a part of the study. This was not an issue in this study. If this had occurred the researcher was prepared to discuss the concern with the participant and a decision would have been made together as to whether the information could be a part of the study, or if it should be shared with someone outside the study instead.

Role confusion can sometimes become an issue in qualitative nursing research as the nurse develops a relationship with the participant. This can be harmful to the participant and impact on the research (Streubert \& Carpenter, 1999). It was made clear to the mothers in this study that the nurse was in a research role and not that of a counselor, 
educator, etc. so as to try to prevent problems. Encounters focused on the topic of investigation.

\section{Limitations of the Study}

It was recognized at the outset of this study that the group would be small and by no means considered representative of the general population of mothers of children with life-threatening food allergies. These mothers were expected to be quite articulate in comparison to many other parents. There was no expectation of being able to generalize the findings from the study to the broader population. The expectation was that this research would give some insight to allow for a greater level of sensitivity in approaching other parents and may stimulate further research related to families living with this issue.

\section{Conclusion}

Phenomenology is increasingly being considered as a research method that can help improve nursing knowledge, especially when little is known about a topic. This section has discussed the historical philosophical background for phenomenology and the steps and considerations related to it as a research method. It has more specifically described van Manen's approach (1997) and related it to this current study of the experience of parenting a child with a life-threatening food allergy. The research design for this study has been outlined accordingly. 


\title{
CHAPTER FOUR
}

\section{FINDINGS}

\author{
Introduction
}

This chapter outlines the findings of the qualitative study looking at the mother's perspective of parenting a child with a life-threatening food allergy. The chapter begins with a description of the study sample focusing on the mothers interviewed, but also includes characteristics of the other family members. This sample description is followed by the findings from the interviews conducted with the mothers.

\section{Description of the Sample}

Six mothers of children 6-11 years old, considered at risk for a life-threatening food allergy participated in the study. The mothers all lived within a Midwestern Canadian city or in one of its surrounding bedroom communities. Mothers ranged in age from $34-$ 47 years old. The majority of mothers worked at least part time outside their home. Maternal education level varied from completing high school to an undergraduate degree. The group included women of mainly European descent. Two of the mothers had a history of a significant allergic reaction themselves while some mothers had milder allergic conditions. One mother had very little experience with allergies other than through her child. The mothers' characteristics are further summarized in Table 1.

Five of the children of interest were male and one female. The children ranged between $31 / 2-81 / 2$ years since being diagnosed as at risk for a serious food allergy reaction. At the time of the first interview all attended school, ranging in level from 
kindergarten to grade 5 . All but one child was allergic to peanuts, and the number of problem foods identified ranged from one to four per child. One family had a second child, a 3 year old male, with severe food allergies. A second family included an 11 year old male with some degree of milk allergy or intolerance. Some of the other children in these families had other types of allergic conditions as did some of the children who were the focus of the interviews. Characteristics of the children are also found in Table 1.

Two homes were single parent households, but the child's natural father was regularly in contact with the child in each case. Two homes included the child's natural father amongst the inhabitants. Stepfathers resided in the other two homes, though the natural father was also quite involved with one of these children. Family size ranged from one to four children. Total household income, as noted by the mother, varied amongst the families over three income levels with the majority being above $\$ 39,000$. Two families moved during the study period, one from an apartment to a house in a different neighbourhood and the other into another house in their same general neighbourhood. 
TABLE 1

Demographic and Health Characteristics

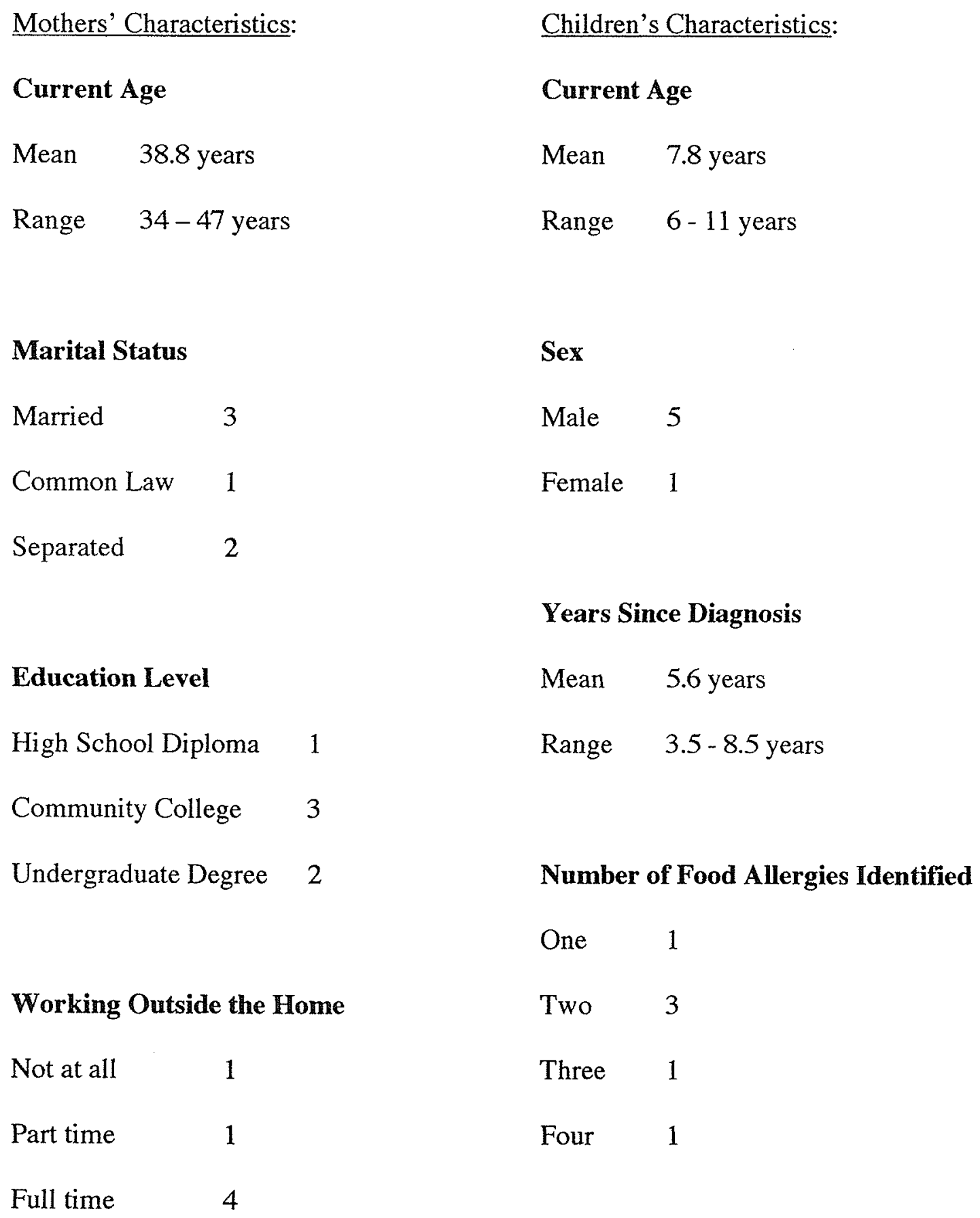


Household Income Level

$\$ 20-29,000 \quad 1$

$\$ 40-49,000 \quad 2$

$\$ 50,000+$

3

Number of Other Children

None

One

Three

1

3

2

Age of other Children

Mean $\quad 9.8$ years

Range $\quad 3-22$ years
Types of Food Allergies

Peanut 5

Egg 3

Nuts $\quad 3$

Milk 1

Seeds 1

Potato 1 
Findings: Living with Risk

The overall theme or essence that emerged from the analysis of this study, which encompasses the mothers' experience of parenting a child with a life-threatening food allergy is described as "Living with Risk". All human beings live with risks that have consequences of varying severity, and mothers in general live with the knowledge that risks exist for their child as a normal part of life. At some point early in the experience of living with a child who has a serious food allergy mothers began to understand the risks that this problem might pose, including that the child could suffer a serious reaction or death as a consequence of ingesting a food. Along with this knowledge comes fear of these possibilities and the need to protect the child from harm. In addition, the mothers were concerned about the child's quality of life and issues related to normal development. They all worked at ensuring their child's safety and at supporting the child's participation, as fully as possible, in activities normal for age and that fit with the family's belief system. Supporting the child in living a normal life means constantly balancing risks and safety and as suggested by one mother "You have to balance the safety, but you have to give the kid a life."

Risks related to a food allergy can be encountered everywhere in the environment. Some risks are quite apparent while others are less so. Risks continue to exist as long as the child remains allergic, but the nature of risk changes as the child matures. The mothers learned to see the risks and deal with the risks in ways that allow them to live with the experience.

The theme "Living with Risk" is supported by five sub-themes, the explanation of which will form the body of the "Findings" section. The first, "Living with Fear", deals 
with the fear that results from realizing the child's life could be at risk and underlies the ongoing experience. The categories related to this theme explore the sources and quality of that fear, which varies in intensity and according to the situation. These categories also cover the past, the present, and the future. The second sub-theme, "Worry about Wellbeing", identifies how the mothers viewed the child's development and the importance of supporting normal development. The third sub-theme, "Looking for Control", involves dealing with risk by managing the environment and working with other people. The fourth sub-theme, entitled "Relying on Resources", describes the personal, people and organizational, and information resources used by the mothers in the process of coping with and adjusting to their experience. The final sub-theme, "It's Hard But It's Not", concludes with how the mothers see this experience integrated into their and their families' lives today.

\section{Living with the Fear}

According to Webster's Dictionary (1983) fear is an unpleasant emotion caused by anticipation or awareness of danger and implies anxiety. In common language it is a word that is used to describe a range in intensity of emotion from that of mild concern or worry to terror. All mothers who participated in this study expressed some instances of fear related to their experience of being the mother of a child with a food allergy. Five of the mothers believed that their children are at risk for a life-threatening reaction, while the sixth mother wondered whether this is still an issue for her child. Variations existed in the intensity of the emotion between mothers and additionally across time and situation for any one mother. Certain situations, more often in the past, have evoked a 
strong sense of fear, while current experiences are more likely to involve varying degrees of anxiety or concern directed at specific situations. Though variation has existed in the intensity of the emotion, there are some common situations to which it was attached. The Surfacing of Fear

For some mothers the fear first surfaces with the initial reactions to a food. Initial reactions in this discussion are considered to be any reaction that occurred before the child was officially diagnosed as having a serious food allergy by an allergist. For some children these early reactions were quite visually significant. One mother who described her child's initial reaction as blowing up like the "Michelin Man", an extremely puffy looking character from a tire company advertisement, described her own reaction: "I completely freaked out. I thought oh my God he'sss...he's dying or something's going on".

Some of the other mothers had obviously been concerned or upset about the reaction experience, but did not identify them as being scary. In some cases this may be because the reaction was much milder in appearance, but for others their interpretation of the experience was possibly based on their own past experience with allergies or lack of it.

For one mother it was the lack of experience:

But I don't think it sunk in because like I say I have no idea of food allergies. Like you know, I just didn't. I mean at the hospital they didn't say 'this is a life-threatening food allergy' either. They just said '[child] has an allergy'. So allergy to me means hay fever, runny eyes.

A second mother with personal experience with allergies saw the reaction in terms of her own past reactions, which had never been diagnosed as life-threatening. She realized it was an allergic reaction when it occurred, but didn't recognize the degree of risk. The fear appeared later: "hindsight I probably was a little more scared than I was at the time". 
For these mothers, the intensity of fear seemed to increase as they learned more about serious food allergies and formed some understanding of what the allergy might mean in terms of their child's life.

Besides causing feelings of fear, for some of the mothers these initial reactions took on other meanings. As the problem became better understood, 'luck' was attributed to their child's initial reaction by three of the study's participants. Two of the mothers looked back on these reactions as being a warning combined with luck. The first equated it to having a heart attack:

Now we had our warning. Like a heart attack you know. So if you can survive the first one, now you've got your warning. Now you make your lifestyle changes to adapt to that warning and then you go from there and hope.

The second mother gave her child toast with peanut butter when the child was 5 months old. Initially other people made her feel guilty for giving toast to such a young child. She now believes it was very fortunate that she did, because the child only sucked on the toast rather than eating it, resulting in the warning. All three mothers felt lucky that the reactions hadn't been more serious based on their current understanding of the allergies.

For some mothers the timing of the allergic reaction had value and meaning. Two mothers expressed a belief that it was best that the reaction occurred when the child was young. Reasons given included that it was easier to remove the food from the diet when the child hadn't yet become use to eating it, things are easier to enforce when children are small, and they (family and child) had time to grow into the experience. One mother speculated that the experience might be easier if the other children in the family were also younger when this problem occurs in a family. In this particular family the child with the allergy was the youngest. By the time this child suffered a reaction the older 
children had grown accustomed to certain foods, which the mother had to ban from the home. On the other hand another mother believed it was fortunate that the child was a little older when the reaction occurred. The child was $41 / 2$ years old at the time, and the mother believes the child still has a memory of the reaction and because of this can better understand the seriousness of the problem. She believes it makes it easier than if a child is expected to avoid a food just because they are told to avoid it.

Eventually all children were referred to an allergist for assessment of the child's food allergy. For a majority of the mothers it was at a visit to the allergist, but not necessarily the first visit, that they realized the risks and the fear increased. As suggested by one mother, she could deny the problem to herself until they spent time with the allergist. Another mother left the allergist's office after her child's initial assessment "devastated" believing that she had been told the allergy would kill her child, it was just a matter of time:

It was just kinda like 'whoo', hit me in the face! Like oh my God he's gonna die, you know....this is devastating, you know. You're gonna have to watch his every single move for the rest of his life....Cause like the way this doctor (laughs) it's like well I don't know how long you'll have. It will eventually kill you.

Another mother on seeing the allergist was pleased at and relieved by the expertise, education, and guidance that was available to her, but stated that though she experienced some relief with this encounter she was left with a fear for the future. For a fourth mother the first assessment helped her to realize the seriousness of the problem and left her feeling alone with the problem and afraid: "You know you feel kind of lost. Umm alone I mean I was like oh my God like my kid is gonna die." One mother sensed the allergy was serious before attending the allergist, but it was seeing the child's reaction to the allergy skin tests that seemed to really emphasize to her the seriousness of the problem. This 
same mother described the experience of realizing the implications of the allergy as being "overwhelming". Realization of the seriousness of the allergy and its implications appears to have occurred for a final mother during a second visit to the allergist for reassessment and repeat testing a year or so after diagnosis:

So they ummm tested [child] and [child] didn't outgrow it and that's when it started to sink in that this is for life....I think that's when I sat in the doctor's office and cried. Cause it's starting to sink in.

\section{Leaving the Safety of Home}

As their children began to go out into the world and were cared for by other people, the mothers had to face new risks, concerns, and fears: "You know [child] goes to birthday parties all of a sudden. [Child]'s starting kindergarten soon. And then life gets hard". Though for some of the mothers experiences had already occurred with babysitters and nursery schools, the child's entering the school system at approximately age five was especially anxiety provoking. Up until that point all the mothers were generally able to supervise the child's activities and contacts, but as one mother said "you can't be there all the time" in reference to the school experience. For a couple of the mothers the early school years were quite scary. One of these mothers shared the following about her thoughts on the phone ringing during the school day in the early years, fearing the worst and relieved that it was for something other than an allergic reaction:

I phone home constantly for messages. I phone home for the school. There is nothing worse than hearing the secretary's voice on the telephone. This is [School]. You just hold your breath until they say '[Child]'s in the office with a stomachache.' You know it's just like oh, thank God!

At school entry worry may occur over the ability of the young child to protect themselves as expressed in the following way:

I know when he first went to school I used to think about it a lot. Like ohh you 
know. What if there's something at lunch? What would happen? What if you know and ahhh because he was too little to, you know."

Over time the mothers have become more comfortable with their child's school experience in relationship to the food allergy, but they found it hard to completely relax. As expressed by one mother "We still have to watch", and according to another mother there will always be a worry giving an example of the fact the child's classroom may be safe but there is the rest of the school to consider. The mother, originally very anxious about the phone ringing during the early grades and worried about the child "coming home alive", was comfortable with the school situation this past fall even though her child is attending a new school. She attributed this largely to the fact she was feeling good about the child's increasing maturity, while another mother was also comfortable because last year was a good school year and she was expecting the same this year.

\section{Fear in the Present}

Fear remains a current experience. Though the mothers do not constantly worry about the risks to their children today, they still realize the serious nature of the problem. Fear may be recognized as a continuous thread through the experience as in the statement "I guess the bottom line for this whole experience is the feeling of fear all the time", but even this mother described it as a background of fear now that her child is older. Being able to assign the fear to the background may be related to coming to terms with it through years of experience living with the problem and the best ways to deal with it. How far the fear is in the background varies probably due to a number of personal and situational factors, and for some mothers it is closer to the surface of their daily lives than for others. Variation exists in how frequently the problem is worried about as demonstrated in the following: 
....it's not something that I'm scared of every single day....But it is something you think about every single day.

Neither of us think about it anymore. It's just part of who [child] is.

Sooo I wish that aahhh I didn't have the fear, the fear's a terrible, it's a terrible thing you know, so most of the time you just kinda go through life and then the odd time you sit down and go 'oh my gosh'. You think about what [child] has....

In addition to the amount the mothers think about the problem they have indicated that there is variation in the intensity of their feelings about the risk or their willingness to think about it:

Worrying about whether he will die or not I don't even dare go there....Just too scary to think about.

....every once in awhile I'll think about it and it, it scares me because it is. It could happen in an instant.

I don't think about him dying. Umm not because it's not a reality but just because I just don't see it. Umm, I guess I don't worry about it.

Though concern about the food allergy is in the background for all mothers, situations that are new or out of the ordinary can easily call it forth: "so it's the unknown of things [child] doesn't do normally that's scary". It may just be that the situation needs to be thought about and planned around, or the situation may create concern, anxiety, or an even more intense level of emotion. These situations include common childhood or family experiences that generally take place outside the safety of home such as special school events, family celebrations and holidays, travelling, activities such as going to regular camps, day camps, sleepovers, sports events, eating in restaurants, and birthday parties.

Two mothers, whose children were allergic to peanuts, described the experience of their child attending a sporting event and feeling an increased level of anxiety because of 
the presence or possible presence of peanuts. The first mother was with her child, while the second mother was not:

I looked down and there's a big pile of peanut shells. Because someone has had peanuts you know. And I feel like turning around and saying [Child] don't inhale.

....they went to a [baseball] game aahh last Thursday in the afternoon. Well that's a nightmare because he's. I sent him his lunch and his drink, but where's he sitting? Is there peanut shells all over the floor? Did the person sitting in the chair before him eat peanuts?

School events are a significant and common cause for concern. The mothers were able to give many examples of intermittent events that occurred at school and included eating, especially in the lower grades. These examples included the celebration of birthdays and special holidays, special lunch days such as hotdog day, potluck dinners, picnics, and cultural celebrations. Some schools had a canteen where children could buy food. School fieldtrips were especially worrisome and increased the level of fear for one of the mothers: "I know that all [EpiPen ${ }^{\circledR}$ and puffer] goes on a field trip, where it ends up and who takes care of that and what happens is a fear for me all the time."

Even for a mother who is rarely concerned about her child's food allergy fear can become acute. One of the mothers recalled a recent experience where her child went on vacation with the father with whom the child currently has limited contact. When the father arrived to pick the child up he brought a bag of treats, the majority of which the child could not eat due to the food allergy. This mother felt obligated to let the child go with the father and spent time re-educating him and his partner, but this event had obviously made the mother quite fearful: “That's the first time I've actually felt a fear for - [child's] life or a loss of control." 
Stories about allergy deaths can initiate feelings of fear for some mothers. Most of the mothers spoke of stories they had heard about children or adults who had died from allergic reactions. These stories seemed to make most of them anxious, but there also appeared to be some interest in the stories for what could be learned. For one of the mothers reading a story reminds her of the seriousness of her child's allergy and that people do die from allergic reactions: "if you read something about an allergy reaction to something. That someone died or you know. That kind of brings it home. You know and you think ooohhh it does happen." A second mother referred to a young girl allergic to peanut and believed to have died after knowingly eating some candy, which contained peanut, in an attempt to make herself a little sick, so she could go home from school. In talking about the story the mother says: "I mean I was quite keen to hear that story in the details for my own. Just you know, what my child might do."

Though the mothers fear their child having a serious reaction, the fact the children have not experienced any recent reactions was viewed to some extent with mixed emotions. Nobody wanted their child to have a reaction, and they were happy that there had not been any reactions for most children since the original ones. One mother saw this as a sign that they were doing things right and that they did have some control. Some mothers believed that they would be more worried if there had been a recent reaction and possibly more cautious then they are currently. One mother wondered if the lack of reactions was giving her and the family a "false sense of security", while another commented that "sometimes you have to be shaken up a bit" to remain alert.

Though a reasonable degree of confidence was expressed amongst the mothers about recognizing a reaction and dealing with it by giving the EpiPen ${ }^{\otimes}$, there is still some 
degree of fear around these steps. This was expressed by a couple of the mothers, one who felt confident she would give it and one who felt a little less confident:

....there is a certain amount of fear factor using that EpiPen ${ }^{\circledR}$. [It] is because you're committing yourself to sticking a needle into your child and administering a drug and also that whole thing of acknowledging the fact, yes this is a reaction.

I, I'm definitely afraid of one [a reaction]. Annn having to give the EpiPen ${ }^{*} . .$. I worry more will I be able to do without panicking what needs to be done.

\section{Reflections on the Future}

Though the mothers have all attained a certain level of comfort for the present, they wonder and to some extent worry about the future when the children will be even more independent:

As [child's] world gets bigger [child] will have things that [child's] not quite so sure about or things won't be as simple. And that I guess is my, our only concern or my concern. Is that as things get a little bit more global... [child's] gonna have things that are a little bit more challenging.

The idea of the unknown or the uncertainty of what may come to pass is apparent in statements such as "Things always change" and "although we think we have a handle on it now, I don't know what the future holds". Some of the concern was directed at specific issues. Three mothers shared concern about the appearance of new allergies, illustrated by the following example: "I'm you know, the allergies change so that's always a fear aaahh of what's gonna hit [child] next."

Mothers wonder whether the child will recognize that they are having a problem if a reaction occurs or whether they will communicate that they are having a problem to the appropriate person such as a teacher. Concern exists about whether the child might miss identifying a risk. One mother who shared this concern told the story of the family being out to dinner in a restaurant and the child choosing something on the menu without 
realizing the sauce contained nut. Being with the child she was able to correct the mistake that time, but she knows she will not always be there. The mothers generally felt that their children are aware of the seriousness of their allergies and how they should behave, but some wondered if the child would always make correct decisions. As one mother suggested, her child is just a kid and just wants to have fun. Though this group of children routinely check with their mothers about the safety of eating certain foods, depending on the stage they are at, they are beginning to make some food-related decisions themselves or at least question the need to avoid certain foods.

These mothers, no matter the age of their child, are all looking ahead with some trepidation to the time their children will be adolescents. There is a realization that at that point the child will be making independent decisions, exposed to a whole new set of experiences, and at risk for the effects of peer pressure. Concerns were expressed about how the children will be treated by other teens, whether they will make good decisions for themselves, and whether there will be a problem with carrying the EpiPen A couple of the mothers' comments related to adolescence are quoted:

The only thing I worry about is again in junior high. Kids are stupid and I often worry about what if somebody puts something, just as a joke, in his sandwich.

I worry you know as a teenager because that's when they start taking risks....I think it won't be a problem for [child] but you know there's that teenage thing of defiance so I do worry about that.

Dating is seen as an activity that will present risks, and one mother joked about her child finding a nice girl with a peanut allergy.

In summary, once the mothers realize the risks to the child from the allergy, they begin to live with fear. This may occur as early as the first reaction or later on as they learn more about the risks. Some situations make the fear more acute. Leaving the safety 
of home to enter the school system can be a time of special concern. Now that the children are settled into school and home is considered safe, for the most part fear remains in the background. It is activities that deviate from the normal for the child that are most likely to cause anxiety for the mother. All the mothers have some concerns about the future.

\section{Worry About Well-Being}

Not only did the mothers in this study worry about whether the child might die from ingesting a food, but also about the risk to "normal" physical, social, and emotional development. Depending on which foods the child is allergic to or the number of allergenic foods, particularly when children were young concern existed about the child receiving adequate nutrition and growing normally. This concern is revealed in the statement "But you know I worry more about [child] growing when I never worried about the other kids like that. That [child's]'s getting enough nutrition". Mothers may worry about the effects of the dietary restrictions or the nature of allergies themselves affecting physical development. Some of these mothers made comments about their children being "small", "short", or "thin". They have been concerned about whether the children were getting adequate vitamins and calcium depending on the food(s) involved. One mother, whose child was allergic to a number of foods in the beginning, described the experience as "horrible" as she worried about how she was going to feed her baby, introduce solids, and whether the child would grow:

-It's like what am I going to give [child]....I was so worried [child] wasn't going to grow. Umm, so somehow we got through it, but it was a very scary time just initially introducing ummm the solids annn, ann getting [child] on to regular food. 
This mother went on to describe her stomach as being in a knot for about three years and wonders if the altered diet has had an effect on how the child eats now and the less than ideal dental status. A second mother remembered the frustration of having a child so young and so limited in diet because of a milk allergy and feeling a bit inadequate herself because people sometimes commented on the child's size.

The mothers were generally adamant about wanting their children to participate in the activities that they considered normal for age and the things other children were able to do as long as these activities fit with what the family considered as being ageappropriate. Mothers are concerned that the allergy not define, limit, or alienate the child, and the mothers generally considered the food allergy problem to be just one part of the child:

Yes it's a big part of [child's] life but it's not the only part of [child's] life.

I never wanted [child] to be...umm 'that's the peanut allergy kid.' I always wanted him to be 'that [child], who yeah, and I think he is allergic to peanuts.'

Some mothers specifically mentioned the fact that the allergy does not stop the child or the family from participating in activities, and that they don't say "no" because of the allergy.

The mothers were also concerned with the child's emotional development. They were concerned with how others might see them and how they might see themselves. It was recognized by one of the mothers that it is not easy, and measures taken to protect the child could affect the child's development. The mother was presently concerned about being overprotective of her young school age child and the effects that would have on development, but concluded: "I'd rather [child] be a little unsure and nervous and less 
confident and be alive". Another mother was anxious about her child's self-identity and the need to prevent him from seeing himself as sick.

Mothers also worried about the child looking different than other children. Some concern was expressed around carrying the EpiPen ${ }^{\circledR}$. Carrying it in a fanny pack can mark the child as different. It is seen as big and bulky and noticeable and puts attention on to the allergy. One of the mothers reacted very strongly to the image she had of a fanny pack that would be worn for life, the first time she saw the allergist:

But [child] has to wear it in this big huge fanny pack and I thought it looks like a third leg, you know....Give [child] an option about not having this huuuge fanny pack or you know. Like you might as well put an $\mathrm{X}$ on your head.

It was difficult for the mothers to think their child might feel restricted by the allergy, and most mothers go to quite a bit of effort to make sure their children can participate in events and eat similar foods at those events that other children will be eating. Some belief was expressed that all children should be able to have treats, desserts, etc., and it can be hard for the mothers when something has to be denied:

You think well you know ice cream is not a necessity of life ummm but, the reality is, is all these things that are [not] a necessity of life, like chocolate bars and chips and ice cream. That's what kids are having. And you know I want my kid to be having the same things.

One mother was distressed at a recent event when something was handed out that her child really wanted and she was not able to supply an adequate substitute, which normally she tries to do. Another mother commented on having to deny desired treats: “And it breaks my heart because...you can't, you know. I would love to say okay [child] this one time."

Mothers also expressed concern about whether other people might treat the child differently or exclude them from activities, though in most cases this did not seem to be a 
problem for these children. One mother explained "that was my other fear that people would say oh you know 'Don't invite that kid over cause than we have to worry about the peanuts'. A couple of the mothers have sensed that other parents were afraid of the children's allergies originally, but they have accepted the children into their homes and have become more comfortable with the problem. A third mother had heard "horror stories" about children not being invited to do things because it was "too much hassle", though she had not found this to be a problem personally. Most mothers were generally happy that their children fit in well with other children, but it was difficult for them when their children expressed feelings of being different or frustrated by their allergies. A mother who sees her child as being shy does worry about the food allergy on top of the child's normal personality making it more difficult for her child to fit in with other children. She believes the child feels different due to food restrictions and describes watching her child's frustration about the restrictions as "very disheartening".

In summary, the mothers worry about the child's physical, emotional and social development. They worry about them fitting in with other children. They are concerned about them appearing normal and feeling good about themselves.

\section{Looking for Control}

The mothers participating in this study have all had a number of years to learn to live with the food allergy risk and the accompanying concerns and fears. In developing an understanding of what it is like for the mothers living in this situation, the issue of control emerged as an important concept related to coping with the experience. The categories 
that contribute to this sub-theme include "Controlling the Environment", "Working with Others", and "Preparing the Child".

For the purposes of this analysis, control is considered to be the ability to ensure the child's safety and social, emotional, and physical well-being through performance of activities related to the environment or by working with other people, including the children themselves. The mothers, with varying degrees of support from others, have taken on the main role in the effort to control the risks and protect the child from suffering an anaphylactic reaction. They have done this by becoming experts on their child's problem, identifying and assessing the risks in each situation, and finding ways to minimize these risks to a personally acceptable level. But as stated by one mother, "It's funny how you...get different, ummm varying degrees of, of what people are comfortable with and that sort of thing." The mothers have exerted control in a variety of ways over the years, and the efforts made have been sometimes challenging, frustrating, costly, and frequently required a lot of time and energy. "It's always planning. Always you know thinking ahead to the next thing. That's what moms do anyway but there's just this added bonus of organizing."

The mothers come to understand that they cannot always be in complete control even though losing control may be scary at times: "I can't really control everything. So and I know that. So I simply have to, to trust.". The efforts to maintain control are shared with others in the home and in the broader environment, as the child becomes more involved in the community. As they get older, more control is taken over by the children themselves. 


\section{Controlling the Environment}

"Controlling the Environment" focuses on two categories. It includes control within the family's home and control required for other places and situations outside the home. All environments to which the child is exposed are considered important, but the home is especially so. This is a place that the mothers believe should be safe and one over which they do have a lot of control. To a great extent control in the home is exerted through food buying, handling, preparation, and storage. Control becomes important in a variety of other environments also, as the child's world expands.

\section{Control in the Home}

Mothers are mainly responsible for buying, storing and preparing the family's food, though some fathers, who live elsewhere, may share part of this role when the child is under their care. In some cases the allergenic food is completely banned from the home to reduce the risk, and possibly so the child can choose from anything available just like other family members. This may be easier for some foods such as peanuts described as a "treat food" and "not essential" by one mother. It becomes more difficult for mothers when a basic food such as milk is involved or a variety of foods, especially when there are other children in the family. The mothers are central to the decisions about what will and will not be allowed. Sometimes foods are allowed into the home when the children are away or sleeping, and then the mothers take extra care to clean up any evidence of the food. Some mothers may regularly allow the food into the home for other family members, under restricted conditions. This means taking extra care in food preparation, making sure foods are not mixed up, and care in cleaning up. The mothers may identify certain storage areas as containing safe foods for the child, while others may be identified 
as containing unsafe products available to other family members only. The mothers see that the foods are well labeled, so they can be easily identified as safe or not.

Buying the food can take much more time when food avoidance is considered, as suggested by a mother who said it took her two hours to do what would normally take a half hour. The mothers take great care in reading product labels in detail before buying, even if it is something they have bought before. Reading and interpreting the labels can be very frustrating and especially so because companies change their products and their labels over time:

And once you find something it's pretty upsetting when they change the ingredients or they no longer make it.

....it's frustrating to, to, deal with the ingredients and labels and for whatever allergy it is there's always something you're unsure of....

The mothers were appreciative of the fact that companies seemed to be increasingly aware of the problem of serious food allergies and felt that labeling was improving: "I mean there's nothing better than you know, comm, food companies that just understand what's going on." Mothers may have to be concerned with grocery costs, which can be higher because extra foods may be required on top of what the family would normally buy, such as special formulas or soya milk in addition to regular milk. Foods may be bought from specialty shops such as health food stores where prices are higher.

In some cases especially, cooking for the child or family can be challenging. Whether the same meal is made for all family members varies amongst the different households and at different times within some homes. The mothers generally try to keep meals as much the same as possible for everyone, at least partly so the child is not singled out. Keeping meals the same becomes more difficult with some foods than others and when a 
number of foods must be restricted for the child, or because there is more than one child with food allergies in the family. A mother with two children having food allergies, totaling three foods between them, finds she is sometimes preparing three different meals to meet everyone's needs and using convenience foods to save time. When she makes meals "from scratch" everyone can eat, it requires extra preparation time and more clean up time afterwards. This extra time was especially a problem for two of the mothers who worked full time outside their homes and had to worry about avoiding basic food groups. Part of their solution has been to prepare ahead and secondly to get help. One of the mothers has contracted with her own mother to feed her children at the end of the day, while the other has hired a live-in person who helps to prepare meals.

Early in the experience finding replacement recipes for some foods can mean a lot of searching. Two of the mothers noted it was frustrating to find egg-free recipes, to the extent one mother found herself crying over trying to make egg-free foods early on, saying "I cried many times over failed recipes." Even now, though not seemingly a big concern, mothers find that the child's food allergy limits some of the recipes they might prepare. For mothers whose children have already outgrown some of their food allergies, they noted that it becomes much easier when the children are able to eat more foods.

As the main person handling and preparing the child's food, some concern was identified about the fear of making a mistake that would expose the child to the restricted food. One mother talked about mixing up the child's milk and pouring milk into the wrong bottle stating "you only do that once". A second mother worries about not - thinking while she is preparing something, accidentally exposing her child to the wrong 
food. She worries not only about the danger, but also about what this would do to her child's sense of trust.

\section{Controlling Other Environments}

In addition to the home environment, the mothers try to control other environments realizing this is not the same as controlling the home. These other environments are largely controlled with the help of other people. Routines can be established for external environments that the children attend regularly (eg. school), but mothers may find it more stressful when events differ from the usual for the child. At a certain point the mothers direct more effort towards situations that are not part of the normal routine rather than the regular daily activities. One mother expressed her anxiety at having to pack food for her child to go anywhere earlier on in the experience: "I was, felt quite limited as I didn't wanna go out. It was too much stress." Occasionally, when mothers are not comfortable that a particular environment can be adequately controlled it will be avoided.

Control outside the home sometimes conflicts with the issue of other peoples' rights. One mother, worried about the exposure to peanuts at sporting events, was willing to accept that others have the right to eat peanuts at sporting events, so you cannot totally avoid them. The issue of rights was more difficult for a mother describing a problem at school. She told the story of parents who insisted it was their child's right to take peanut butter sandwiches to school: "there was one kid in the class whose parents ah wanted to send peanut butter sandwich every day. They feel that they should have that right." Though this mother and the principal arrived at a solution for the problem, she found it difficult to understand how the parents could insist on this when it was her child's life that was involved. 
All environments are viewed from the perspective of whether they are food-safe and nothing can be assumed. One mother described two stories related to her church. The first dealt with the sudden realization her child was going to be taking communion and she did not know if there would be a problem with the holy bread. The second story related to the child attending catechism class where food materials were used. Though one catechism teacher was understanding and willing to adjust, the mother had a lot of difficulty with the second teacher's lack of awareness or concern. Another mother encountered a challenge at her child's school, which followed kosher dietary practices. In this case the mother was very pleased to find the school was willing to work with her to meet her child's needs when necessary.

Moving to a new neighbourhood can also have an impact on control requiring the mother to re-establish a safe environment:

So then you get comfortable. And then you know something changes and all of a sudden you gotta, gotta start again on, you know, new school or, or we move. And all of a sudden you gotta change things or you have to be totally aware again. Like consciously aware of things.

Three of the mothers talked about some of the issues they had experienced with a move. Moving requires that mothers prepare new neighbours, including adults and children, about the allergy and the risks. It means the children may be in new schools or even new school divisions, which may have a different approach from the previous school. This requires interventions and adjustment on the mother's part. For one mother entering a new school system was seen as a positive event because it did not allow her or her child to get too comfortable. Also she saw it as a normal life experience for her child, which was important just for that reason. Moving to a new neighbourhood may mean looking for new supports and new babysitters also. 
Mothers work hard at controlling a variety of situations, but interruptions to the routine occur regularly and as noted by one mother "And then you get use to that new situation and then something else comes up". These non-routine experiences are of special concern to the mothers, because they are occurring in environments that are not under the mother's control, and risks are expected: "so any, yeah, any new situation requires thought, planning, vigilance". The environment in which the activity takes place and the people who are in charge in those environments may be new and unknown to the mother. The mothers generally spend time checking the situation out in advance and planning to the extent that they are able to feel that the child can safely attend the event. They need to know that those who are temporarily in charge of their children understand the problem, though as the child gets older and the environments more diverse the mothers place more faith in the children themselves:

I'm forgetting there's hockey and coaches don't care if your kid has an allergy. They don't think it affects them. So half the time they don't know. So it's up to the child to take care of [themselves].

Time and effort may be spent on food preparation so the child does not feel left out, and the mother also needs to feel she has adequately prepared the child for the occasion. Volunteering for events is one common activity that mothers use to help control the environment, especially in new situations. At least one mother felt volunteering has also helped her generally raise awareness about serious food allergies with other people. Special events like birthdays and sleepovers require attention and planning. The mothers check with the other parents to make sure that they understand the child's problem if they do not already know the child, to find out about the activities that will take place, and the foods that might be served. The mothers prepare their children on how 
to approach the food at the event, and they make sure they send foods as a replacement if necessary. In some cases they have gone to a lot of effort in planning ahead to the extent of making sure what they send is almost exactly the same as the food being served. On other occasions they send food that is meant for all the children so everyone is the same. Some of the work that might be involved is apparent as one mother talks about a birthday party at a bowling lane:

....as per usual a week or two before the birthday party I'm planning and I'm organizing and I'm talking to the parent and I'm baking and I'm phoning the restaurant and you know this sort of thing.

Food and eating is an important part of holiday celebrations such as Halloween, Easter, Passover, Hanukkah and Christmas. Chocolate for instance plays a big role in some of these celebrations and can be especially a problem for children allergic to milk, nuts, or peanuts. The mothers make varying degrees of effort to find ways around the problem, such as replacement foods. Though it may take extra time to find replacements, the mothers learn what they can use and finding the replacements becomes a part of their routine. They also make rules such as for the handling of Halloween treats and need to be sure that other people involved in the celebrations (eg. extended family) are clear on what is allowed. When children are younger these events are also celebrated in environments such as school. A mother of one of the younger children remarked on this issue:

All those occasions [Halloween, Christmas and Easter] there's always, it's always extra effort you know. Annn, and I know that there's a lot of parents including myself that make special things during those occasions that they can have. If even it means, you know, making for the whole class.

This type of activity means the mother can take comfort in knowing her child is safe, can have something they like, and can take part the same as the other children, but there can be a sense of relief as the child gets older and these outside events become fewer. 
The mothers find that there are definite limitations to eating out in restaurants. They prefer places where everyone can eat, but the number and types of restaurants they can go to as a family are restricted. They tend to stick with restaurants they have learned to trust and going anywhere new often means checking things out in advance to avoid problems and disappointment. Having restaurants prepare foods for the child can still be stressful for at least some of the mothers as expressed by one: "I do not relax when we're out eating with [child], never, ever." In general, they have discovered and are appreciative of the growing awareness and concern about food allergies amongst restaurant staff.

Family travel is another activity that requires increased attention and preplanning on the part of the mothers. It may be seen as necessary to pack some safe food for the trips. One of the mothers in looking back on the early years of going to the lake in the summer described how two cars were taken because one of the cars was full of food, so she was sure the child had enough of the right foods. The mothers make sure they know the availability of medical facilities at their destinations. The food allergy has caused some limitations on where mothers are comfortable with the family going. One mother talked about her discomfort with leaving Canada, while another mother was okay with both Canada and the United States, but was not anxious to go beyond these countries. One mother described being "petrified" of having her child on an airplane, and suggested that she believed the food allergy did delay the family's travelling.

The mothers anticipate future situations and how they might be controlled. Some of the mothers expressed concern about their children attending camp and-were beginning to consider how they might deal with the risks presented by this new situation. Even 
though this was not to be happening immediately they had already arrived at some solutions that would allow them to feel the situation could be safe.

In summary, mothers work hard at controlling a variety of physical environments and situations to keep their children safe, but also participating in normal childhood events. They regularly work with other people to do this.

\section{Working with Others}

As the mothers look for control related to the risks, their fears, and the environment, they find it is necessary to work with other individuals. These people include immediate and extended family members, people encountered in the community, and the children themselves.

\section{Working with the Family}

These mothers have become the family experts on dealing with the food allergies by attending doctor's appointments, obtaining information, and through regular active involvement and problem solving. They share this expertise with other family members to gain support with risk control and to ensure the safety of the home environment. The mothers prepare and monitor their partners, other children, and possibly extended family.

Though the mothers have prepared their partners to help in protecting the child, if both parents are available, it is more likely that the mother's expertise is deferred to in deciding whether a food product is safe for consumption or not. This seems especially the case if the situation has occurred in the home or if the partner is not the child's biological father. When the children spend time with their biological fathers, who live elsewhere, the mothers give control over to the fathers. Depending on their confidence in the father's knowledge and approach to risk, this has been easier for some mothers than others. 
The mothers work with their other children to maintain control. They teach the children very early about the restrictions and the importance of maintaining them. Like everyone else the children are taught to follow certain rules related to their sibling's food allergy. The mothers have been concerned that the situation is not made overly restrictive, so that the child with the allergy is not seen as different or resented. Mothers normally have to teach children respect for each other and with these mothers it includes helping siblings learn not to tease the affected child about the problem foods. The mothers in this group were generally satisfied that the other children in their family were okay with the problem and the necessary measures. Some appreciated that other children in the family took on a protective role, helping to make sure the child was not exposed to the problem food. A mother, who has other older children, originally found some difficulty with food restrictions as these children were already quite use to eating the problem foods when their sibling developed allergies. Early on at least she had to deal with the oldest child sometimes teasing about having to eat "[child] food". A second mother having two young children with food allergies and a total of three problem foods has had to make sure that the children were taking care not only with what they were allergic to, but also their sibling's food allergens. As two of the foods were major food groups, it was too difficult to totally eliminate them from the home.

The children in this group are all generally involved with extended family such as grandparents, aunts, and uncles. The contacts may be irregular, fairly frequent, or almost daily. Often contact occurs at special family events that involve dinners. The mothers have all prepared extended family to help maintain control and have generally been pleased with their receptiveness to including the child and dealing with the allergy. Even 
with preparation, mothers must remain vigilant in other family members' homes, as discovered by a mother whose child ate pumpkin pie, which may have contained peanuts, at a Thanksgiving dinner. Fortunately the child was okay, but it distracted the mother for the evening, as she worried about whether the child was going to react. A second mother was surprised to find her child being offered a candy containing peanut by family members she believed should know better. Some mothers find they are not comfortable with having their child stay with other family for extended periods. The mothers are not confident that safety measures will be enforced due to lack of recognition. One of the mothers talked about her in-laws and their understanding: "They weren't trying to be hurtful or...they just didn't understand like a lot of people." Two of the mothers, separated from the child's biologic fathers, also had to consider in-laws whom the children visited, but with whom they had little direct ongoing contact. They had done some preparation of these people in the past before the separations, but now had to rely on their ex-husbands to make sure the children were safe. They were not entirely comfortable with those arrangements, as one mother suggested she was always just a little bit more worried when the child was with the father because of the exposure to his family. For some there was the comforting knowledge that the child was now old enough to be careful about what was eaten when with other family.

\section{Working with the Community}

When the child is young, mothers can exercise direct control either by being physically available or assigning the child's supervision to a small number of people who have been carefully selected and prepared. Caregivers change as the child matures and include babysitters, teachers, and other adults who are in charge of the child for short 
time periods. Having a child with severe food allergies can be an extra worry when trying to find a reliable babysitter. One mother acknowledged that her babysitters tended to be a little older than the normal young teens and required careful screening and another mother was reluctant to give up a reliable babysitter even when the family moved. For one mother a live-in caregiver was the answer to her babysitter problem.

There is always a need as one mother explained to go through an "orientation" with all new caregivers. Some mothers made mention of how they approach other people, such as other parents and teachers, about the allergy to ensure the child is protected. Mothers referred to not making a big "to do", not "ticking them off", and being "tactful", when talking to others. These approaches are seen as helpful in gaining peoples' cooperation and for at least one of these mothers as not overly focusing on the allergy. A couple of the mothers seemed to have a more openly assertive style when preparing others.

The child's entering the school system is an especially challenging time for the mothers, but they have usually found the school staff to be very supportive of the children's safety requirements. The mothers make special efforts to make sure the teachers and principals are informed about the child's allergy and how best to handle it to decrease the risks. They make sure procedures are in place to protect the child, and clear policies related to managing food allergies in the schools that are enforced are a comfort to the mothers. They make sure the child has the EpiPen ${ }^{\circledR}$ at school and in exchange expect that the school staff know how to and are prepared to use it. As one mother said about keeping her child safe she feels she has an "agreement" with the school. She will provide certain things and she expects certain things of the school staff. On occasion 
mothers have assumed that specific controls are in place to learn to their disappointment or anger this is not the case. In realizing this, they have been quick to make sure corrective actions are taken by the school. The mothers instruct teachers to check with them about the safety of foods and sometimes other materials like those for crafts before being given to the child.

\section{Preparing the Child}

The mothers have taken on the main role in helping the child learn to live with the allergy. If an allergy is present in the first couple of years of life, the mother can protect the child without expecting or requiring help from the child. Following this, the risks increase as the child's environment broadens and the mother not always present and in control. This group of mothers all realize the child has to be prepared for the real world and would like them to have a healthy attitude about their problem:

....can't put child into a bubble

....the reality is that you have to learn to deal with it in [the] real world.

Because you can't have the false sense of security.... [child's] got to be integrated"

I want [child] to learn how to live with it because when, when he gets to high school there's too many kids.... Who's going to be responsible?

There is a need for the child to learn to live with the reality of the problem because he or she will eventually be responsible and making more and more of their own choices as they get older. The mothers realize the children need to help control the risks. One mother frightened by the fact her child could die from eating something and knowing she could not always be there felt that at least she could control the child's knowledge. The mothers begin to prepare the children as early as possible and as stated by one mother "we always made it our goal to get [child] to be the one in control" and further talked 
about the need to empower her child. Another mother compared the child's learning how to control risk to learning and displaying good manners, that it should just become another part of the child's life.

At a certain point the mothers have found their children do not want them to be involved with activities. The degree of comfort mothers have with passing more control over to their child varies from one to another and tends to be stronger as the children get older. How the mother feels about the child may also make a difference, as mothers talked about trusting the child and the child's maturity. Though some mothers talked of losing control to the child as being scary, some also expressed their belief that the child's taking more control is appropriate and a normal transition in life. In spite of the fact it can be scary, some mothers expressed a sense of relief with the child's increasing maturity and the greater role the child can play, as in the examples:

I'm feeling a little better because [child]'s learning to do the EpiPen ${ }^{\text {(B) }}$

But now that [child]'s older and has proved to me that [child] is in so much more control it's taken a lot of pressure off me.

Helping the child develop an appropriate attitude towards the allergy and the risks is a concern for the mothers. In most cases they believe their children understand now that their allergy is serious, but exactly how to address the seriousness of the problem with young children is a definite issue. They recognize that the children need to be aware of the possible consequences of eating the food to which they are allergic, so they will avoid the food, but they do not want the children to be paranoid or "crippled" by fear. Some of the mothers have shared their thoughts on this issue such as the mother who said "we don't say die", instead they talk of the child getting sick. Other mothers related that their child has been told they could die from their allergy, but are not sure what this might 
actually mean to the child. A couple of the mothers expressed their thoughts on talking about the severity in the following way:

I guess it is still difficult cause you don't want to freak them out either

But also don't want him to walk around thinking that he's got a severe life-threatening allergy that is gonna kill him. Umm, I want him to live a normal life.

Some mothers expressed concern about not revealing their own fear or frustration about the food allergy to their children believing it would affect their attitude towards it and therefore they carefully control what they say and how they act. "I've tried not to put the paranoia on [child], but at the same time [child] has to know." One mother who had cried on occasion because of her fear of different situations suggested she would never let her child see her doing that.

Some of the lessons about attitude appeared when the children expressed a concern related to having the allergy, such as annoyance at a limitation. The mothers tended to agree with their child that it was not easy. In addition sometimes it was presented as a fact of life. At other times comparisons to children or people with other problems were used to try to put the allergy in perspective as just another problem in life. It is often emphasized that there are other people and children with problems who are worse off.

The interviews identified some of the other strategies these mothers used to teach their children about control of the allergy. There was some indication of joint problem-solving between child and mother as they talked about how certain problems might be managed. Children are taught to make choices like the child who has been given the ability to choose daily from a collection of available EpiPen ${ }^{*}$ carriers. Other children are given situations in which they can choose foods with support, such as the child choosing from the restaurant menu. Children have been observed by mothers for the choices they make 
in risky situations, such as the child exposed to a person eating peanuts at a sports event. Mothers model behaviour as they check out labels, approach other people, make choices, etc. One mother worked at teaching her child that it was not necessary to make a "big to do" about the allergy and how to approach specific situations in a more casual, but effective manner. Mothers help their children identify risks before they are exposed to situations, and they talk to them about how to handle situations. Some of the teaching occurs along with other life skills. As an example, one mother, concerned about whether her child will communicate a problem to the teacher, includes teaching about the communication of reactions in with complaints of other illnesses, bullying, etc.

Rules appear to make an important contribution towards control for mothers. They establish food rules for the children at a very early age, teaching the children to always check with them before eating anything they have not provided. Depending on the circumstances other people may be allowed to approve foods, but the children must always check and as stated by one mother the "rules can't be bent". Other rules are made, as children leave the home about safety measures such as always carrying the EpiPen and wearing the Medic Alert ${ }^{\mathrm{TM}}$ bracelet. It is common, however, for these mothers to still feel the need to give the children reminders especially about carrying the EpiPen ${ }^{\circledR}$, but according to one it is just like other reminders that come out such as 'Do you have your lunch'. For one mother the rule of always wearing the EpiPen ${ }^{1}$ means less confusion for her young school age child and that it will be available if needed. For a second mother there is the belief that it is a natural thing for her older child to wear the EpiPen ${ }^{\circledast}$ now, because it has always been worn. Though the rules are important, a couple of mothers 
expressed their thoughts on not wanting to appear that they were "harping" or "nagging" the child about things related to the food allergy.

As the children get older, new rules may have to be made for new circumstances as suggested by a mother thinking about junior high school: "we'll just set rules and [child ] will know them". The mothers may also have to adjust to the fact that older children may start to make some of their own decisions about foods, such as a child who decided on his own that he could eat a package of candies because they have been safe before.

The mother's previous experience of having an allergy herself may be helpful in preparing the child. Some of the mothers in this study have or had allergies, though not all necessarily as serious as those of their children. There was some belief expressed that this was helpful in empathizing with the child and helping to prepare the child to live with the allergy problem.

In summary, the mothers work with the child, family members, and appropriate people in the community to ensure the child's safety and general well-being. This work to manage risk through control is carried out in a variety of ways.

\section{Relying on Resources}

The fourth sub-theme identified in the text of the mothers' experience focuses on the resources these women made use of in living with their experience. They have employed a collection of resources over the years for assistance in coming to terms with the threat of the allergy, deal with their fears, and control the risks. Especially important amongst these are personal resources, the support gained from other people,-and information. 


\section{Personal Resources}

The mothers' own attitudes and beliefs appear to have been extremely important in helping them cope with this experience and the risks. Their belief in the fact that their children should be able to lead normal lives has helped to create the circumstances so these children are able to participate with their peers. One mother influenced by her own parent's optimistic approach to life has used this quality to help her see that things could be worse and to dwell on the things that can be done rather than on the negatives. A positive approach was also apparent in another mother "I find I can adjust to pretty much anything that comes you know." It was common for the mothers to compare their children to other children with other types of problems such as diabetes. The risk of being killed by the food allergy was also put into perspective by comparing it to other normal risks such as suffering a bicycle accident or by going out and being hit by a truck:

I mean every time you send a child out to play in the street you kinda think 'oh, oh well they're just gonna play on the street'. You don't assume that a car's gonna come 90 miles an hour. So it's not that, but to have something labelled saying 'this could kill him at any single time, you know. And that's the shock of having that. I mean you get used to that feeling after awhile and it becomes like sending the child out on to the street.

Taking the situation "day by day" has helped some mothers live with this experience. "Being on top of it" and feeling confident that they have prepared well were attitudes expressed by the mothers as they discussed the importance of asking questions, looking for information, planning ahead, being involved and making sure about their children's allergies and activities:

I myself have been on top of it you know. Umm, like I haven't waited to miss something.

So that thh the way that I deal with it is to make sure that I've, I feel I've done everything I can do. That there's no loose ends. And then I feel okay. Well I've done 
everything I can do you know.

Most of the mothers tended to hold on to the hope that their child would still "outgrow" the allergy. This hope was viewed with varying amounts of optimism. Some of the mothers had already experienced their children outgrowing other food allergies, and one of the mothers believes it is quite possible for her child to outgrow the peanut allergy. Some of the mothers retain the hope, even though they say it is beginning to seem less likely as the child ages. Even when there is decreasing hope of outgrowing the problem, there is hope for research to find the solution, as identified by one mother as finding the "magic pill" so it will go away.

The mothers' ability to trust others was apparent on different occasions during the interviews. Often it was related to trusting the child, but also other people. Lack of trust appeared to make things more difficult:

I mean a lot of it, you have to, you have to trust other people for a certain amount.

You have to trust [child] and [child]'s judgement.

I was upset because I trusted the doctor and that was my first learning experience of not trusting anybody.

Not thinking about it all the time is one way the mothers cope with the allergy. For one mother working some hours outside the home has helped her keep busy and takes her mind off the risks. This same mother has found she doesn't always want to talk about the allergy even though she knew people often asked out of concern and the desire to learn from her. The mothers expressed how difficult it would be to function or have their children function normally if the allergy and the risks were always there in their thoughts:

If I thought about it all the time I would never let [child] out of the house. 
I don't get up every morning thinking okay [child]'s going to school today, what's gonna. I don't worry like that about it. Because I don't think I would be able to get through it and I think it would make it even worse for [child].

....you equip yourself with what you feel you have to do so that you have a comfort level and [child] has a comfort level and then you go from there. Because it can be aaahhh. It could drive you nuts. You know it could make you totally, totally paranoid I think.

\section{Help From Others}

The mothers also looked to other people for support. Having a supportive partner appears to ease the stress while a non-supportive partner increases it. One mother, now single, missed having that second adult in the home to share the responsibility and decision-making related to the food allergy problem, especially if the child was to have a reaction. Two of the mothers believe and value that they and their partners work together as a team, with one referring to the "moral support" that comes from the relationship. The mothers take the leading role, but felt their partners were actively involved when necessary. One mother identified the fact that she has sometimes restricted the amount of concern that she shared with her partner. She considered him very supportive in handling the problem, but felt there were times she had fears that he would not want to talk about. One of the mothers felt a poor marriage was further stressed by this problem. The marriage dissolved and she believes the problem likely made some contribution, though was not a leading cause. She found her husband's lack of support very difficult, especially when it came to dealing with his extended family.

Some of the mothers talked about how the fathers were able to see the experience differently. Fathers are commonly seen as being able to help broaden the child's environment and experience. They encourage activities that the mothers might not encourage and going more places, helping to normalize the child's life. The mothers 
generally seemed to see this in a positive light, though one mother has mixed emotions about the fact the father is more adventurous with the child's diet. Though worrisome to her, she appreciated that it allowed the child to eat a greater variety of foods. She is still very anxious about trying new foods herself and feels the child would be much more restricted if it were left to her. Most of the other fathers are seen as quite cautious about what the child eats, due to their more limited knowledge and experience with the allergy and, according to one mother, because her partner's general nature is to be cautious. Stepfathers are regarded as supportive also, but possibly even more cautious about feeding the child.

Though extended family was generally viewed as helpful, maternal grandmothers were especially helpful. Often they helped with food preparation, especially for special occasions such as birthdays. They made special treats for the children, sometimes offered babysitting services and emotional support. One of the mothers talked about sharing her tears with her mother, after "ranting and raving" at her husband to help relieve her

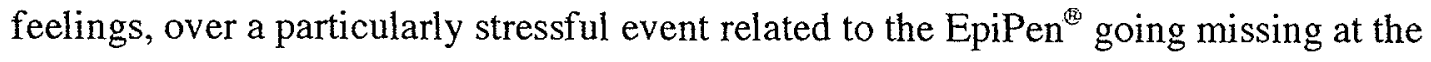
hockey rink.

The mothers were very pleased by the concern and increasing awareness that is displayed by other people. Though a couple of stories were told about people who did not seem to understand, these stories were really in the minority. One mother identified how good it feels when others go out of their way to be helpful. Teachers were generally seen in a very positive light, and there was a lot of appreciation expressed for teachers who go out of their way to make sure the child is safe and still able to participate in activities like other children. Some of the mothers found other children to be very helpful also. They 
believe the children often help to enforce the food restriction rules because they just want to help or protect their friend.

Though there is a support group for families of children with severe allergies not all of the mothers were aware of this fact. From the mothers who were aware of the group there were mixed responses. Two of the mothers had been quite involved in the support group and found it very helpful for getting information, sharing stories, finding solutions to problems and for one mother the fact the children also got together at least once a year. Two of the mothers felt that attendance at the support group was not for them. One of these mothers had attended one meeting and found it too upsetting and felt for her there was too much information, though she could understand its helping other people. This ability for the group to overwhelm people was recognized by another mother who had attended meetings and said the support group recommended attendance at least three meetings before dropping out. A mother who attended the meetings identified the problem of learning a lot more about the problem. Increased knowledge could make it harder because of the increased understanding. The second mother who knew about the group, but had not attended a meeting, was also concemed about hearing too much of an extreme view of the problem. One mother sharing her view identified some of these mixed feelings:

....cause the more you learn the more scared you get. And that's why going to the support meetings I found verrry hard. I mean very useful because I learnt a lot. But very hard to come home and you're exhausted and drained annn, and sad and scared because you've learnt so much. And the more you learn the worse it gets. You know there's more things to worry about. But that's what, that's what I had to do.

Some of the mothers noted that a person could not really understand this experience ifthey haven't lived with it and found talking with others who had was very helpful: 
....you don't understand aaa other people's worries about it til you have it

I think that's how a lot of parents do get by, is by talking to other parents. Ummm you know the practical things.

Some of the mothers had found other parents informally that they were able to talk to about the experience. As the mothers are now more experienced and the children older, a couple of the mothers feel they have less need for the support group, but one noted that she could probably be helpful to others because of her experience.

The mothers praised companies that seemed aware of food allergies. Though labels can be frustrating, they are appreciated for the information they provide reducing the need to make a phone call to check something out. The information also gives options according to one mother. The clearer the information the better, and as remarked by a mother "I mean there's nothing better than, you know, commm, food companies that just understand what's going on."

Health Care Providers Place in the Support Network

Physicians can be an important support for mothers. Most of the mothers identified the allergist as being very helpful. This partly relates to the expert level of knowledge, but the physician's manner is also very important. They appreciated those physicians who were sympathetic and empathetic. One of the mothers spoke of her appreciation of her physician's concern and availability: "[doctor] doesn't...rush me or anything. Or you know minimize what I'm worried about'.

The mothers wanted to be advised by someone with appropriate knowledge and wanted health care providers to be honest when they did not have answers. Some of the mothers remarked on both the good and bad experiences they have had with-physicians along the way. Besides the support they received themselves the physician's treatment of 
the child is very important and they appreciated child-focused encounters. Physicians who had a positive approach to the problem were more desirable than if they just concentrate on the negatives:

You can say 'you have $A, B$ and $C$ and these are the things we are going to do so that nothing bad happens'....Y You have to stress the severity but not make it sound like it's aaaa an automatic definite [death sentence].

Just knowing there is an "open door policy" for questions and concerns was very important to some of the mothers, and they liked to feel their calls will be welcomed.

Nurses were mentioned infrequently, but when they were it was usually in a positive light after encounters in the hospital, school, or doctor's office. A couple of the mothers also felt they had benefited from contact with a dietitian.

On a final note this group of mothers had some suggestions for health care providers. Getting in to see the specialist as soon as possible was seen as very important by one mother, who felt she had to "beg" her physician for a referral and then had to wait for the appointment. Three mothers suggested that the severity of the allergy should be clearly stressed when the problem is diagnosed. One mother who did not know her child could possibly die from a nut allergy reaction until she did investigation on her own, advised that parents be told very clearly and it not be "sugar coated". One mother emphasized that those involved must also know it is possible for the children to participate in a normal life in spite of all the precautions that need to be taken. Families need to be given options for dealing with issues such as carrying the EpiPen ${ }^{\circledR}$ and positive ways of managing problems. Information must be given right at the beginning about things to avoid, how to contact companies, how to use the EpiPen ${ }^{1}$, and the availability of a support group. Three mothers mentioned how at the beginning they did not know what to 
ask and only discovered over time there were things they had to know. The mothers did not appreciate being left on their own to find information:

I should have been taught originally and I didn't know to ask. Again because it was aaalll, all new to me too. I didn't know that I should have known.... So that, I remember being disappointed that $I$ didn't know that [steps in administering EpiPen ${ }^{\circledR}$ ] but you know, not knowing to ask that.

A suggestion was made about the value of having someone such as a nurse available for teaching, counseling, contact, and follow up after the original appointment.

In summary, the mothers' own attitudes and beliefs helped them to live with this experience. They derived a lot of support from other people or organizations, and partners especially can make an important contribution towards helping mothers cope. Talking with other parents who live with the experience can be very beneficial, even though an organized support group may not be the answer for everyone.

\section{Information Resources}

The mothers all felt it was important to learn about the allergy and its management, but there was some acknowledgement that learning more could make the situation scarier: "if you don't know any, anything about it there's nothing to worry about." They felt they should be given information when the diagnosis was made that would help them ensure their child was not exposed to unsafe products and referred to other people who understood the day to day problems. Though some of the mothers were pleased with the information they had been given others, were very disappointed with what they saw as a lack of information from physicians.

The mothers were all very active in finding information, which required more work on the part of some mothers. At least three of the mothers looked to the Internet for information. Some of those who did not attend support group meetings still received the 
newsletter or information from other allergy organizations. One mother suggested the need for refresher information, and a mother who attended a public forum on food allergies and anaphylaxis found it helpful and recommended that more of these events be held. Other people who lived with the problem were able to provide additional information and solutions to problems.

\section{It's Hard But It's Not}

The final sub-theme is titled "It"s Hard But It's Not". That it was both hard and not hard was the conflicting conclusion arrived at generally by the mothers at this time in their experience. Originally having to adjust to this problem may be viewed as a major lifestyle change for the mothers and the family, as remarked on by three of the mothers. It appears that so many things must be avoided or at least be given a lot of consideration. There is a concern about what the limitations will be for the child, family, and self. The mothers, as expressed by one, may question whether they will ever be able to go out again. The experience requires extra work from the mothers, especially if more than one type of food is involved. There is the recognition of risk and the fear related to different situations. Mothers worry about how the child will be able to live a normal life. Even at this stage, to outsiders it seems like a hard situation with which to live. It was common for the mothers to have others express how hard it must be, as in the following: "A lot of people think 'oh that must be so much work', but you know you just get used to it."

Though these mothers acknowledged that there was some difficult times over the years, and they had worked hard to help their children live normally, they did not find it that hard on a day to day basis anymore: 
In the beginning it wasn't easy. I think today it is much easier.

It's always in the back of your mind. It's, it's always will be an issue but umm, it's not a controlling issue.

....it's always hard but I think it's in the background. You get use to the lifestyle and it is easier.

The mothers have learned to deal with this situation by being flexible. They have changed and adjusted because they have realized they have to deal with the problem, and they have dealt with it as different situations occur:

....you manage it like everything else that comes along, you grow with it.

Well you don't sit and moan and cry and complain that you can't have all this stuff. That's a fact of life. You just have to change.

....you sort of problem solve everything...aahh eventually you get through it somehow or other

Umm you have to deal with it. You have to live with it....So for me, it's not something that is a difficult thing to live with every single day. That is what I have to do....We adjusted our lives right from the very beginning cause you didn't have a choice and that's just the way we live.

As the mothers talked about their experiences the signs of their adaptation were identified in their reflections about their children, families, and selves. They have allowed and encouraged their children to lead lives similar to their peers with some modifications when considered appropriate. Besides supporting their children's normal development, they have developed an approach to the risks that has played a significant role in keeping the children safe. The problem is viewed as just one part of the child's identity: "That's jussst a very small part of [child]. [Child]'s this. [Child]'s that. [Child]'s you know a whole bunch of different things and [child] also has a peanut allergy."

The families as a whole participate in normal family activities largely based on the mothers' encouragement and efforts. As for themselves, though there may have been 
some limitations early in their experience, such as decisions about working outside the home, they view it as causing few limitations to their lives today. One mother expressed concern about seeing her child's problem as a limitation to her life, especially about communicating that attitude to the child. Another mother felt that instead of limiting her, it encouraged her to become more involved in school activities than she might have been otherwise. A third mother acknowledged that it was mildly limiting but you 'figure out what your priorities are".

In the end the mothers have integrated the experience into their lives and it has become one more part of their lives. It is a very important part, but just like for their children it is just one part:

I think you know if it's just part of your life, if you don't look at it as being special or different just your life, it's not a big deal.

.... although it's important and it's very severe that there is a life after....

Ann it's something that you get accustomed to dealing with and it just becomes a part of like brushing your teeth or doing anything else. It's just part of the norm of your family.

\section{Conclusion}

In conclusion, the findings of this analysis points to a group of mothers whose experience parenting a child with a life-threatening food allergy involves "living with risk", which is apparent once the mothers begin to recognize the implication of the allergy. From the recognition of risks, comes fear for the child's life. The fear is a dynamic emotion, which varies between mothers, over time and situations, but is always there somewhere in the background. The mothers also are concerned about risks to the child's well-being and normal development. To cope with their fears and concerns and to 
ensure the child's safety the mothers work hard at managing the risks through various means of control. Resources that help the mothers live with this experience have been identified. The mothers have all had a number of years to adjust to the experience of living with the food allergy and the accompanying risk. They have expressed how the experience is both hard and easy, but now integrated into the norm of their own lives and those of their child's and family's. 


\title{
CHAPTER FIVE
}

\section{DISCUSSION AND CONCLUSIONS}

\author{
Introduction
}

This final chapter will begin by reviewing the appropriateness of the use of the methodology of phenomenology for gaining insight into the mother's experience of parenting a child with a life-threatening food allergy. It will further discuss how the mothers in this study saw the experience against the background of what is generally expected of mothers in North American society today and known about parenting a child with a chronic medical condition in general. The issues of stress, coping, and adaptation will be addressed as they relate to the study and as compared to parents caring for children with other medical problems. Limitations of the study will be identified. The chapter will conclude with recommendations for nursing practice, education, and research based on the knowledge gained from this group of women.

The Study Method and Study Purpose

Qualitative research is recognized as an important approach for studying issues about which little is known. Phenomenology, the qualitative methodology used to study a group of mothers of children with serious food allergies, was an appropriate research approach for the stated purpose of the study. This original purpose was to gain a better understanding of what it might be like to be the mother of such a child, as the topic had yet to be addressed in the professional literature. Attention was to be paid to what might characterize the experience; the meanings the mothers assigned to it; and identification of 
stressors, coping strategies, and signs of adaptation. The researcher was especially interested in how health care professionals might be able to help make the experience easier for mothers whose children were diagnosed with this problem.

Phenomenology is a methodology used to examine what it is like to live a particular human experience by focusing on the day to day experiences of those living it. Many modern phenomenologists emphasize the importance of the combination of mind and body to help individuals perceive and interpret the world and give their experience meaning. According to van Manen (1997) we know things through our body, relationships, and interactions. Through dialogue and interaction with those living the experience of interest, reflection upon those dialogues, and further interpretation of the individual and group text, it is believed that the researcher can gain some insight into what it is like to live the experience. Gaining an understanding of the experience can assist that person in acting more thoughtfully and tactfully towards those living the experience (van Manen, 1997). It is possible that this understanding can be conveyed to others, helping them to also better understand the experience.

The use of phenomenology in this case has elicited a better understanding of the mother's experience of parenting a child with a life-threatening food allergy. The use of a semi-structured interview format allowed a small group of women having personal knowledge of the phenomenon to share their thoughts, activities, interactions, and memories. They were able to articulate what they considered as important in defining what it is like to be a mother of a child with a serious food allergy. This process has resulted in an extensive text related to these women's daily lives, as self-perceived, especially addressing the present and recent past. Though they did not view the overall 
experience in exactly the same way this can be explained by the fact that human beings are complex and affected by many different factors. Through the researcher's reflection on the material provided, interpretation of the text, and writing and rewriting as recommended by van Manen (1997) a picture has emerged of what this experience might be like for those living it. The experience is both unique and common if considered within the scope of what is generally considered the norm for the mother's role. The dominant theme, "Living with Risk" and the five sub-themes form the structure of the experience as interpreted by this researcher.

In addition, it was originally noted that using a conceptual framework to guide a phenomenological study was generally considered inappropriate, but Family Systems Theory and Family Stress Theory formed part of the background in which this experience was considered. The researcher believes that these theories made a valuable contribution to helping her understand families and how they might cope with stress, which in turn supported the interpretation of the mother's experience.

Mothering a Child with a Life-Threatening Food Allergy:

The Unique within the Norm

Being a mother means occupying an important position in both the family and society. Most often it is women who are mothers, though Ruddick (1990) and some instances of experience would argue that being female is not a necessity for the role. The position of mother brings with it certain expectations as to the incumbent's duties, skills, and obligations. These expectations arise out of the needs of the family and its individual members and from the beliefs of the mother herself, other family members, and society 
in general. Mothers, though not always exclusively, are most often considered the family care providers, housekeepers, cooks, managers, health leaders and decision-makers, educators, and counselors (Anderson \& Elfert, 1989; Burke et al., 1999; Faulkner, 1996; Friedman \& Heady, 1998; McGoldrick in Friedman, 1998). These various interrelated activities performed by mothers support the functioning of the home and family. Evidence suggests the women in this study performed all of these duties for their families with varying amounts of support, and that the child's allergy had an impact on the duty requirements and performance.

Mothers are usually the family members responsible for dealing with health care and the family experts in health matters, though others may 'help out' (Anderson \& Elfert, 1989; Burke et al., 1999). The mothers in this study were the health leaders in their families, a fact that was demonstrated in a variety of ways. It was usually the mothers who attended doctor's appointments and received information provided by the healthcare professional. It was the mothers who obtained and disseminated information about the food allergy to other people, and it was the mothers who trained other people about how to manage the child's allergy including a possible reaction. In the majority of cases though fathers had direct responsibility at times for ensuring the child's safety with regards to the food allergy and generally, they were the recipients of information from the mothers and in many instances deferred to the mothers' expertise.

Typically children as a group are especially dependent on their mothers and generally present many challenges to these mothers. According to Ruddick (1990), maternal work normally revolves around the demands for preservation of the child's life and support of emotional and intellectual growth and social acceptability. Though all three demands are 
important, especially essential to mothering is recognizing the child's vulnerability and the commitment to preservation of life. In addition, a common maternal goal is for the child to grow into a happy, productive, independent human being. Skills, effort, and resources are required by mothers to help meet these demands. Ruddick refers to the need for love, nurturance, and training and has pointed out the fact that at times the demands to protect, encourage growth, and support socialization can conflict with each other.

The environment holds many risks for the child, risks to meeting the demands. These risks, when recognized, can create anxiety for the mother resulting in efforts to decrease the risk and therefore the anxiety. Efforts are made to adjust the environment, which includes other people, or are directed at the child so he or she can live successfully within the environment.

Having a child with a chronic problem presents additional challenges that have a direct impact on the whole family, but especially the child's mother (Burke et al., 1999; Englund, Rydström \& Norberg, 2001; Faulkner, 1996; Gibson, 1995; Jerrett \& Costello, 1996). The six participants in this study have illustrated some of the possible effects on mothers that could be attributed to having a child with a life-threatening food allergy. The experience of mothering a child with this problem suggests a unique experience, but one that is also situated within the norm of maternal work.

\section{Living with Risk}

Living with risk is a normal part of the human experience. Risks exist for all children, and being a mother means being alert to signs of danger that can affect the vulnerable child. Risks may exist that threaten the child's life, growth, or social acceptability. 
The introduction of a chronic health condition into a child's life can increase the risks to that child, affect the whole family, but especially have impact on the mother. The type of risk may be condition dependent, such as the risk of a hypoglycemic reaction in diabetes, while some risks may be more general across conditions, such as possible risk to the child's emotional health. Biomedical research and experience have identified the physical risk related to having a serious food allergy, factors that increase the risk, and medical approaches towards decreasing risk. Children can die from allergic reactions to foods, especially some foods. This study has translated this risk into the every day experience revealing the impact of the risk on the study participants, as they fulfill their role as mothers to their children.

Though they may not see the risk in exactly the same way, the women in this study have all recognized their children's physical vulnerability. They live with the knowledge that their children are at an increased risk for death, and they have a primary responsibility for protecting them. They also recognized possible risk to the children's psychological and social growth and the need to support the children in their development and gaining of independence. Just as suggested by Ruddick (1990), this maternal experience too results in the need for the mothers to sometimes deal with conflict between the demands for preservation of life, growth, and social acceptability.

Mothers of children with serious food allergies live with different sources of risk and a greater level of child-related risk than do most other mothers. These risks are found in all environments and experiences that are a normal part of children's lives. Some of the risks cannot be removed, remaining ever present. Risks that might exist in unfamiliar environments are not always known, and risks change over time as the child develops, 
with some uncertainty as to what they might be in the future. These risks the mothers face arise from food, something that may certainly cause some problem in other conditions such as obesity, lactose intolerance, or diabetes, but not with the same immediate, severe consequences.

Food occupies an important place in human life and has many different meanings. Food is directly connected to a mother's care for her child, and it is still women who are mainly responsible for the majority of activities related to food. Though this may vary from family to family, it was largely the case in the families involved with this study. Food is considered a basic need and a normal part of existence, but its use is not only in providing nourishment for normal development. Food can also convey love, pleasure, comfort, reward, and is an important part of socialization. Food was valued for nourishment by the mothers in this study. In addition, some of its other meanings for the mothers were revealed in the text of their experience of dealing with concerns and issues around having to deny their children certain foods, making alterations in the family diet, and worrying about food in other settings because of the risk involved.

Understanding the risk children with severe food allergies might face on a daily basis and how mothers might interpret and respond to these risks is necessary in order to offer support to the family.

The Worry and the Fear

The recognition and acknowledgement of risk to the child is likely to cause most mothers' anxiety. Mothers routinely worry about risks to their child's well-being, and it - is not difficult to imagine the fear that can develop, if they perceive a threat to life. It is 
possible for mothers to experience these emotions related to their child at any stage in the child's life.

A number of researchers have identified fears and worries of parents of children having diabetes and asthma, conditions that share some similarities with serious food allergies (Englund et al., 2001; Faulkner, 1996; Faulkner \& Clark, 1998; Hatton et al.,1995; Kieckhefer \& Ratcliffe, 2000; Kumat \& Moore, 1999; MacDonald, 1996; Vandagriff, Marrero, Ingersoll \& Fineberg, 1992). Concerns included the child's dying; uncertainty; disease complications; financial burden; time and energy required; hypoglycemic reactions; overprotectiveness; future threats to safety; long-term effects of medication; the condition not going away or improving; effects on growth and psychological development; causing their child pain; leaving the child in someone else's care; and interference with their own activities. An article focused on the development of an anaphylaxis training package for schools, suggested that parents of children at risk for anaphylaxis are concerned about balancing a normal lifestyle with safety and dealing with school staff (Vickers, Mynard \& Ewan,1997). Based on their clinical experience, Primeau et al. (2000) identified a fear of accidental exposure amongst parents of peanut allergic children.

The women in this study have demonstrated that they too live with the fear that their child might die due to the ingestion of a food allergen. The fear seems more acute early in the experience, when the mother begins to understand the impact of the allergy and the future is uncertain, and before she feels she has control of the situation. The fear is likely to increase again when the mother relinquishes some responsibility for the child's protection such as to babysitters, nursery schools, and especially at school entry. 
Establishing routines helps to settle the fear, but events that disturb the routine can cause the fear to resurface. The mothers continue to have some fear of the future and the uncertainty of what might occur, as their school age children become adolescents and then young adults. It is also likely that personal factors affect the degree of fear experienced.

Kieckhefer and Ratcliffe (2000) have suggested that parental fears of those whose children have asthma can decrease over time. Their parents of adolescents expressed less fear than their parents of younger children. Whether this trend had to do with age, the amount of time since diagnosis, or the degree of trouble presently experienced was undetermined by the researchers. For these children in this study it has been a few years since diagnosis and the majority of the children have not had any recent food related reactions, which may contribute, as some mothers suggested, to their own more relaxed attitude. The mothers have learned over time how to deal with many of the risks, and current fear is most often connected to changes in the child's routine. Some of the mothers related feeling less fearful because of the trust they had in their children, especially those children who were older. The mothers have been training the children since they were very young to take on varying degrees of responsibility for their own safety according to their stage of development, and as they demonstrate this responsibility through their actions it seems to become easier for the mothers.

Mothers generally worry about the well-being of their children and whether they are progressing as expected in regards to their physical, mental, emotional, and social -growth. Parents of children with other chronic conditions have revealed their concern about the effect of the condition on growth and psychological development and about 
being overprotective. Having a chronic illness is a deviation from the norm and may be seen as a stigma by other people, resulting in different treatment, rejection, and isolation (Joachim \& Acorn, 2000). This may be especially a problem if the condition is visible. If not visible, a decision needs to be made as to whether the condition should be disclosed. Seeing a child as normal, even if chronically ill, is important to parents in spite of the fact some restrictions may be imposed (Anderson, 1981).

The mothers in this study were all concerned about the effects the food allergy could have on their child's normal social and emotional development and about being overprotective. Though the condition is invisible it must be disclosed for the child's safety. Wearing a MedicAlert ${ }^{\circledR}$ bracelet and carrying an EpiPen ${ }^{\circledR}$ contribute to making the condition visible. The worry about stigmatization can be heard in the mothers' concerns about the children feeling or appearing different, being restricted from normal activities, or being made to feel different by others. As in Anderson's research, most of the mothers tended to emphasize the normality of their children, as they talked about their children's many positive 'normal' qualities, the fact they fit in with other children and their social environment, and did not suffer any discrimination based on their allergies. These mothers all carried out a variety of activities that assisted their children's development in a manner they considered to be normal for children their age, and the mothers of the older children were especially concerned about supporting their child's growing independence, even though it came with some added anxieties.

Though some fear may exist for the future, mothers of children with serious food allergies can learn how to live with the fear so it is not a constant focus in their lives. 
Understanding the situations that cause fear and anxiety for these women and how they have dealt with them can help professionals advise other mothers living this experience.

\section{Coping with Risk}

The beginning step in the process of coping is appraisal of a situation as being stressful or impacting on the individual's well-being and placing demands on their resources (Lazarus \& Folkman, 1984). Once such a situation is recognized as requiring attention, a variety of strategies can be used to help deal with the discomfort. These coping strategies may be either emotional or problem-focused behaviours. In addition, the coping process requires resources from within the person themselves and access to other resources from the external environment in support of the process.

Recognizing or anticipating risk and suffering child-related anxiety can be viewed as a source of stress requiring some reaction on the part of the parent on whom the child is dependent. The world cannot ever be completely controlled, and no child can be totally protected from danger due to chance and unpredictable behaviour (Ruddick, 1990). Mothers have to cope with this reality of life and commonly make efforts to control their child's world as much as possible to keep the child safe and at the same time reduce their own level of emotional distress. According to Lazarus and Folkman (1984) when control implies effort, it is synonymous with coping. Control can be exerted through efforts directed at the environment or at the person to create a satisfying fit between the two. When considering the child as suggested by Ruddick, safety needs to be balanced against the requirements for growth and acceptability. As a part of maternal work, mothers normally balance the child's demands against each other and the environment, finding ways to support the child's needs on a daily basis. 
The mother uses her own resources in the coping process and may need to develop new resources. Maternal reasoning is distinct in its focus, and the way in which mothers approach their work is based on factors such as intellectual capacity, values, attitudes, and general life philosophy (Ruddick, 1990). Her problem-solving skills, understanding of a problem, and choices are all affected by her intellectual capacity. Additionally, it is also likely that a mother's way of viewing the demands and ways of meeting them is affected by experience, environmental context, and some might also consider instinct (Gibson, 1995; MacDonald, 1996). With a focus on mothers of children with chronic illness, Gibson identified the importance of having a sense of empowerment, which is associated with knowledge, confidence, assertiveness, and an ability to collaborate with others. Additional resources for coping can include social support, and material and informational resources.

Having a child with a chronic condition requires additional coping due to conditionrelated risks, fears, and concerns. The child may appear more vulnerable than if considered 'normal'. Control is an important aspect of coping, and controlling the child's environment can be considered a problem-focused strategy for dealing with stress related to the risks. Jerrett \& Costello (1996) note a commitment by parents to environmental control in caring for children with asthma. Englund et al. (2001) also interested in the need for control with children who have asthma, refer to "meticulous planning and control" to help protect the child. Educating others about the child's condition and following up on this preparation are important activities that help many parents establish and broaden their control (Englund et al.; Faulkner, 1996). Englund et al. also suggested 
that their findings related to parents of children $6-16$ years old indicated that some control is always required independent of age.

Control is an activity that is connected to vigilance, a concept which suggests careful monitoring, 'being on guard', and making special efforts with control strategies. The recognition of vigilance has appeared in research looking at children with chronic diseases such as asthma (Englund, et al.; MacDonald, 1996; Palmer, 2001) and diabetes (Hatton et al.,1995). Palmer refers to the "vigilant manager" a person who cares for and advocates for the child. MacDonald connects vigilance with assertiveness in her discussion of mothers "mastering uncertainty".

The mothers in this study too have demonstrated that having a child with a serious food allergy means additional stress and the need to deal with it by using different strategies. Exposure to risk increases and/or changes as the child grows. Gaining control of the problem was essential and meant some degree of control over the environment, child, family, self, and others. Vigilance, accompanied by the feeling that they had done as much as they could, was an important part of the mothers' daily lives and used by all the mothers to help deal with this experience. It involved careful control and planning just as for children having diabetes and asthma and in many cases more so. Vigilance is demonstrated in the mothers' careful monitoring of the child's daily activities and by anticipating and preventing problems.

As the primary home manager, the mothers worked at keeping the home environment safe. Vigilance is revealed in the mother's management of the home, food related activities, and through her management of family life and its members around this specific issue. It was present in the way she shopped, how she stored food, what she 
prepared, and how she prepared it. Even though the consequences of a food exposure are perhaps somewhat different in children having diabetes, Faulkner (1996) noted some similar issues for the mothers of these children such as the need to read labels on food products.

Vigilance is apparent in the interactions of mothers of children with severe food allergies with people outside the home such as: extended family, other parents, teachers, friends, coaches, babysitters, camp supervisors, casual acquaintances, restaurant staff, and people in places of worship. The mother's focus on vigilance and control is apparent in these interactions whether she is enlisting their help, educating them to keep her child safe, raising general community awareness, or just in casual social conversation.

Vigilance is there in training the child. As children grow, mothers normally educate their children in matters of safety in preparation for the fact they won't always be there themselves when a child is exposed to risk. Having a child with a serious food allergy adds an extra dimension to this preparation. These mothers began working on food safety education early in their children's lives, as mothers do with other types of safety education.

Rules have been recognized as important for parents in the process of accommodating children's asthma (Jerrett \& Costello,1996). Rules have also played an important part in maintaining vigilance and control for the mothers in this study. Rules were established early and taught to the children as soon as the mothers believed they would understand. Though the rules may have undergone some change as the children grew, they still make an important contribution to the mothers' sense of control. Food related rules were also made for other family members and people outside the home. 
According to some of the mothers in this study, the requirement for control on their part may decrease as the child matures, becomes more independent, and becomes more knowledgeable about the allergy. Though some effort at control may always be there as for Englund et al.'s parents (2001), the mothers of the older children especially in this study were anxious to not appear over controlling or to be interfering excessively with their children's attempts to achieve independence. Important to decreasing their sense of control appears to be their increasing trust in the child and evidence of the child taking increased responsibility for their condition.

Entry into the school system can be difficult for parents of children having chronic conditions and has been shown to be stressful for those whose children have diabetes (Hodges \& Parker, 1987; Parker et al.,1994). When children are at school the parents no longer have direct control over what is happening. Parents of children having diabetes lacked confidence that school staff were properly prepared to care for a child and felt the staff did not recognize that school parties and field trips needed advance planning. Problems with school conflicts have also been identified by parents of children having asthma (Palmer, 2001), and Vickers et al. (1997) noted that parents of children at risk for anaphylaxis found dealing with school staff difficult. The women in this study have experienced similar school related issues especially when first entering the system, but with time, effort, and skill have worked through most of their concerns.

Besides control, parents have also used other strategies for coping with their children's chronic medical conditions. Included amongst these strategies are informationgathering, assertiveness and advocacy, relying on support from family or other people, normalization, distancing, minimization, comparison, problem-solving, and maintaining 
hope (Burkhart, 1993; Gibson, 1995; Hatton et al.,1995; Holaday, 1984; Jerrett \&

Costello, 1996; Knafl \& Deatrick, 1986; Lowes \& Lyne, 1999; MacDonald, 1996;

Palmer, 2001). Cohen (1993) identifies "living a day at a time" in coping with

uncertainty, a philosophy expressed by a couple of the mothers in this study. Evidence of the use of all of these strategies, both emotional and problem-focused, was found in the experience of the mothers coping with their child's severe food allergy. All of the mothers have used some of the strategies to a large degree, such as information-gathering and problem-solving. Individual mothers used other strategies, such as comparison and minimization, to varying degrees.

Getting information can be part of an empowering process (Gibson, 1995; Holaday, 1984). Information can come from different sources, and the mothers can be self-taught or learn from professionals or others experienced in the condition. Different sources of information provide different types of information, all of which are probably important. Holaday identified a need for information about the seriousness of the problem, possible problems that could be encountered, and the effects of the condition on the child's life. Mothers need the information to help them understand the situation, master it, and adjust, a fact confirmed by the women in this study. Mothers caring for a child with a serious food allergy have to learn to recognize the special risks related to food, ways of decreasing risk on an every day basis, and how to do this in ways that will support a child and family's normal growth and development. For some of these mothers having inadequate information early in their experience created anxiety, anger and frustration They all realized they needed information to protect their child and found various ways over time to get that information. Today information-gathering is most often related to 
food products, but some of the mothers identified watching for new information about food allergies and their treatment, an effort which may support the maintenance of hope.

Normalization to integrate children into society is also a coping strategy (Holaday, 1984). Efforts to maximize the child's capabilities and integrate children into mainstream society helps to decrease parents' concerns and makes the future seem more optimistic. Many examples existed of the efforts carried out by the mothers in this study to allow their children to participate in the same activities as those of their peers.

Social support is an important resource for coping with stress generally and very important for the stress related to a child's chronic medical condition (Clark, 1997; Gibson, 1995; Lazarus \& Folkman, 1984). It contributes to empowering mothers (Gibson). Support may come from different sources including the family, health care providers, the community, and support groups (Burkhart, 1993). Partner support is especially important (Gibson).

Social support is important to mothers of children with severe food allergies. Family was an important source for the mothers participating in this study. All of the women who lived with partners felt they benefited from their partners' support. Mothers found previous partners who weren't supportive added to their level of stress, though some mothers found previous partners were supportive when it came to the child's food allergy and were viewed positively for their assistance. Maternal grandmothers were a strong source of support for some of the mothers.

Support Groups are seen as beneficial in offering support to people in similar circumstances (Johnson, 1982; Nugent, Hughes, Ball, \& Davis, 1992). People who have 'been there' can provide insights and help increase understanding of the problem. Nugent 
et al. referred to support groups as a "climate of caring" and Johnson identified that they offer acceptance. Many other benefits have been suggested. Parents can share common concerns and emotions including feelings of fear and guilt and get assistance in dealing with these emotions. Participants are helped to identify personal strengths and resources for coping with the stress. They can learn about the particular condition, its treatment, what to expect and the options. Parents can learn how the children might react and how to help them develop normally.

Mothers need to be aware of the support group's existence before it can be beneficial, but not all mothers may feel that attending group meetings is an experience that would be beneficial for them. Not all of the mothers in this study were aware that there was a support group in their city. Some of the mothers did rely on the group for information whether they attended meetings or just received the newsletter. Based on the experience of some of the mothers, attendance at meetings may be viewed as heightening emotional distress through such a focused activity or as an exposure to an approach that conflicts with the mother's own philosophy. Even if they did not belong to a support group some of the mothers found value in sharing their experience with other parents of children having severe food allergies, so found support informally.

Once the mothers in this study realized the allergy-related threat, they began to cope with the risks, as they understood them. A clear understanding of the condition and its acceptance are important for successful coping. Professional caregivers can better support mothers facing the diagnosis of a severe food allergy in their child if they have an understanding of the coping strategies and resources mothers might use in their efforts 
to adjust to the knowledge of risk. By using the strategies and resources they did, the mothers in this study have been able to fit this experience into their every day lives.

\section{It's Hard, But It's Not}

The goal of coping is to adjust to the particular circumstances recognized as putting extra demands on the individual. Human beings continuously adapt to the stresses and changes that are a part of life, including those related to having children. Mothers adjusting to a child's chronic illness have been noted to express feelings of knowing they must adjust and doing what they feel they have to do (Gibson, 1995; Hatton et al.,1995), sentiments also expressed by some of the mothers in this group. These beliefs may support a successful adjustment, but negative adjustments are also possible. In the case of chronic conditions adjusting or adapting to the situation would be expected to be a dynamic process as changes occur in the condition, environment, and people.

As the mother plays a central role in the family, how she, the child, and the family live may all provide some indication for how she has adjusted to her child's problem. A feeling of confidence, control, and competence may all indicate good parental adjustment to having a child with a chronic condition (Gibson; Holaday, 1984). For children to grow in a positive manner mothers must be attentive, but not too attentive causing development to be stifled (Ruddick, 1990). Anderson and Elfert (1989) suggested that mothers caring for children with a chronic illness can find their needs "overshadowed" by those of their child, while some parents have seen the possibility of diabetes consuming their lives and the need to avoid that situation (Faulkner,1996; Hatton et al., 1995). There is an assumption by many that normalization, which includes acknowledging the condition, believing it has little impact, seeing family life as normal, 
and demonstrating 'normal' family behaviours is a sign of good adjustment, though the assumption may be questioned by some (Knafl \& Deatrick, 1986). Canam (1993) has outlined eight tasks that she believes are necessary for parental adaptation to a chronic condition that consider the condition, child, and family.

The mothers in this study for the most part felt confident and knowledgeable at this point in time about meeting their child's needs in relationship to the food allergy. It is possible that these beliefs have contributed to moving their sense of fear into the background. They have been able to successfully work with others to protect their children, though the approaches have varied to some extent between the mothers. They have all recognized that food risks will always be a part of the child's normal environment, until such time, if it occurs, the child outgrows the allergy or it can otherwise be dealt with. Hatton et al. (1995) identify combining hope with realism as part of long term adaptation, and none of these mothers have entirely given up hope for a time at which the allergy will no longer be a problem though the expectation was greater for some mothers than others.

Having a child with a chronic condition means extra maternal work. It might be expected that mothers would experience some limitation on their own activities because of the care required, as did some of Anderson and Elfert's (1989) parents. The mothers in this study, when asked did not feel that their lives were limited by their child's condition today. The difference between the two views may be explained by a variety of factors including: sample size, number of contacts, the chronic condition, duration since diagnosis, the way in which the question was asked, or perception differences. Anderson and Elfert's study involved a larger sample and more contacts with each family. The 
mothers in this study seemed comfortable in expressing their thoughts about their experience, but it is possible that even if they do feel limited today they were not comfortable in expressing their feelings about this to the researcher when asked directly. Possibly more would have been revealed with further contacts or if questioned in a different way, but it may instead have to do with the nature of the child's condition or where the mothers were in their experience. These mothers have all had a few years to adjust. Limited information was reported about the diagnoses in Anderson and Elfert's study and no information about the length of time since diagnosis.

It is not uncommon for mothers to feel guilty when their children suffer from conditions affecting their health or causing them to deviate from what is otherwise considered normal (Anderson \& Elfert, 1989; Park \& Martinson, 1998). Though a couple of the mothers alluded to feelings of guilt in the past about their contribution to the allergy or about not realizing its seriousness and reacting appropriately, feelings of guilt did not generally seem to be a major concern today for the group as a whole. At least such feelings were not expressed.

A measure of adjustment may be how well the child's condition is managed and how well the child is able to function in relationship to daily activities. For these children the allergy does seem well managed, as recent reactions are almost nonexistent in the group. In addition, based on the mothers' descriptions of the children's activities it would seem development is progressing normally.

It is expected that a child's chronic illness will affect the child and the whole family. Though at least a couple of the mothers stated that originally the allergy meant a 'lifestyle change', the majority expressed their belief that the allergy interfered very little 
in what the child or family wanted to do today. Keeping the family life as normal as possible was recognized as important by the mothers, as it was for some of Anderson's families (1981). There were obviously some restrictions around eating out and travel. Though acknowledged as restrictions, the limitations on these activities did not in general seem to be seen as major concerns.

Chronic conditions can interfere with the relationship between women and their partners. In considering partner relationships with this group it seemed more likely that the allergy was a reason for the mothers and their partners to work together rather than causing problems to the relationship. Only one mother raised the issue of whether the allergy had an effect on the fact her marriage had not worked, but in her analysis it may have caused further stress, but was not central to the break up.

Adjustment or adaptation means integrating the experience into the family's life. These mothers believe that they and their families have been able to make this experience just one more part of their life, the child's life, and the family's life. It is not always easy, but it is easier today than it was in the beginning.

Though the experience of mothering a child with a life-threatening food allergy has been centered within the norm of being a mother, it is not meant to minimize the experience. The experience is unique. It is associated with unique and more frequent risks and fears and places a higher level of demand on mothers then that which is normally experienced, especially in the early years of living with the condition. These women have demonstrated that mothers can adapt over time to the experience, so it is not as one mother suggested "this elephant sitting in the room". To mother a child with this 
problem is different, but connected to what it means to be a mother under more normal conditions.

\section{Study Limitations}

Inherent in the qualitative approach to research is the inability to generalize the study findings to represent the broader population, and therefore generalization was never an expectation in this case. Women were purposively chosen who were expected to be able to articulate what it was like to be a mother in a very specific situation and willing to share their thoughts on the subject. The need was for a rich text speaking to the experience. In this case the children were primarily male, all fell within the school age group, and none were diagnosed recently. Though there was some variation in the mothers' marital status, family income was mostly in a higher income bracket, there was very little cultural variation, and this specific group of mothers seemed generally well adjusted to the experience based on what they communicated. It is possible that a sample that included more variability may have revealed additional information about this experience. Finally, the study took place during one narrow period of time.

\section{Implications for Practice}

Having confidence in the child's physician was important to the mothers in this study, but it is possible that other knowledgeable, empathetic health care providers can also offer important support. Nurses may have contact with families of children having severe food allergies in a variety of settings. By having some understanding of what is involved in living with this experience the nurse can offer care, education, and support in a more 
informed and sensitive manner. Suggestions are made here for practice based on the mothers' description of their experience and the recommendations that they made about what they found or felt other mothers would find helpful in dealing with the experience. There is recognition by the mothers and the researcher that these children were diagnosed a few years in the past and some of what was suggested might be more commonly available in the present, but it is not guaranteed.

To begin, nurses must understand what serious food allergies are from the biomedical perspective. They must understand the pathophysiology, the risks, the prognosis, and how to advise families dealing with this problem based on a constantly growing body of knowledge. It is also important to understand the many ways in which the allergy can be an issue in every day life impacting on all the activities that normally take place.

Ideally an allergy specialist should be involved as soon as possible following a suspected reaction. As the diagnosis is important to the child's safety and has a significant impact on the child, mother and other family members, it is important that it be made quickly and correctly. When a child is diagnosed as having a severe food allergy clear information must be given at the beginning outlining the seriousness of the problem and the measures that need to be taken to ensure the child's safety. This information should be delivered with some reassurance and optimism related to the child's prognosis for a healthy life, but with the acknowledgement also that there may be many challenges, fears, and worries along the way.

It is important to remember, as noted by some of the mothers in this study, that they do not necessarily know what they need to ask, and the information should be given not just verbally, but also in writing for future reference. It can be anticipated that hearing 
this diagnosis might be a stressful and that what is said and what is heard might not always be the same thing.

The mothers in this study indicated the importance of having adequate information to help them protect their children. Printed resources should be given that include what needs to be avoided, the importance and 'how to' of reading labels, how to contact companies, and how to deal with other problems that the mothers might expect to encounter according to the child's current level of development. They need to know about special risks such as bakeries, buffets, bulk foods, and restaurants and should be made aware of local and national organizations dedicated to providing information and support. Examples can be given of rules and approaches that have helped other mothers deal with different situations. Reading material and websites can be recommended for further information, as many good sources of information are now available. Mothers should have a contact number for a knowledgeable professional they can contact with questions and concerns. It seemed to be comforting to some of the mothers just to know someone was available if they needed professional advice, and a nurse specialist would be a useful resource for mothers in this situation.

The medical practitioner or the health educator can give general dietary guidelines, but more dietary support may be required. Depending on the number of foods involved, the type of food, the age of the child, or the mother's feeling of confidence the professional should consider making a referral to a dietitian. Expert advice can then be given to adjust the child's diet, so it avoids the necessary foods but contributes adequate nutrition to help the child grow. As noted by some of the mothers in the study not knowing what to feed a young child especially is extremely stressful. 
As total avoidance is not always possible and accidents occur, it is essential that the mother and other family members are helped to develop a response action plan and taught to recognize a possible reaction and how to administer the EpiPen ${ }^{\circledR}$ as soon as a possible reaction is identified. Those involved should have the opportunity to demonstrate the use of an EpiPen ${ }^{\circledR}$ trainer and having 'reaction drills' at home should be encouraged.

It is important to consider the possible sources of stress that might be connected to the food allergy but additionally any existing stressors when attempting to assist mothers in dealing with this problem. A combination of stressors is likely to make dealing with the food allergy even more difficult. Identifying the sources of stress is the first step towards dealing with them. Appropriate strategies for handling them can then be discussed based on an understanding of the resources available to or required by the individual to assist in this process.

Having support is an important resource to mothers, especially from those who are also living the experience. As some mothers said, you cannot really understand unless you are living with it. The existence of existing supports should be explored and recommendations should be made for additional ones. Mothers should be made aware of a parent support group if one is available and the resources it offers. Not all mothers may wish to attend group meetings, but may want to use other services such as newsletters. Some mothers may prefer to make contact with other individuals. Small, group classes to provide education may be helpful in that they can also provide some peer support at the same time. People will learn and find support in different ways, so offering options must be considered. 
It is important to remember that changes will occur over time as the child matures. Medical reevaluation is required periodically, but nurses also have a role over time. Contact should be maintained to ensure mothers have the information and other resources they need. New information, problem-solving efforts, support to the mother, and assistance with preparing the child may continue to be useful contributions as the child matures, becomes involved in new experiences, takes on more responsibility, and works towards independence.

Helping to raise community awareness is another activity that the practitioner might consider. This activity indirectly helps support mothers living this experience, as many of the mothers in the study mentioned their appreciation for the seemingly increasing public awareness of serious food allergies.

Though social changes are occurring and in many cases fathers are taking on a greater role in relationship to their children's health care it is still expected that for the near future mothers will have the biggest role in seeing to the child's safety. Nurses are often in a position to help mothers and other family members adjust to this experience.

\section{Implications for Nursing Education}

As nursing education supports practice, recommendations are also made for education. The problem of food-induced anaphylaxis should be recognized as a problem normally appearing in the pediatric population, but also one that maybe present for a person's life. As with other conditions, the pathophysiology of severe food allergies and its implications are important and must be understood along with the medical management, but the condition should also be viewed from the broader perspective of 
what this experience might be like for those living it. Areas of academic interest that should contribute towards a student's understanding of this experience include:

- individual behaviour especially as it relates to stress, coping, and adaptation

- the family system, dynamics, issues of daily life, and relationship to the community

- the impact and issues related to similar chronic pediatric conditions

- normal child development

This study related to food-induced anaphylaxis has contributed towards an understanding of how this problem might affect mothers. It also shows the influence that mothers might bring to bear on the situation evolving from a child being diagnosed with severe food allergies. In addition, it suggests a need to look at a child's diagnosis of lifethreatening food allergy from other perspectives that require further research to contribute to knowledge in the above areas related to this specific condition.

\section{Research Recommendations}

This study should be considered an initial attempt at trying to understand one aspect of serious food allergies in children from other than a biomedical perspective and suggests the possibilities for many more projects to increase understanding so as to help individuals living with it. A small group of mothers has been studied at one point in their experience. Other studies might look at mothers living in different circumstances or at different times in their experience such as closer to the time of the child's diagnosis or a serious reaction. Further research should focus on the changes that occur over time. Variations in approaches to mothering might be compared to outcomes in the child's 
attitudes and behaviours. A question should be asked about the effect of cultural variation on the mother's experience.

Further research should consider what this experience is like for other family members, such as the child themselves, the father, and siblings. Most of the mothers mentioned concerns about their children as adolescents. This is another group that could offer valuable insight into how to prepare children and possibly parents for this stage of life. In relation to the family it might be questioned as to what influence different family management styles might have on how this experience is dealt with in a family.

Preparing the child to understand the problem without being paralyzed is a concern for mothers. It is suggested that this is another area for study. There is a need to understand the factors that might influence the preparation process, when it should begin, how it should be conducted over time, and how it should be evaluated.

The mothers in this study were asked whether they would recognize a reaction and give the EpiPen ${ }^{3}$. Though the mothers felt they would recognize a reaction there were some issues raised about the decision to use the EpiPen ${ }^{1}$. Practice has also identified that this is an area that would benefit from further investigation.

Many suggestions were made for nursing practice related to assessment, education, and counseling. Further research is required to understand this experience from the perspective of all involved. Research is also required to create effective nursing interventions for mothers, children, and other family members that support successful adaptations to the condition. 


\section{Conclusion}

This study has looked at the experience of the mother when the child has been diagnosed as having a life-threatening food allergy. Phenomenology was used as the research approach. The mothers have shared their thoughts on what it is like to be in this situation and revealed how it is unique within the experience of being a mother. "Living with Risk" was identified as the dominant theme or the essence of the experience supported by five sub-themes. Mothers of children with serious food allergies share some similarities with parents whose children have other chronic conditions such as asthma and diabetes when considering stresses, coping, and outcomes, but the experience is not exactly the same. Nurses are in a position to help mothers adjust to the experience, but there are still many questions to be answered about living with this condition. 


\section{References}

Adjusting to Anaphylactic Allergies. (2000). The MAIN Event, 2 (2), 4 - 5.

Allergy Section, Canadian Pediatric Society (1994). Fatal anaphylactic reactions to food in children. Canadian Medical Association Journal, 150 (3), 337 - 339.

Anderson, J. M. (1981). The social construction of illness experience: Families with a chronically ill child. Journal of Advanced Nursing, $6427-434$.

Anderson, J. M., \& Elfert, H. (1989). Managing chronic illness in the family: Women as caretakers. Journal of Advanced Nursing, 14, 735 - 743.

Asher, M., \& Price, J. (1998). Childhood asthma: Parents' views of professional advice. Community Practitioner, 71 (5), 177 - 178.

Austin, J. K. (1991). Family adaptation to a child's chronic illness. Annual Review of Nursing Research, 9, $103-120$.

Baumann, S. L., \& Braddick, M. (1999). Out of their element: Fathers of children who are "Not the Same". Joumal of Pediatric Nursing, 14 (6), 369 - 378.

Block, K., Brandt, P., \& Magyary, D. (1995). A nursing assessment standard for early intervention: Family coping. Journal of Pediatric Nursing, 10 (1), 28 - 39.

Brink, P. J. (1991). Issues of reliability and validity. In J. M. Morse (Ed.), Qualitative nursing research: A contemporary dialogue (Revised ed., pp. 164 - 186). Newbury Park: SAGE Publications.

Bunce, C. (1997). Constant caution. Nursing Times, 93 (34), 28 - 29.

Burke, S. O., Kauffmann, E., Harrison, M. B., \& Wiskin, N. (1999). Assessment of stressors in families with a child who has a chronic condition. MCN, 24 (2), 98 - 106. 
Burkhart, P. V. (1993). Health perceptions of mothers of children with chronic conditions. Maternal-Child Nursing Journal, 21 (4), 122 - 129.

Burks, A. W., Jr. (1999). Childhood food allergy. Immunology and Allergy Clinics of North America, 19 (2), 397 - 407.

Burks, A. W., \& Sampson, H. A. (1997). Anaphylaxis and food allergy. In D. D. Metcalfe, H. A. Sampson, \& R. A. Simon (Eds.), Food allergy: Adverse reactions to foods and food additives (pp. 245 - 257). Cambridge, MA: Blackwell Science Canam, C. (1993). Common adaptive tasks facing parents of children with chronic conditions. Journal of Advanced Nursing, 18, 46 - 53.

Cheng, P., \& Tang, C. S. (1995). Coping and psychological distress of Chinese parents of children with down syndrome. Mental Retardation, 33 (1), 10 - 20.

Clark, B. (1997). Management of a preschool child's asthma: The parents' perspective. Unpublished master's thesis, University of Manitoba, Winnipeg, Canada.

Clark, S., Gaeta, T. J., Kamarthi, G. S., \& Camargo Jr., C. A. (2001). ICD-9 coding of emergency department visits for food allergy. Academic Emergency Medicine, 8 (5), 515.

Clawson, J. A. (1996). A child with chronic illness and the process of family adaptation. Journal of Pediatric Nursing, 11 (1), 52 - 61.

Cohen, M. H. (1993). The unknown and the unknowable - Managing sustained uncertainty. Western Journal of Nursing Research, 15 (1), 77 - 96.

Cohen, M. Z. (1987). A historical overview of the phenomenologic movement. Image, $\underline{19}(1), 31-34$. 
Cohen, M. Z., \& Omery, A. (1994). Schools of phenomenology: Implications for research. In Morse, J. M. (Ed.), Critical issues in qualitative research methods (pp. 136 156). Thousand Oaks: SAGE.

Collins, B. (2000). Father's day. Food Allergy News, 9 (5), 3.

Coyne, I. T. (1997). Sampling in qualitative research. Purposeful and theoretical sampling; Merging or clear boundaries? Journal of Advanced Nursing, 26, 623 - 630.

Donnelly, J. E., Donnelly, W. J., \& Thong, Y. H. (1987). Parental perceptions and attitudes toward asthma and its treatment: A controlled study. Social Science and Medicine, 24 (5), 431 - 437.

Englund, A-C. D., Rydström, \& Norberg, A. (2001). Being the parent of a child with asthma. Pediatric Nursing, 27 (4), 365-73.

Faulkner, M. S. (1996). Family responses to children with diabetes and their influence on self-care. Journal of Pediatric Nursing, 11 (2), 82 - 93.

Faulkner, M. S., \& Clark, F. S. (1998). Quality of life for parents of children and adolescents with type I diabetes. The Diabetes Educator, 24 (6), 721 - 727.

Friedman, M. M. (1998). Introduction to the family. In Friedman, M. M. Family nursing: Research, theory, \& practice (pp. 3 - 30). Stamford, CT: Appleton \& Lange.

Friedman, M. M., \& Heady, S. A. (1998). Family role structure. In Friedman, M. M. Family nursing: Research, theory, \& practice (pp. 293 - 326). Stamford, CT: Appleton \& Lange.

Friedman, M. M., Svavarsdottir, E. K., \& McCubbin, M. (1998). Family stress and coping processes: Family adaptation. In Friedman, M. M. Family nursing: Research, theory, \& practice (pp. 435 - 478). Stamford, CT: Appleton \& Lange. 
Futcher, J. A. (1988). Chronic illness and family dynamics. Pediatric Nursing, 14 (5), $381-385$.

Gallo, A. M. (1991). Family adaptation in childhood illness: A case report. Journal of Pediatric Health Care, 5 (2), 78 - 85.

Gibson, C. (1988). Perspective in parental coping with a chronically ill child: The case of cystic fibrosis. Issues in Comprehensive Pediatric Nursing, 11, 33 - 41.

Gibson, C. H. (1995). The process of empowerment in mothers of chronically ill children. Journal of Advanced Nursing 21, 1201 - 1210.

Hanson, S. M. H., \& Bozett, F. W. (1987). Fatherhood and changing family roles. Family \& Community Health, 9 (4), 9 - 21.

Hatton, D. L., Canam, C., Thorne, S., \& Hughes, A. (1995). Parent's perceptions of caring for an infant or toddler with diabetes. Journal of Advanced Nursing, 22, $569-$ 577.

Hayes, V. E. (1997). Families and children's chronic conditions: Knowledge development and methodological considerations. Scholarly Inquiry for Nursing Practice, $11(4), 259-290$.

Heaman, D. J. (1995). Perceived stressors and coping strategies of parents who have children with developmental disabilities: A comparison of mothers with fathers. Journal of Pediatric Nursing, 10 (5), 311 - 320 .

Hodges, L. C., \& Parker, J. (1987). Concerns of parents with diabetic children. Pediatric Nursing, 13 (1), 22 - 24, 68.

Holaday, B. (1984). Challenges of rearing a chronically ill child: Caring and coping. Nursing Clinics of North America, 19 (2), 361 - 368. 
Hopper, J. (2000). A dad's letter to dads: Is it time for a system update? Food Allergy News, 9 (6), 3.

Horner, S. D. (1997). Uncertainty in mothers' care for their ill children. $\underline{\text { Journal of }}$ Advanced Nursing, 26, 658 - 663.

Horner, S. D. (1998). Catching the asthma: Family care for school-aged children with asthma. Journal of Pediatric Nursing. 13 (6), 356 - 366.

Hughes, M., McCollum, J., Sheftel, D., \& Sanchez, G. (1994). How parents cope with the experience of neonatal intensive care. Children's Health Care, 23 (1), 1 - 14.

Hymovich, D. P., \& Hagopian, G. A. (1992). Chronic illness in children and adults: A psychosocial approach (pp. 137 - 169). Philadelphia: W. B. Saunders Company.

Jerrett, M. D., \& Costello, E. A. (1996). Gaining control: Parents' experiences of accommodating children's asthma. Clinical Nursing Research, 5 (3), 294 - 308.

Jessop, D. J., \& Stein, R. E. K. (1985). Uncertainty and its relation to the psychological and social correlates of chronic illness in children. Social Science and Medicine, 20 (10), 993 - 999.

Joachim, G., \& Acorn, S. (2000). Stigma of visible and invisible chronic conditions. Journal of Advanced Nursing. 32 (1), $243-248$.

Johnson, M. P. (1982). Support groups for parents of chronically ill children. Pediatric Nursing, $8160-163$.

Kagy, L., \& Blaiss, M. S. (1998). Anaphylaxis in children. Pediatric Annals. 27, 727 $-734$.

Katz, S., \& Krulik, T. (1999). Fathers of children with chronic illness: Do they differ from fathers of healthy children?. Journal of Family Nursing, 5 (3), $292-315$. 
Kieckhefer, G. M., \& Ratcliffe, M. (2000). What parents of children with asthma tell us. Journal of Pediatric Health Care, 14 (3), 122 - 126.

Knafl, K. A., \& Deatrick, J. A. (1986). How families manage chronic conditions: An analysis of the concept of normalization. Research in Nursing \& Health, 9, 215-222.

Kovacs, M., Finkelstein, R., Feinberg, T. L., Crouse-Novak, M., Paulauskas, S., \& Pollock, M. (1985). Initial psychologic responses of parents to the diagnosis of insulindependent diabetes mellitus in their children. Diabetes Care, 8 (6), 568 - 575.

Krulik, T., Turner-Henson, A., Kanematsu, Y., Al -Ma'aitah, R., Swan, J., \& Holaday, B. (1999). Parenting stress and mothers of young children with chronic illness: A crosscultural study. Journal of Pediatric Nursing. 14 (2), 130 - 140.

Kurnat, E. L., \& Moore, C. M. (1999). The impact of a chronic condition on the families of children with asthma. Pediatric Nursing, 25 (3), 288 - 292.

LaMontagne, L. L., Hepworth, J. T., Johnson, B. D. \& Deshpande, J. K. (1994). Psychophysiological responses of parents to pediatric critical care stress. Clinical Nursing Research, 3 (2), 104 - 118.

Lamontagne, L. L., Johnson, B. D., \& Hepworth, J. T. (1995). Evolution of parental stress and coping processes: A framework for critical care practice. Journal of Pediatric Nursing, 10 (4), $212-218$.

Lazarus, R. S., \& Folkman, S. (1984). Stress, appraisal, and coping New York: Springer Publishing Company.

Lieberman, P. (1998). Anaphylaxis and anaphylactoid reactions. In Middelton, E., Jr., Reed, C. E., Ellis, E. F., Adkinson, N. F., Jr., Yunginger, J. W., \& Busse, W. W. (Eds.) Allergy principles \& practice: Volume II. ( 5th ed., pp. 1079 - 1092). St. Louis: Mosby. 
Lowes, L., \& Lyne, P. (1999). A normal lifestyle: Parental stress and coping in childhood diabetes. British Journal of Nursing, 8 (3), $133-139$.

MacDonald, H. (1996). "Mastering Uncertainty:" Mothering the child with asthma. Pediatric Nursing, 22 (1), 55 - 59.

Mailick, M. D., Holden, G., \& Walther, V. N. (1994). Coping with childhood asthma: Caretakers' views. Health \& Social Work, 19 (2), 103 - 111.

May, K. A. (1991). Interview techniques in qualitative research: Concerns and challenges. In J. M. Morse (Ed.), Qualitative nursing research: A contemporary dialogue (Revised ed., pp. 188 - 201). Newbury Park: SAGE Publications.

McCubbin, M. (1989). Family stress and family strengths: A comparison of singleand two-parent families with handicapped children. Research in Nursing \& Health, 12, $101-110$

McKeever, P. T. (1981). Fathering the chronically ill child. MCN,6, 124-128.

Mish, F. C. et al. (Ed.). (1983). Webster's ninth new collegiate dictionary. Springfield: Merriam-Webster Inc.

Morse, J. (1992). Phenomenology. In Qualitative health research (pp. 91 - 92). Newbury Park: SAGE Publications.

Munhall, P. L. (1994). Revisioning phenomenology: Nursing and health science research. New York: National League for Nursing Press.

Nugent, K., Hughes, R., Ball, B., \& Davis, K. (1992). A practice model for a parent support group. Pediatric Nursing, 18 (1), $11-16$.

Ownby, D. R. (1999). Pediatric anaphylaxis, insect stings, and bites. Immunology and Allergy Clinics of North America, 19 (2), $347-361$. 
Palmer, E. A. (2001). Family caregiver experiences with asthma in school-age children. Pediatric Nursing, 27 (1), $75-81$.

Park, E. S., \& Martinson, I. M. (1998). Socioemotional experiences of Korean families with asthmatic children. Journal of Family Nursing, 4 (3), 291 - 308.

Parker, H., Swift, P. G. F., Botha, J.L., \& Raymond, N. T. (1994). Early onset diabetes: Parents' views. Diabetic Medicine, 11, 593 - 596.

Polit, D. F., \& Hungler, B. P. (1995). Nursing research: Principles and methods $\left(5^{\text {th }}\right.$ ed.). Philadelphia: J. B. Lippincott Company.

Primeau, M.-N., Kagan, R., Joseph, L., Lim, H., Dufresne, C., Duffy, C., Prhcal, D., \& Clarke, A. (2000). The psychological burden of peanut allergy as perceived by adults with peanut allergy and the parents of peanut-allergic children. Clinical and Experimental Allergy, 30, $1135-1143$.

Ray, M. A. (1994). The richness of phenomenology: Philosophic, theoretic, and methodologic concerns. In J. M. Morse (Ed.), Critical issues in qualitative research methods. (pp. 117 - 133). Thousand Oaks: SAGE.

Ruddick, S. (1990). Maternal thinking: Toward a politics of peace. New York; Ballantyne Books.

Sampson, H. A. (1997a). Immediate reactions to foods in infants and children. In D. D. Metcalfe, H. A. Sampson, \& R. A. Simon (Eds.), Food allergy: Adverse reactions to foods and food additives (pp. 169 - 182). Cambridge, MA: Blackwell Science.

Sampson, H. A. (1997b). Food allergy. Journal of the American Medical Association, 278 (22), $1888-1894$. 
Sampson, H. A. (1999a). Food allergy. Part 1: Immunopathogenesis and clinical disorders. Journal of Allergy and Clinical Immunology, 103 (5), 717 - 728.

Sampson, H. A. (1999b). Food allergy. Part 2: Diagnosis and management. Journal of Allergy and Clinical Immunology, 103 (6), 981989.

Sampson, H. A., \& Burks, A. W. (1996). Mechanisms of food allergy. Annual Review of Nutrition, 16, 161 - 177.

Sampson, H. A., Mendelson, L., \& Rosen, J. P. (1992). Fatal and near-fatal anaphylactic reactions to food in children and adolescents. New England Journal of Medicine, 327 (6), 380 - 384.

Sandelowski, M. (1993). Rigor or rigor mortis: The problem of rigor in qualitative research revisited. Advances in Nursing Science, 16 (2), 1 - 8.

Sandelowski, M. (1995). Focus on qualitative methods: Sample size in qualitative research. Research in Nursing \& Health, 18, 179 - 183.

Simons, F. E. R., Chad, Z. H., \& Gold, M. (2002). Real-time reporting of anaphylaxis in infants, children, and adolescents by physicians involved in the Canadian pediatric surveillance program. Journal of Allergy and Clinical Immunology,109 (1), S181

Spiegelberg, H. (1982). The phenomenological movement: A historical introduction (3rd ed.) The Hague: Martinus Nijhoff Publishers

Streubert, H. J., \& Carpenter, D. R. (1999). Qualitative research in nursing: Advancing the human imperative (2nd ed., pp. 33 - 63). Philadelphia: Lippincott Vandagriff, J. L., Marrero, D. G., Ingersoll, G. M., \& Fineberg, N. S. (1992). Parents - of children with diabetes: What are they worried about? The Diabetes Educator, 18 (4), $299-302$. 
van Manen, M. (1997). Researching lived experience. Althouse Press

Venters, M. (1981). Familial coping with chronic and severe childhood illness: The case of cystic fibrosis. Social Science and Medicine, 15A, 289 - 297.

Vickers, D. W., Maynard, L., \& Ewan, P. W. (1997). Management of children with potential anaphylactic reactions in the community: A training package and proposal for good practice. Clinical and Experimental Allergy, 27, 898 - 903.

Wills, B. S. H. (1999). The experience of Hong Kong Chinese parents of children with acute lymphocytic leukemia. Journal of Pediatric Nursing, 14 (4), 231 - 238.

Wong, D. L. (1995a). Family influences on child health promotion. In Whaley \& Wong's nursing care of infants and children ( $5^{\text {th }}$ ed., pp. 65 - 104). St. Louis: Mosby

Wong, D. L. (1995b). The child with endocrine dysfunction. In Whaley \& Wong's nursing care of infants and children ( $5^{\text {th }}$ ed., pp. 1764 - 1791). St. Louis: Mosby.

Yoos, L. (1987). Chronic childhood illnesses: Developmental issues. Pediatric Nursing, 13 (1), $25-28$.

Yunginger, J. W. (1992). Lethal food allergy in children. New England Journal of Medicine, 327 (6), $421-422$.

Yunginger, J. W., Sweeney, K. G., Sturner, W. Q., Giannandrea, L. A., Teigland, J. D., Bray, M., Benson, P. A., York, J. A., Biedrzycki, L., Squillace, D. L., \& Helm, R. M. (1988). Fatal food-induced anaphylaxis. Journal of the American Medical Association, $\underline{260}$ (10), $1450-1452$. 


\title{
Appendix A
}

\section{Parenting a Child with a Life-Threatening Food Allergy: The Mother's Perspective}

\author{
Initial Recruitment Invitation
}

Dear Parent,

My name is Cathy Gillespie, and I am a pediatric nurse and a student in the Master of Nursing program at the University of Manitoba. To complete this nursing program, I am doing a research project about what it is like being a mother whose child has a lifethreatening food allergy. I believe that a better understanding of this experience can help nurses and other professionals who work with families where this is an issue.

It is my intention to interview a small group of mothers to learn more about how they see the experience. Each mother will be interviewed two or three times and the interviews tape-recorded. The identity of any mother who participates will be kept confidential. After interviewing all the mothers, I will put the information together and write up my study. You will be given the opportunity to receive a summary of the study.

Please tell the person who gave you this information whether you would or wouldn't like to hear more about being in this study. If you are interested, they will give me your phone number, and I will call you and tell you more about it. If you decide to participate after talking to me, we will set up an interview time convenient for you. If you decide not to participate, you can say no without any problem. Participation is voluntary.

Thank you for considering this information.

Yours sincerely,

Cathy Gillespie RN, BA, CAE

Master of Nursing Student

University of Manitoba 


\title{
Appendix B
}

\section{Parenting a Child with a Life-Threatening Food Allergy: The Mother's Perspective}

\author{
Researcher's Telephone Script
}

Hello

My name is Cathy Gillespie, and I am a student in the Master of Nursing program at the University of Manitoba. I have been told by from that you have received some information about a study I am doing and are willing to hear more about it.

I am a pediatric nurse and have worked with families whose children have lifethreatening food allergies. I am interested in how families experience this problem, but there is very little written about it in nursing or other professional journals. I believe as nurses or other professionals who care for these children, we need to understand the experience as much as we can. I know it will not be exactly the same for each family or each person in a family, but I have chosen mothers for this study.

I will be doing individual interviews with a small number of mothers who agree to participate. Each mother will be interviewed two to three times. The interviews are likely to range from $1-2$ hours. They will be done at a time and place convenient for each mother. The interviews will be tape-recorded, so I do not miss any important information.

A transcriber will type the interviews, and then I will read them and look for common issues and concerns. Dr. Karen Chalmers and Roberta Woodgate from the University of Manitoba and Dr. Wade Watson from the Children's Hospital, supervisors for my work, may also read the interviews. I will be the only person who knows the identities of each mother. All names will be replaced with a code. The tapes and transcripts will be stored securely and destroyed when no longer required.

The information I get from the interviews will be written up for my thesis. It is also my intention to publish the study in a professional journal and present it at a professional meeting. I want to share the information with other nurses and health care workers, but at no time will a specific mother or child be named. A summary of the study will be available to you after its completion, if you are interested.

If you agree to participate, you can drop out of the study at any time, ask to stop the interview at any point, or refuse to answer any question. Are there any questions you would like to ask about the study? Do you think you would like to be a part of this study? 
(If "no") Thank you very much for your time. I appreciate having had the opportunity of speaking to you.

(If "I would like to think about it") I would certainly appreciate you doing that. When should I call you back to get your decision?

(If "yes") Thank you for your interest. When would be a good time to do the first interview? Would you like to do it at your home? (If "no") Where would you like to do it? You can come to my office if you prefer or we can pick another place.

When we meet, I will ask you to sign a consent saying you will participate based on the information I have given you, and I will ask you to fill out a short form for background information on you, your child, and family. For the interview it may be helpful to think about your feelings about this experience and any events or decisions related to the allergy that stick out in your mind. I am interested in your thoughts, ideas, and views on what is like parenting a child with this problem. This may include things that have helped, got in the way, been made more difficult, or it may have to do with other people who are involved with your child.

Thank you for your time. I will look forward to meeting you on

at at

(Any questions from a mother that arise out of this conversation will be answered and noted on this sheet) 


\section{Appendix C}

Parenting a Child with a Life-Threatening Food Allergy:

The Mother's Perspective

Demographic Data

Mother's Code Number

Mother's Age

1) Marital Status :

Married/Common Law

Divorced Single

2) Sex of Child with Food Allergy:

Male Female

3) Age of Child

Age at Diagnosis of Food Allergy

4) Severe Food Allergies Include:

5) Other Family Members Living in Home:

Child's Father Age

Child's Brother(s): Number Age(s)

Child's Sister(s): Number Age(s)

Other People: Number Age(s)

Family Relationship

6) Mother's Occupation Full Time Part Time

7) Father's Occupation Full Time Part Time 
8) Highest Level of Education Achieved by Mother :

Less Than High School High School Diploma

Community College/Vocational School Undergraduate Degree

Graduate Degree Other (specify)

9) Highest Level of Education Achieved by Father :

Less Than High School High School Diploma

Community College/Vocational School Undergraduate Degree Graduate Degree Other (specify)

10) Family Income (yearly):

Less Than $\$ 10,000$ $\$ 10,000$ - \$19,999 $\$ 20,000$ - $\$ 29,999$ $\$ 30,000$ - \$39,999 $\$ 40,000$ - $\$ 49,999$ $\$ \mathbf{5 0 , 0 0 0}$ or more

11) What is your ethnic background?

12) What is father's ethnic background? 


\section{Appendix D}

\section{Parenting a Child with a Life-Threatening Food Allergy: \\ The Mother's Perspective \\ Interview Questionnaire}

1) (Child's name) has a serious food allergy. I would like to try and understand what it is like to be a mother and care for a child with this problem. Can you tell me about some of the experiences you've had related to your child's allergy that stand out for you and your thoughts and feelings about them?

2) Can you tell me about what you remember about (child's name) first reaction to the food? How did it make you feel?

3) Can you tell me about when you first saw the allergist? What do you remember about the visit?

4) Has (child's name) had a reaction to the food since then? (If yes) tell me about that experience.

5) How do you find this problem affects you and your family's life now on a day to day basis? Can you give me some examples?

6) Would you please tell me about any special concerns you have related to (child's name) food allergy?

7) What have you found has helped you most deal with (child's name) food allergy?

8) What have you found that has not been helpful in caring for your child?

9) Is there anything that would be helpful to you that you have not had?

10) On looking back at your experiences is there anything you would like to tell doctors or nurses that would help them assist mothers in looking after their children? 
11) Would you like to add anything about being the mother of a child with a serious food allergy? 


\title{
Appendix $\mathbf{E}$
}

\section{Parenting a Child with a Life-Threatening Food Allergy:}

\author{
The Mother's Perspective
}

\author{
Consent Form
}

Researcher: Cathy Gillespie, RN

Supervisor: Dr. Karen Chalmers

\section{Phone: \\ Phone: .}

I study. The aim of the study is to better understand what it is like for a mother to care for a child with a serious food allergy. By learning about this experience, health care providers may be able to help other families. I have been given written information about the study. I have read the information and any questions I had have been answered.

I understand the study is being done by a registered nurse, Cathy Gillespie, a student in the Master of Nursing program at the University of Manitoba, for her thesis. Dr. Karen Chalmers, from the Faculty of Nursing, University of Manitoba, will supervise the study. I can contact them if necessary at the above phone numbers during regular work hours. The University of Manitoba Education/Nursing Ethical Review Committee has approved the study, and any concern about how the study is conducted can be reported to the Ethics Secretariat at 4747122 or to Dr. Karen Chalmers.

I understand that I am being asked to participate in two to three interviews carried out by Cathy Gillespie. The interviews will be tape-recorded and each will take about $1-2$ hours. I will be asked to talk about my experience as the mother of a child with a serious food allergy. The interviews will take place at a time and place convenient to me. If a third interview is done it will take place by phone and take less than 20 minutes. I will also be asked to fill out a short form for background information about my family and myself, which will take about 5 minutes to complete.

I understand that my identity and all my information will be kept confidential except for a situation in which there is a legal requirement to disclose identity (e.g. abuse situations). A transcriber will type the interviews. The researcher and her thesis committee (Dr. Chalmers and Roberta Woodgate, Faculty of Nursing and Dr. Wade Watson, Faculty of Medicine) will have access to the typed interviews, but only the researcher will know my identity. The researcher will replace my name with a code number. The tapes and the data will be stored in a locked cabinet in the researcher's home and destroyed when no longer needed. My identity will not be revealed in any publication or presentation that results from the study. 
I understand that the study has no known risks or benefits for me personally or my child. Participation in the study is voluntary. I can refuse to answer any question, stop the interview, or quit the study at any time, and it will not affect me or my child's care in anyway.

By signing this consent, I agree to participate in the study "Parenting a Child with a Life-Threatening Food Allergy: The Mother's Perspective" according to the written information provided in this consent. I have received a copy of the consent for my own records.

Participant

Date

Researcher

Date

I would like to receive a summary of the research results following the completion of the study:

Yes

No

Name

Address 